\title{
Development of an Acoustic Sensor for On-Line Gas Temperature Measurement in Gasifiers
}

\section{Final Report}

Reporting Period: $\quad$ June 11, 2003 through June 30, 2008

Prepared for:

NETL AAD Document Control Bldg.921

US Department of Energy

National Energy Technology Laboratory

PO Box 10940

Pittsburgh, PA 15236-0940

DOE NETL Cooperative Agreement No.: DE-FC26-03NT41617

Prepared by: $\quad$ Dr. Peter Ariessohn

Enertechnix, Inc.

23616 SE 225th Street

PO Box 469

Maple Valley, WA 98038

Date Issued: $\quad$ July 31, 2008

Prime Contractor: $\quad$ Enertechnix, Inc.

P.O. Box 469

Maple Valley, WA 98038

Subcontractor: ConocoPhillips

Technology Solutions Division

600 N. Dairy Ashford

Houston, TX 77079-1176

Principal Investigator: $\quad$ Peter Ariessohn, Ph.D.

Director of Research \& Development

Enertechnix, Inc.

Consultants: $\quad$ Prof. Hans Hornung

California Institute of Technology

DOE Project Officer: Kamalendu Das

U.S. Department of Energy, NETL 


\section{DISCLAIMER}

“This report was prepared as an account of work sponsored by an agency of the United States Government. Neither the United States Government nor any agency thereof, nor any of their employees, makes any warranty, express or implied, or assumes any legal liability or responsibility for the accuracy, completeness, or usefulness of any information, apparatus, product, or process disclosed, or represents that its use would not infringe privately owned rights. Reference herein to any specific commercial product, process, or service by trade name, trademark, manufacturer, or otherwise does not necessarily constitute or imply its endorsement, recommendation, or favoring by the United States Government or any agency thereof. The views and opinions of authors expressed herein do not necessarily state or reflect those of the United States Government or any agency thereof.”

\section{ABSTRACT}

This project was awarded under U.S. Department of Energy (DOE) National Energy Technology Laboratory (NETL) Program Solicitation DE-PS26-02NT41422 and specifically addresses Technical Topical Area 2 - Gasification Technologies. The project team includes Enertechnix, Inc. as the main contractor and ConocoPhillips Company as a technical partner, who also provides access to the SG Solutions Gasification Facility (formerly Wabash River Energy Limited), host for the field-testing portion of the research.

The objective of this project was to adapt acoustic pyrometer technology to make it suitable for measuring gas temperature inside a coal gasifier, to develop a prototype sensor based on this technology, and to demonstrate its performance through testing on a commercial gasifier. The project was organized in three phases, each of approximately one year duration. The first phase consisted of researching a variety of sound generation and coupling approaches suitable for use with a high pressure process, evaluation of the impact of gas composition variability on the acoustic temperature measurement approach, evaluation of the impact of suspended particles and gas properties on sound attenuation, evaluation of slagging issues and development of concepts to deal with this issue, development and testing of key prototype components to allow selection of the best approaches, and development of a conceptual design for a field prototype sensor that could be tested on an operating gasifier. The second phase consisted of designing and fabricating a series of prototype sensors, testing them in the laboratory, and developing a conceptual design for a field prototype sensor. The third phase consisted of designing and fabricating the field prototype, and testing it in the lab and in a commercial gasifier to demonstrate the ability to obtain accurate measurements of gas temperature in an operating gasifier. Following the completion of the initial 3 year project, several continuations were awarded by the Department of Energy to allow Enertechnix to conduct extended testing of the sensor at the Wabash River facility.

In February, 2008 the sensor was installed on the gasifier in preparation for a long-term test. During the initial testing of the sensor a stainless steel tube on the sensor failed and allowed syngas to escape. The syngas self-ignited and the ensuing small fire damaged some of the components on the sensor. There was no damage to the gasifier or other equipment and no 
injuries resulted from this incident. Two meetings were held to identify the root causes of the incident-one at Wabash River and one at Enertechnix. A list of recommended improvements that would have addressed the causes of the incident was created and presented to the Department of Energy on May 2, 2008. However, the DOE decided not to pursue these improvements and terminated the project.

This report describes all of the activities conducted during the project and reports the findings of each activity in detail. The investigation of potential sound generation and coupling methods led to the selection of a reflected shock method which has been developed into a functioning prototype device. The principles of operation of this device and its performance characteristics are described in the report. Modeling of the attenuation of sound by suspended particles and by interaction of the sound pulses with the high temperature syngas inside the gasifier was conducted and the predictions of those models were used to determine the required sound pulse intensity to allow the sound pulses to be detected after passage through the gasifier environment. These modeling results are presented in this report. A study of the likely spatial and temporal variability of gas composition inside the gasifier was performed and the results of that study was used to predict the impact of that variability on the accuracy of the acoustic temperature method. These results are reported here. A design for a port rodding mechanism was developed to deal with potential slagging issues and was incorporated into the prototype sensor. This port rodding mechanism operated flawlessly during the field testing, but because these tests were performed in a region of the gasifier that experiences little slagging, the effectiveness of the rodding mechanism in dealing with highly slagging conditions was not fully demonstrated. This report describes the design and operation of the automated Gasifier Acoustic Pyrometer (autoGAP) which was tested at the Wabash River facility. The results of the tests are reported and analyzed in detail.

All of the objectives of the initial $R \& D$ project were achieved and a field prototype acoustic pyrometer sensor was successfully tested at the Wabash River gasifier plant. Acoustic signals were propagated through the gases inside the gasifier and were detected by the receiver unit, the times of flight of these sound pulses were measured and these propagation times were converted into temperatures which agreed very well with thermocouple measurements made in the same location as the acoustic measurements. In September, 2006, the acoustic pyrometer system was operated under computer control and was shown to be capable of making measurements every 10 minutes (or more frequently) for 2 days. However, the field prototype did not perform successfully and the extended 6 month test that was planned to be conducted in 2008 was not successful.

The basic principle of operation of the sensor was demonstrated to be valid and accurate internal gas temperature measurements were obtained on the Wabash River gasifier. However, materials issues prevented the completion of a long-term test. Enertechnix believes that the acoustic pyrometer technology has merit as a tool for measuring internal gasifier temperatures, but further development would be required to produce a reliable sensor for this application. 


\section{TABLE OF CONTENTS}

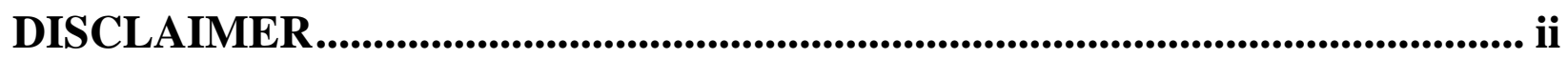

ABSTRACT ...................................................................................................................

EXECUTIVE SUMMARY ...................................................................................v

TOPICAL TECHNICAL REPORT.................................................................1

1. Principles of acoustic pyrometry and practical considerations ....................1

2. EGS1 test facility ...........................................................................................4

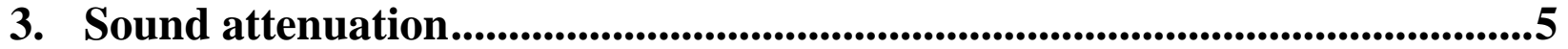

3.1. Vibrational relaxation of high temperature gas molecules .................................... 5

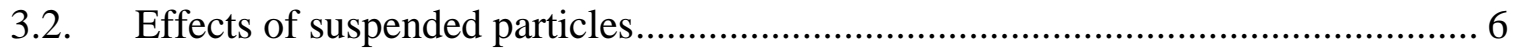

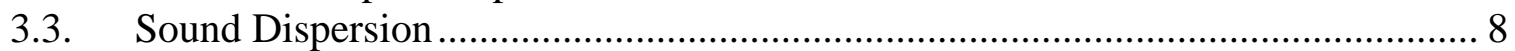

4. Gas Composition Effects ........................................................................9

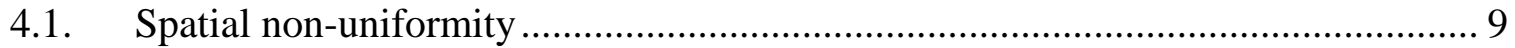

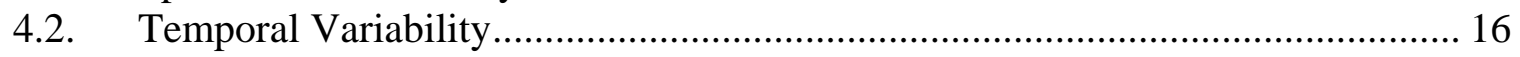

5. Sound generation and coupling methods ...............................................................18

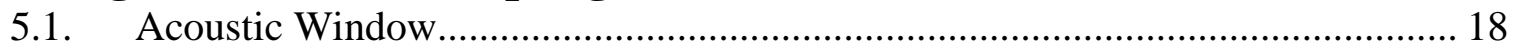

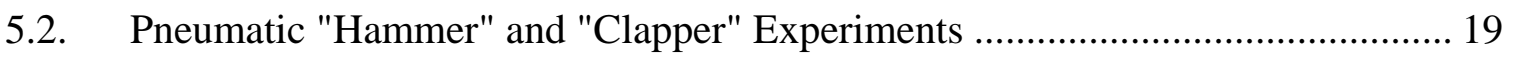

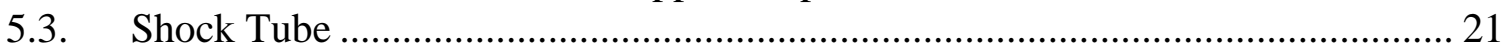

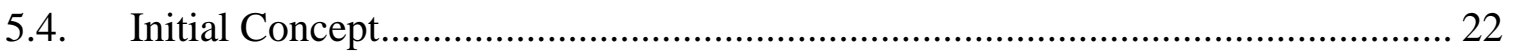

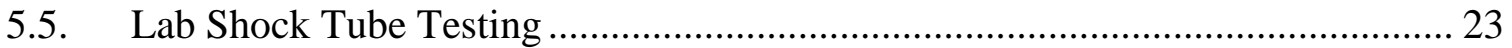

5.6. EGS1 Direct Shock Experiments .............................................................. 26

5.7. EGS1 Reflected Shock Experiments ............................................................ 27

6. Prototype sensor development............................................................29

6.1. Field prototype sensor conceptual design .................................................. 29

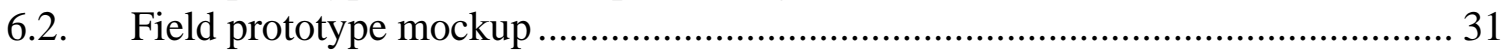

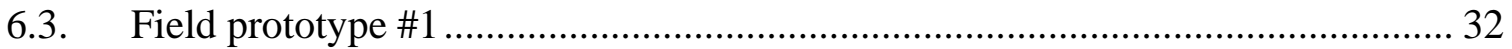

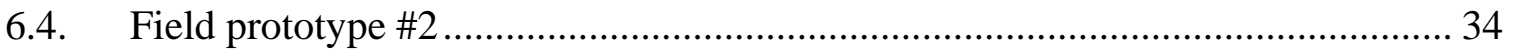

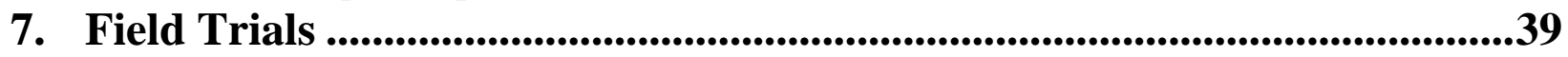

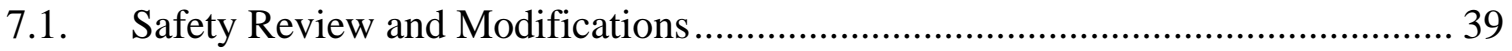

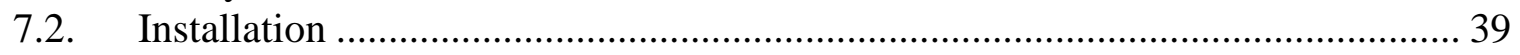

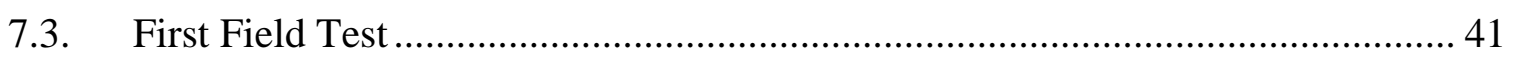

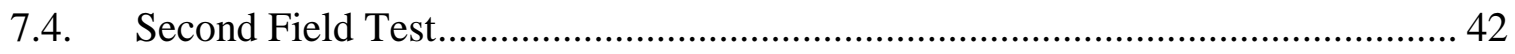

8. Commercial Sensor Conceptual Design ......................................................49

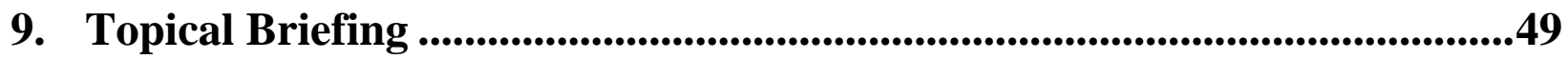

10. References...........................................................................................49 


\section{EXECUTIVE SUMMARY}

Since 1989 the U.S. Department of Energy has supported development of advanced coal gasification technology. The Wabash River and TECO IGCC demonstration projects supported by the DOE have demonstrated the ability of these plants to achieve high levels of energy efficiency and extremely low emissions of hazardous pollutants. However, a continuing challenge for this technology is the tradeoff between high carbon conversion which requires operation with high internal gas temperatures, and limited refractory life which is exacerbated by those high operating temperatures. Attempts to control internal gas temperature so as to operate these gasifiers at the optimum temperature have been hampered by the lack of a reliable technology for measuring internal gas temperatures. Thermocouples have serious survival problems and provide useful temperature information for only a few days or weeks after startup before burning out. For this reason, the Department of Energy has funded several research projects to develop more robust and reliable temperature measurement approaches for use in coal gasifiers.

Enertechnix has developed a line of acoustic gas temperature sensors for use in coal-fired electric utility boilers, kraft recovery boilers, cement kilns and petrochemical process heaters. Acoustic pyrometry provides several significant advantages for gas temperature measurement in hostile process environments. First, it is non-intrusive so survival of the measurement components is not a serious problem. Second, it provides a line-of-sight average temperature rather than a point measurement, so the measured temperature is more representative of the process conditions than a thermocouple measurement. Unlike radiation pyrometers, the measured temperature is a linear average over the full path rather than a complicated function of gas temperature and distance along the line of sight. For this reason, acoustic pyrometry can be used to provide detailed two-dimensional temperature maps through the use of multiple path measurements in a plane. Therefore, acoustic pyrometry is an attractive choice for measuring gas temperature inside a gasifier.

The objectives of this project were to adapt acoustic pyrometer technology to make it suitable for measuring gas temperature inside a coal gasifier, to develop a prototype sensor based on this technology, and to demonstrate its performance through testing on a commercial gasifier. The project was organized in three phases, each of approximately one year duration. In year 1 Enertechnix conducted experiments with a variety of sound generation and coupling methods and a suitable approach was identified and successfully demonstrated on a gasifier simulator that Enertechnix constructed for this project. The selected approach employs a shock tube which is driven by the high pressure gases which exist within the gasifier itself, obviating the need for an external source of high pressure gas. Experiments with a prototype device demonstrated the ability to produce strong sound pulses and the ability to utilize the propagation time of these pulses in the gasifier simulator to accurately measure gas temperature. The effect of gas composition variation on measurement accuracy was investigated using CFD modeling data provided by Reaction Engineering, International, and process information supplied by ConocoPhillips Company. The impact of suspended particles in the gasifier environment was investigated through computational modeling and found to be tolerable in environments typical 
of entrained flow gasifiers. A conceptual design for a field prototype sensor was developed that incorporates provision for slag rodding to maintain clear acoustic access to the gasifier interior.

In year 2 Enertechnix developed and successfully tested several laboratory prototypes. At the end of year 2 a fully functional field prototype sensor was designed and fabricated.

In year 3 Enertechnix completed fabrication of the first field prototype sensor (“auto-GAP”) and carried out a series of tests at its facilities in Tenino, WA. An extended plant shutdown and the need for modifications to the sensor delayed installation and field testing until April, 2006. Installation and system checkout was completed the day before the plant's scheduled spring outage, so only a one day test was performed at that time. Several minor problems were identified which prevented proper operation of the sensor and no usable data were collected at that time.

In September, 2006, immediately after a shutdown, a second field test was performed during which the sensor performed flawlessly; a large number of measurements were obtained over a two day period. The acoustic signals were strong enough to be clearly detected above the background noise level inside the gasifier and accurate time-of-flight measurements were made. These were converted into gas temperatures using estimates of the syngas composition at the measurement location and the resulting temperatures were in very good agreement with measurements obtained from thermocouples mounted in the same plane as the acoustic sensor. The system operated in automatic mode under computer control and obtained temperature readings once every 10 minutes throughout the testing period except for a few occasions when it was operated in manual mode to obtain temperature readings as frequently as once every three minutes. At the end of the second day of testing, a leak developed in the sensor and testing was halted. An examination of the sensor revealed that one of the seals had become severely damaged and since it was not possible to replace the seal without dismantling the sensor, a decision was made to discontinue testing.

In 2007, numerous modifications were made to the sensor in an attempt to make it more rugged and reliable. Following extensive testing at Enertechnix, the sensor was shipped to Wabash River and installed on the gasifier in February, 2008. On March $6^{\text {th }}$, as the sensor was being manually checked out in preparation for starting the extended test, a stainless steel tube failed and allowed syngas to escape. The syngas self-ignited and the ensuing small fire damaged some of the components on the sensor. There was no damage to the gasifier or other equipment and no injuries resulted from this incident. Two meetings were held to identify the root causes of the incident-one at Wabash River and one at Enertechnix. A list of recommended improvements that would have addressed the causes of the incident was created and presented to the Department of Energy on May 2, 2008. However, the DOE decided not to pursue these improvements and terminated the project.

The basic principle of operation of the sensor has been demonstrated to be valid and accurate internal gas temperature measurements were obtained on the Wabash River gasifier. Despite the materials issues that prevented the completion of an extended demonstration test, Enertechnix believes that the acoustic pyrometer technology has merit as a tool for measuring internal 
gasifier temperatures, but further development would be required to produce a reliable sensor for this application. 


\section{TOPICAL TECHNICAL REPORT}

\section{Principles of acoustic pyrometry and practical considerations}

Acoustic pyrometry offers a fundamentally simple, non-intrusive method for measuring gas temperatures inside harsh industrial processes and in recent years, acoustic pyrometry has begun to be widely adopted in the power generation industry for measuring gas temperature inside coal-fired boilers. The method is based on the relationship between gas temperature and sound speed. From simple thermodynamic arguments it is easy to show that, in an ideal gas, sound waves will propagate at a speed given by

$$
c=\sqrt{\frac{\gamma R T}{M}}
$$

where $\gamma$ is the specific heat ratio, $\mathrm{R}$ is the universal gas constant, $\mathrm{T}$ is the absolute temperature, and $\mathrm{M}$ is the mean molecular weight of the gas mixture $[1,2]$. Both $\mathrm{M}$ and $\gamma$ depend on gas composition, and $\gamma$ is also a very weak function of temperature. Therefore, if the gas composition is known, or can be calculated, the absolute temperature can be inferred from a measure of sound speed. The measurement of sound speed along a path in a nonuniform temperature environment yields an average of the square root of temperature, which in most practical cases is nearly indistinguishable from the square root of the average temperature itself.

Acoustic pyrometry has a number of advantages over optical methods. First, cleanliness of port openings is much less critical than for optical measurements. Second, once the path length is determined, no calibration is required since the measurement of the time of flight is not affected by drift or changes in sensitivity of the components. Third, the measurement represents a true spatial average of the temperature along the line of sight connecting the sound source and receiver. Because of this averaging, it is straightforward to implement tomographic reconstruction techniques to generate two-dimensional temperature maps within a plane by utilizing several sound generators and receivers. The temperature range over which the measurement is valid is large, encompassing the full range of gasifier operation. Because the wavelengths of the acoustic waves used in this technique are on the order of centimeters (many orders of magnitude larger than the dimensions of suspended char or slag particles), scattering or attenuation by the suspended particles is much less significant than for electromagnetic techniques, even those using millimeter wavelengths.

Enertechnix, Inc. has developed a line of acoustic pyrometers based on this measurement principle, which is gaining widespread acceptance as the preferred method of measuring gas temperatures inside large coal-fired utility boilers, kraft recovery boilers, cement kilns and petrochemical process heaters. However, all of these processes operate at atmospheric pressure and adapting acoustic pyrometry for use in the gasifier environment presents several very significant technical challenges. 
Enertechnix has adopted an approach to acoustic pyrometry which relies on propagating an intense sound pulse through the process atmosphere and measuring both the time at which the pulse is initiated and the time of arrival of the pulse at the receiver. For measurements in processes that operate at atmospheric pressure, Enertechnix has developed a sound source that uses a pressurized reservoir mounted outside the process and connected to the process by means of a barrel (a smooth pipe). The pressure vessel is typically pressurized to 25 atmospheres and the sound pulse is generated by opening a very rapidly operating valve that allows the high pressure gas in the reservoir to escape into the process. This produces a shock wave that propagates into the process and expands hemispherically as it propagates through the process atmosphere. As the wavefront expands, the pressure differential across the wave rapidly decreases and the wave quickly becomes a sound wave that propagates at sonic velocity. One or more receivers placed at other locations around the perimeter of the process will receive the acoustic signal and by measuring the time of arrival at each receiver, the average temperature on all the paths connecting the generator to the receivers can be determined. Experience has shown that a strong shock wave is required to produce a sound pulse that is loud enough to be detected above the background in a large boiler when the measurement path is more than 10 meters long.

In the gasifier environment, the internal process pressure is in the range of 400 to $1200 \mathrm{psi}$. In this case, the use of an external pressure vessel is impractical since achieving a 25 to 1 pressure ratio would require pressurizing the pressure vessel to between 10,000 and 30,000 psi. Therefore, one of the challenges of this project was to develop an alternate method of generating a sound pulse that could be injected into the gasifier environment and used to make a measurement of sound speed inside the gasifier process.

Another issue that required attention had to do with the propagation time inside a typical gasifier. In order to achieve a given level of accuracy in a temperature measurement based on sound speed, the uncertainty in the sound speed measurement must be half the tolerable uncertainty in the temperature. This is because of the square root relationship between temperature and sound speed. Thus, if it is desired to determine the absolute temperature with an accuracy of $1 \%$, it is necessary to measure the sound speed with an accuracy of $1 / 2 \%$. In a large boiler, typical sound propagation times are on the order of 20 to 50 milliseconds, so achieving a measurement accuracy of $1 \frac{2}{2} \%$ implies that the time of flight must be measured with an accuracy of between 100 and 250 microseconds. This requires the receiver to have a frequency response of no more than $10 \mathrm{kHz}$. In the gasifier environment, the path lengths are much shorter and gas temperatures are somewhat higher than in the boiler environment. Therefore, the anticipated sound propagation times are on the order of 2 to 4 milliseconds. In this case, achieving a $1 / 2 \%$ timing accuracy requires that the time of flight be resolved to within 10 to 20 microseconds. This implies that one must measure frequencies in the range of 50 to $200 \mathrm{kHz}$. In addition to requiring higher frequency response components, this also raises concerns relating to the attenuation of sound waves by the process environment inside the gasifier. These issues were addressed during the course of the project and are discussed in detail in subsequent sections of this report.

Another significant challenge in adapting acoustic pyrometry to the gasifier environment has to do with "end corrections". In making a measurement of the sound propagation time, what 
is actually measured is the time between the detection of the wave on the generator side as it enters the barrel connecting the generator to the process, and on the receiver side, the wave is detected after it propagates through the process and through a waveguide that connects the receiver to the process (see Figure 1).

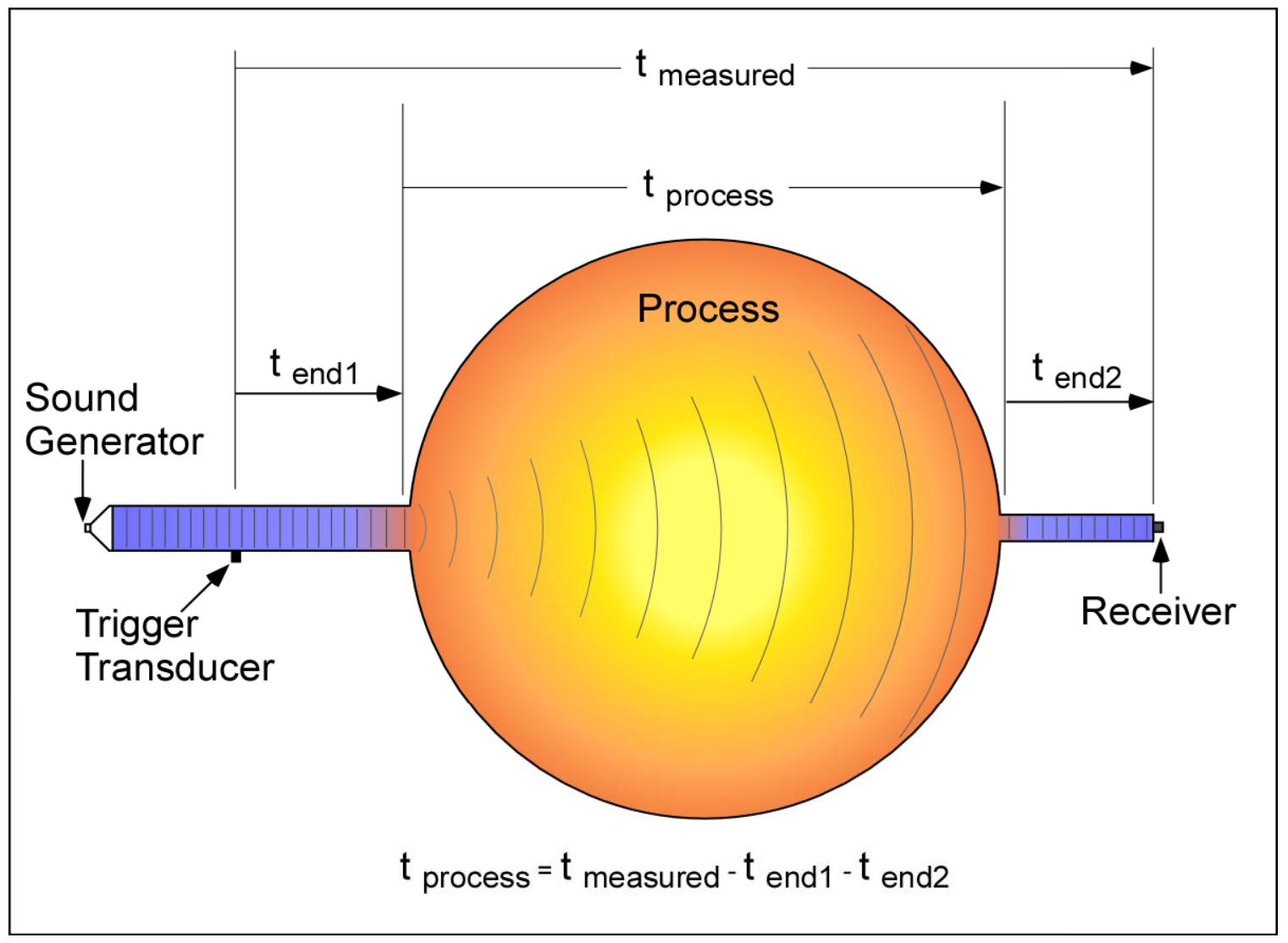

Figure 1. End corrections to measured propagation time

In general it isn't possible to measure these end corrections directly, and they must be estimated from laboratory measurements or models of the sound wave propagation in the barrels. In a typical boiler measurement, the end corrections represent a small fraction of the total measured time of flight - typically 2 to 10 milliseconds out of a total of 50 milliseconds or more. Therefore, small errors in estimating the end corrections do not have a significant impact on the overall accuracy of the measurement. In the gasifier environment, the end corrections will be comparable to those in the boiler application, but the propagation time inside the gasifier will be very much smaller. Therefore, the end corrections can constitute as much as $2 / 3$ of the total measured propagation time and errors in estimating the end corrections can produce large errors in the temperature measurement. Consequently, in the gasifier application, it is critical to have an accurate model of the sound and shock wave propagation inside the receiver and generator barrels, respectively.

Another shock propagation issue relates to shock strength and supersonic propagation. The sound pulse that propagates down the generator barrel is a shock that propagates at supersonic velocity. As the shock expands inside the gasifier chamber, the driving pressure decreases inversely with the square of the distance, so that within a fairly short distance, the shock 
strength becomes small and the Mach number of the wave approaches unity (sonic velocity). For a large-scale boiler where typical path lengths are on the order of 10 to 30 meters, the magnitude of the correction is negligibly small. In a 2-meter wide gasifier, the correction will be more significant and must be accounted for.

\section{EGS1 test facility}

As part of this project, Enertechnix constructed a large pressure vessel - the Enertechnix Gasifier Simulator \#1 (EGS1) - which was used to test various sound generation and coupling methods. The vessel has an inside height of 48 inches and an internal diameter of 22 inches. The cylindrical portion has 1 inch thick walls and has an allowable working pressure of 1000 psi. When the unit is filled with room temperature air, the propagation time of an acoustic wave across the diameter of this vessel is approximately 1.6 milliseconds which is very close to the propagation time of an acoustic wave in syngas at normal gasifier temperature traveling across the width of a full size gasifier. The EGS1 unit is equipped with two diametrically opposed ports at the mid-height location which can be used to test a variety of sound generators and receivers. The unit, which is shown in Figure 2, is located next to Enertechnix' laboratory facility in Tenino, WA.

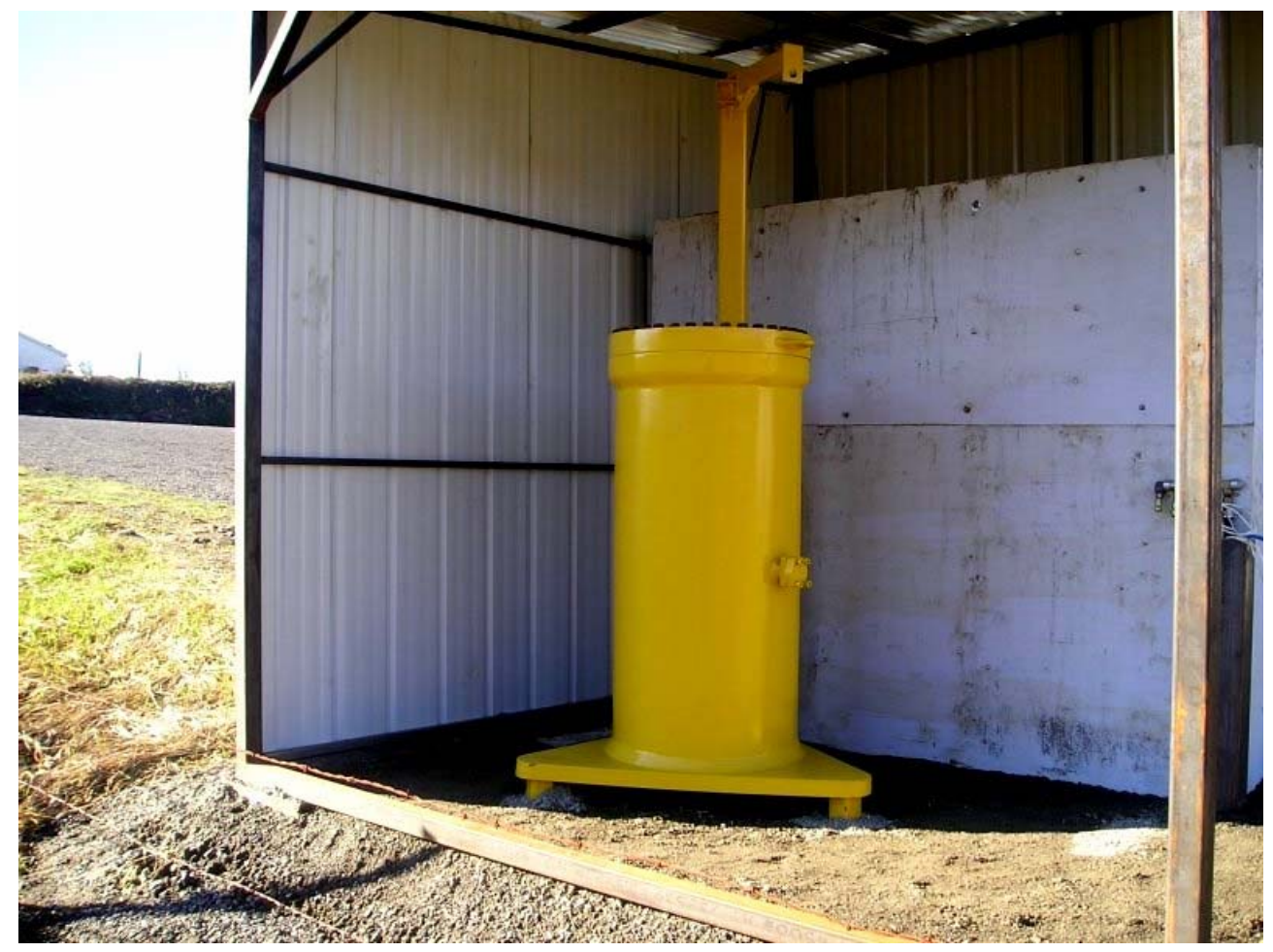

Figure 2. The Enertechnix Gasifier Simulator (EGS1) 


\section{Sound attenuation}

\subsection{Vibrational relaxation of high temperature gas molecules}

In coal-fired boilers, vibrational relaxation of the gas molecules through which a sound wave propagates is not a significant issue primarily because the modest timing accuracy required in these environments allows the use of relatively low frequency sound waves to measure temperature. However, at the high frequencies required in the gasifier environment, this interaction becomes a significant issue. Prof. Hornung at Cal Tech (one of the collaborators on this project) has calculated the attenuation of sound propagating through high temperature syngas at 400 psi and his calculations show that there is very severe attenuation above about $100 \mathrm{kHz}$. Figure 3 shows this behavior for a 2 meter path in syngas at about $3000 \mathrm{deg}$ F.

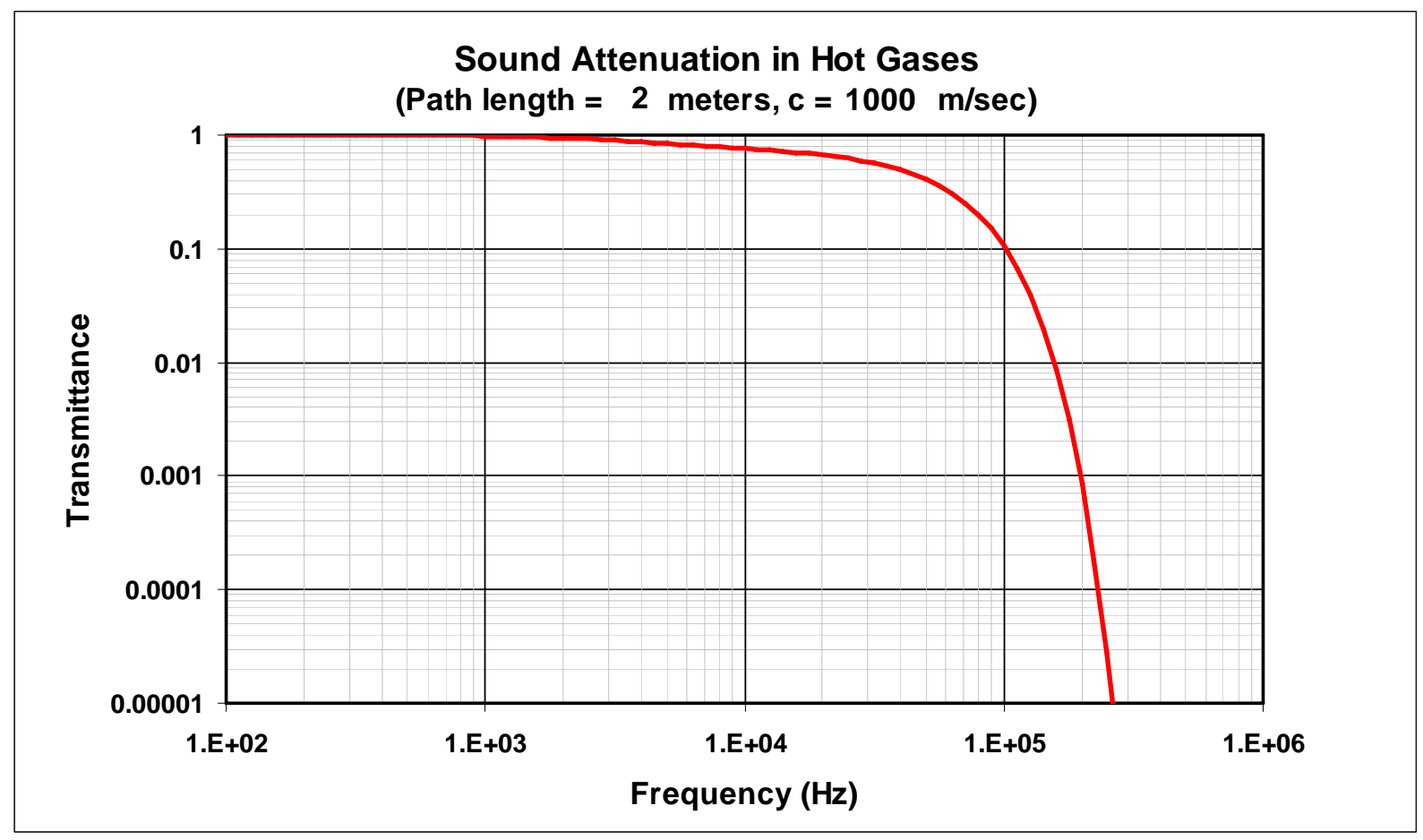

Figure 3. Sound attenuation due to vibrational relaxation of gas molecules.

From this figure, we can see that on a 2 meter path the attenuation due to interaction of the sound wave with the high temperature gases is tolerable up to about $100 \mathrm{kHz}(10 \%$ transmittance), but that at higher frequencies the attenuation becomes extremely large. Therefore, it will not be possible to detect frequencies much above $100 \mathrm{kHz}$ in the gasifier environment at a temperature as high as that used in this calculation. At lower temperatures, the attenuation curve will shift to the right, so it should be possible to use somewhat higher frequencies at lower temperatures.

As discussed earlier, the timing accuracy required in the gasifier environment is on the order of \pm 10 microseconds. This is compatible with detection of frequencies up to 100 to $200 \mathrm{kHz}$. Therefore, the predictions of this model suggest that it should be possible to achieve the 
desired temperature measurement accuracy with an acoustic time-of-flight measurement in a coal gasifier.

\subsection{Effects of suspended particles}

Shaw [3] presents expressions for the impact of suspended particles on sound propagation. These include thermal and viscous damping which produce attenuation, as well as excitation of particle oscillations which, in turn, produce secondary sound emissions with a phase lag. This latter phenomenon results in a shift in sound speed as a function of frequency (dispersion). The model upon which these expressions are based shows that a number of physical properties of the particles and the gas are important in evaluating these phenomena.

We have created a spreadsheet model to calculate attenuation and dispersion based on Shaw's model and have used it to predict the magnitude of these effects as a function of particle loading, particle size, particle and gas densities, gas viscosity and thermal conductivity, particle and gas specific heats, and sound frequency.

Little or no experimental data exists on the size distribution and loading of suspended particles in coal gasifiers. To our knowledge, no direct measurements of these properties have been made in-situ in an operating gasifier. Furthermore, we are not aware of any mechanistic models of particle formation and evolution inside a gasifier. Therefore, we have relied on CFD model predictions of particle mass loading and number density provided by REI. An estimate of particle mass concentration and average diameter was provided by ConocoPhillips but was not used in our calculations except to confirm rough order-of-magnitude agreement with the detailed REI model predictions.

REI has provided local values of particle mass loading and number density at the model node locations along lines A and B (see Figure 6) for operation with both coal and petcoke. From the mass loading and an assumed value for the ash particle density, we can calculate a volume concentration. From the volume concentration and number density we can obtain the mean particle volume and from that we can calculate the mean particle diameter at each node location. These values allow us to estimate average values for particle loading and particle diameter along lines $\mathrm{A}$ and $\mathrm{B}$.

In addition, we have created a spreadsheet model to estimate upper limits on the possible ash loading based on global considerations. In this model, we begin with the ultimate analysis of the fuel (coal or petcoke), the molecular composition of the syngas, the known slurry concentration, and the ratio of oxygen to nitrogen in the oxidizer. By performing a mass balance calculation on each of the atomic species in the fuel (carbon, hydrogen, oxygen, nitrogen, and sulfur), we can determine the amount of oxidizer required to produce the given syngas composition as well as the amount of carbon that winds up as unburned char. Then, given the feed rate of the fuel, we can calculate the mass flow of syngas and the mass flow of ash, from which we can determine the mass fraction of ash in the syngas. From this value and the densities of the syngas and the ash, we can determine the volume concentration of ash in the syngas. This is the maximum possible ash concentration assuming all the ash remains in suspension. 
To estimate the ash volume concentration at the inlet to the second stage (corresponding to Line B in Figure 6), we can make a somewhat crude approximation in which we assume that some fraction of the fuel slurry and all of the oxidizer is introduced into the first stage. If we assume that the ratio of the mass of syngas to mass of fuel slurry plus oxidizer is the same in the first stage as it is for the overall gasifier, we can estimate the ash mass fraction produced in the first stage. This approximation is certainly not correct, but the error in the inferred ash loading value is probably not greater than 20\%. Again, this estimate assumes all the ash remains in suspension. By assuming a certain fraction of the ash deposits on the walls of the first stage vessel and is removed through the slag tap in the bottom, we can estimate the ash loading entering the second stage.

Table 1 shows the estimated particle loading for coal and petcoke gasification based on the REI CFD model and our mass balance model.

\begin{tabular}{|c|c|c|c|c|}
\hline & \multicolumn{2}{|c|}{ Coal } & \multicolumn{2}{|c|}{ Petroleum Coke } \\
\hline & Line $A$ & Line B & Line $A$ & Line B \\
\hline \multicolumn{5}{|l|}{ REI CFD Model } \\
\hline Mass Conc. $\left(\mathrm{kg} / \mathrm{m}^{3}\right)$ & 0.1634 & 0.0582 & 0.13257 & 0.00099 \\
\hline Number Density $\left(\# / \mathrm{m}^{3}\right)$ & $2.80 \times 10^{11}$ & $2.29 \times 10^{11}$ & $1.81 \times 10^{11}$ & $4.98 \times 10^{10}$ \\
\hline \multicolumn{5}{|l|}{ Values Inferred from REI Model } \\
\hline$C_{v}\left(m^{3} / m^{3}\right)$ & $6.106 \times 10^{-5}$ & $2.155 \times 10^{-5}$ & $4.91 \times 10^{-5}$ & $3.65 \times 10^{-7}$ \\
\hline Avg. Particle Volume $\left(\mathrm{m}^{3}\right)$ & $2.52 \times 10^{-16}$ & $1.50 \times 10^{-16}$ & $3.53 \times 10^{-16}$ & $1.29 \times 10^{-17}$ \\
\hline Avg. Particle Diameter (microns) & 7.5 & 6.4 & 8.5 & 2.5 \\
\hline \multicolumn{5}{|l|}{ ETX Mass Balance Model } \\
\hline $\mathrm{C}_{\mathrm{v}}$ (no deposition) & $8.326 \times 10^{-5}$ & $4.301 \times 10^{-5}$ & $3.294 \times 10^{-}$ & $1.157 \times 10^{-}$ \\
\hline $\mathrm{C}_{\mathrm{v}}(50 \%$ deposition) & $6.175 \times 10^{-5}$ & $2.150 \times 10^{-5}$ & $3.2095 \times 10^{-}$ & $3.884 \times 10^{-}$ \\
\hline
\end{tabular}

Table 1. Ash loading and particle size for coal gasification

In Table $1, \mathrm{C}_{\mathrm{v}}$ stands for volume concentration and is calculated assuming an ash density of $2700 \mathrm{~kg} / \mathrm{m}^{3}$. For the case of coal gasification our mass balance model and REI's detailed CFD model yield nearly identical values for the volume concentration of particles assuming 50\% ash deposition in stage 1 . For the case of petcoke gasification our model is in very good agreement for conditions at the entrance to the second stage (line B), but are noticeably lower than the REI predictions for conditions in the second stage. Nevertheless, it is clear that even a very simplistic global model is capable of predicting particle loading in the gasifier to well within a factor of two of that predicted by CFD modeling. It should be kept in mind that the CFD model is itself an idealization of the actual process. The CFD model does not contain any particle generation mechanisms and its predictions are based on assumed ash particle sizes.

Using these estimates of particle size and loading along with estimates of the physical properties of the particles and gases, we have studied the probable attenuation of sound waves 
in the gasifier environment due to the presence of suspended particles. Figure 4 shows the predicted attenuation for a 2 meter path length at a number of different particle loading levels.

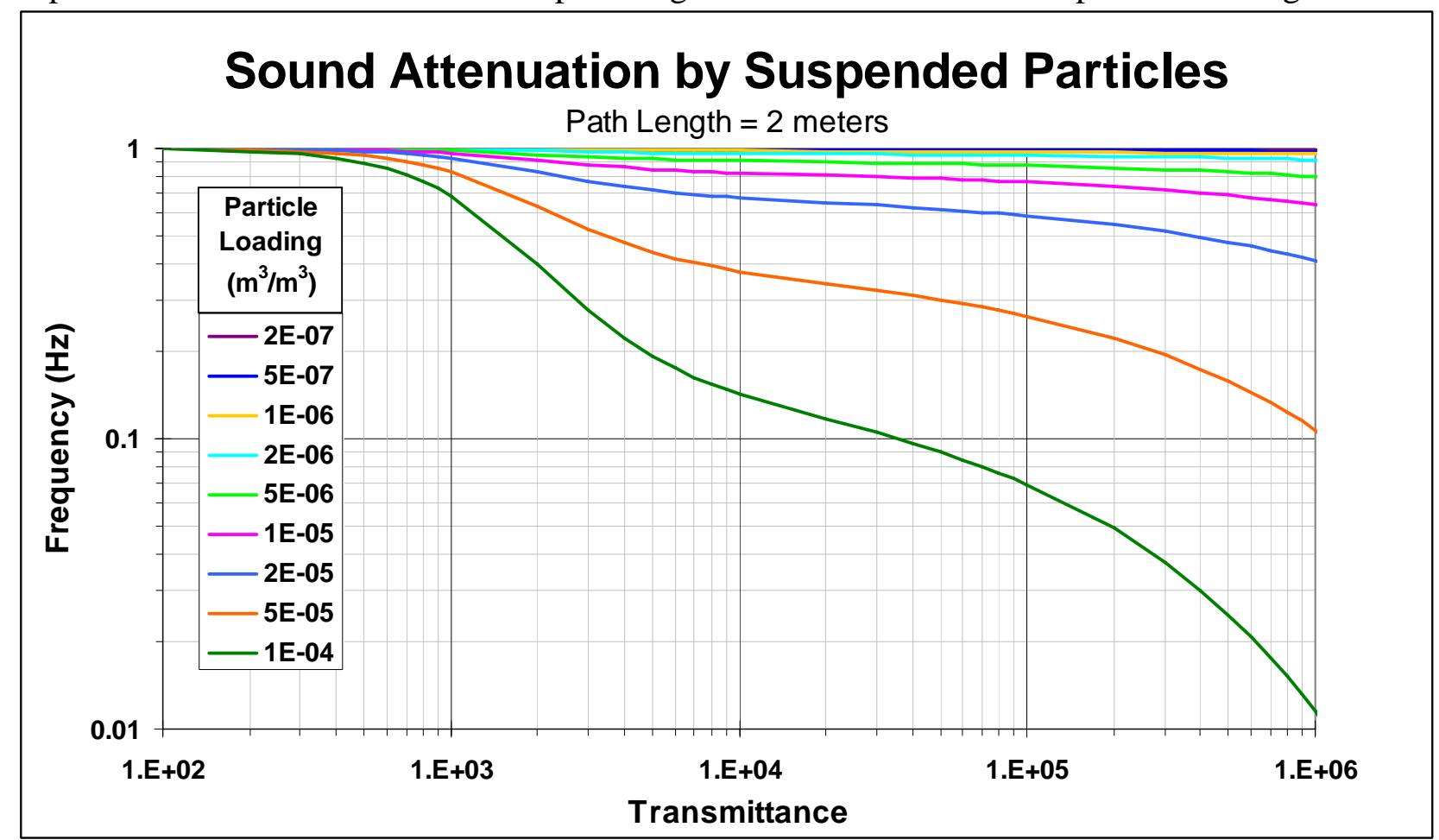

Figure 4. Sound attenuation by suspended particles

This figure shows that at a frequency of $100 \mathrm{kHz}$, particle volume fractions up to about $5 \times 10^{-5}$ produce only modest attenuation of the sound wave. This suggests that it should be possible to make an effective measurement of gas temperature inside a gasifier operating either on petroleum coke or coal.

\subsection{Sound Dispersion}

As mentioned above, suspended particles also produce a shift in sound propagation speed which depends on all of the properties that lead to sound attenuation. We have employed relationships reported by Temkin [4] to calculate the magnitude of this effect assuming the same particle size and loading used in the attenuation calculations above.

As shown in Figure 5, the sound speed ratio (the ratio of sound speed in the particle-laden gas to that in the particle-free gas) deviates significantly from unity only for frequencies below a few kilohertz. This is because the particles - with their finite mass and thermal properties are only able to respond to fluctuations in gas pressure and temperature which occur on time scales that are short relative to the viscous and thermal relaxation times of the particles. For fluctuations that occur more rapidly than that, the particles are unable to respond and remain fixed. Therefore, for these higher frequency fluctuations, the observed sound speed is unaffected by the presence of particles. In Figure 5 we have assumed a particle loading at the upper limit of what is expected in a coal gasifier (see Table 1). 


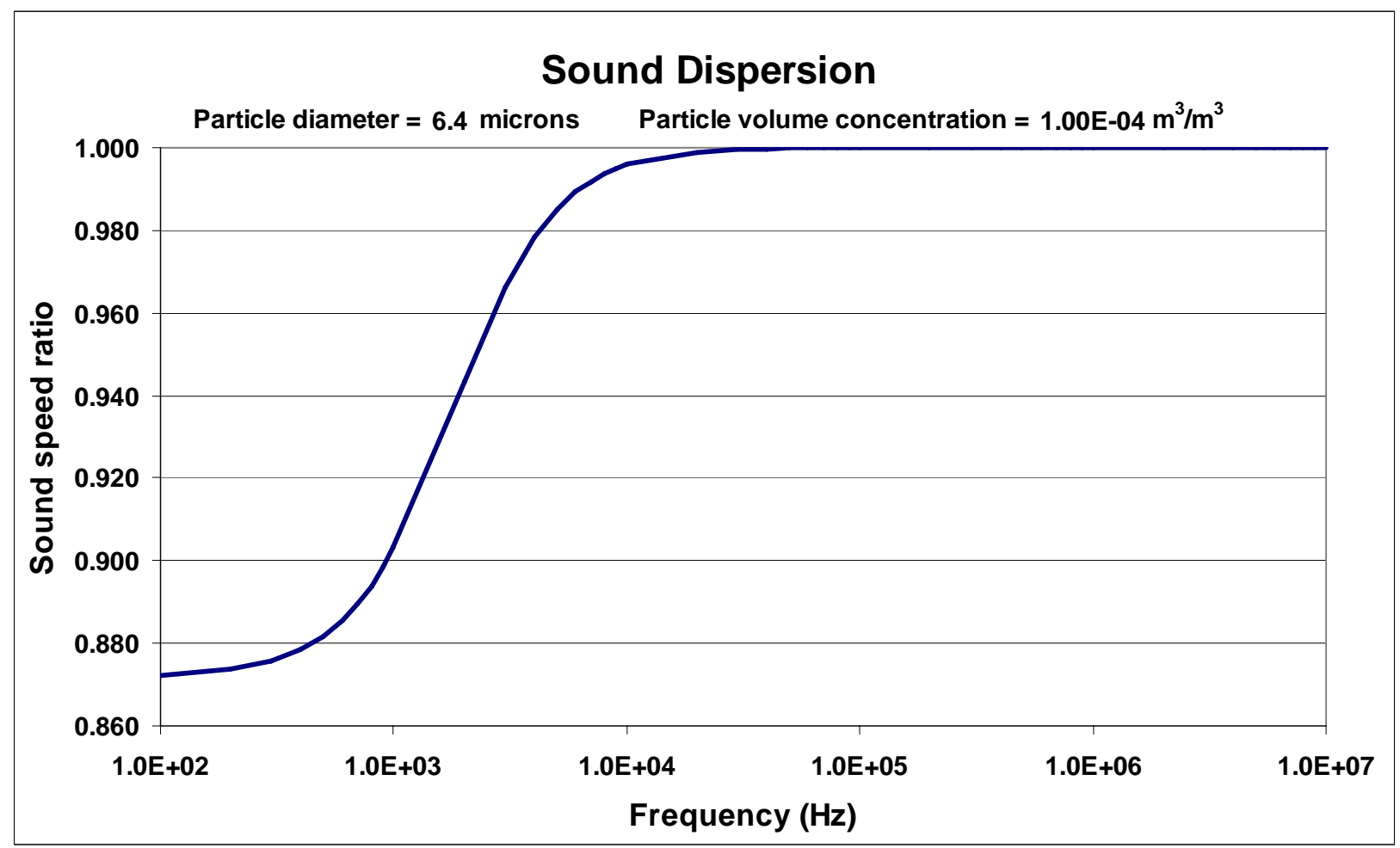

Figure 5. Sound dispersion in the gasifier environment

\section{Gas Composition Effects}

\subsection{Spatial non-uniformity}

The CFD modeling data obtained from Reaction Engineering, International in December, 2003 was analyzed in some detail to determine the degree of spatial variability of gas composition and temperature along a line of sight through the gasifier and to assess the effect of this variability on inferred temperature based on sound speed measurements.

The gasifier modeled by REI is an idealization of an entrained flow two-stage gasifier. Unlike the Wabash gasifier that has a T-shaped vessel with a horizontal cylinder for the first stage and a vertical cylinder for the second stage, the REI model consists of a single vertical cylinder of varying diameter. The geometry of the REI model gasifier is shown in Figure 6. In this model, line A represents a line of sight along a diameter of the gasifier in the second stage; line B represents a line of sight along a diameter at the transition between the first and second stages. 


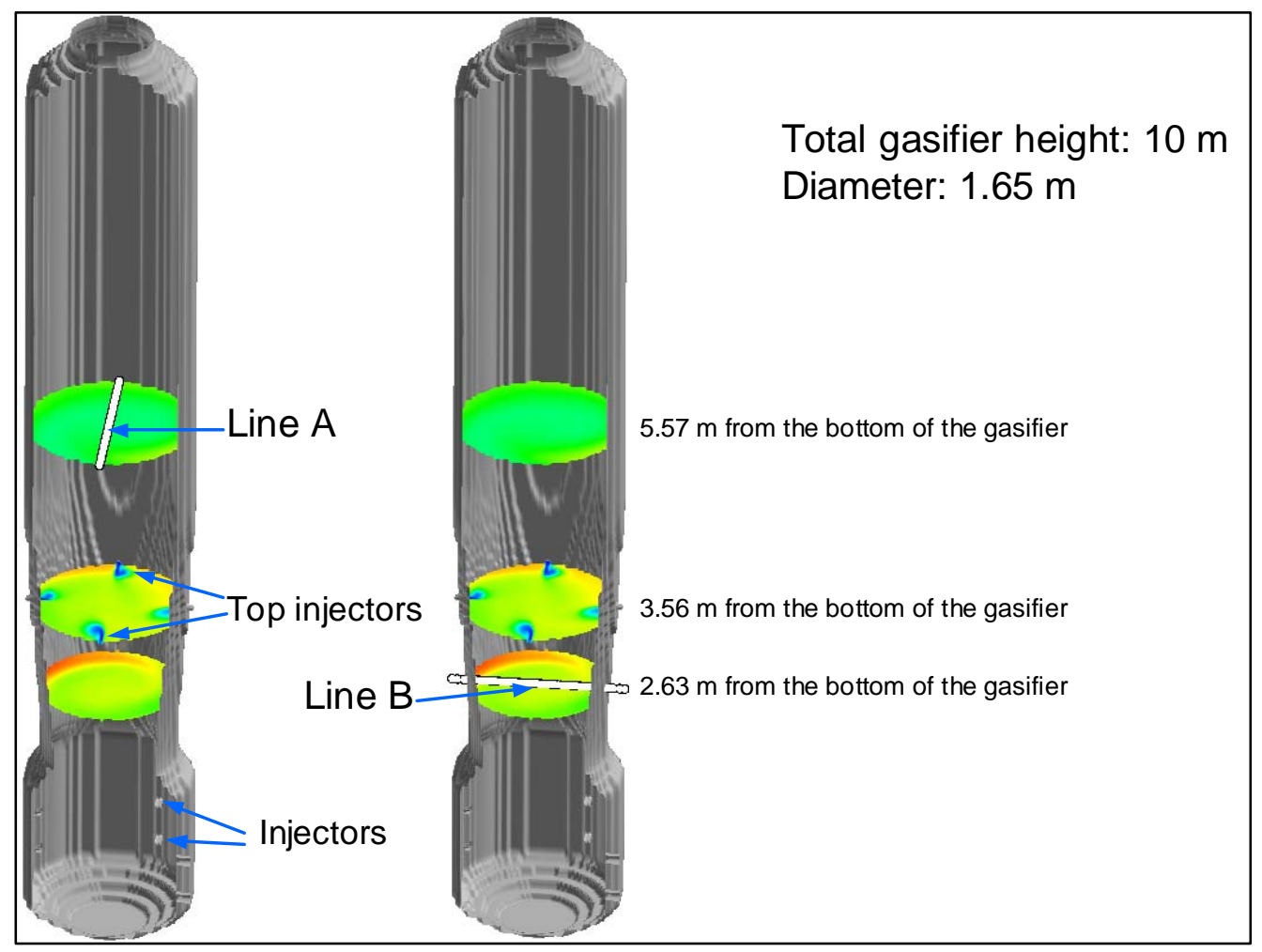

Figure 6. Geometry of the REI 2-stage, entrained flow model gasifier

REI provided data for gas temperature and composition at each node location along lines A and B. From these data, we calculated the thermodynamic and transport properties of the gas at each location. These calculated values were used to compute the time of flight of a sound pulse along these lines from one side of the gasifier to the other; from these times of flight, an inferred average gas temperature was calculated using a variety of assumptions about average gas molecular weight and specific heat ratio.

Figure 7 and Figure 8 show the temperature profiles on lines A and B, respectively, from the REI simulation. Interestingly, unlike boilers with tube walls where the gas temperature is lowest near the walls and highest in the center, the gas temperature profiles in this refractorylined gasifier show the highest temperatures occurring near the walls and much cooler temperatures in the center. In this situation, acoustic temperature measurement is much preferred over optical line of sight methods since the acoustic method provides a true average in which all locations along the line of sight are weighted equally, whereas optical (infrared) pyrometry is inherently more sensitive to regions close to the measurement device; and also, regions where the gases are hottest will emit far more radiation than the cooler regions. Therefore, when the hottest gases are found near the wall, the optical method will produce readings that are far above the true average temperature along the line of sight. The magnitude of this error will be sensitive to the shape of the temperature profile along that line. 


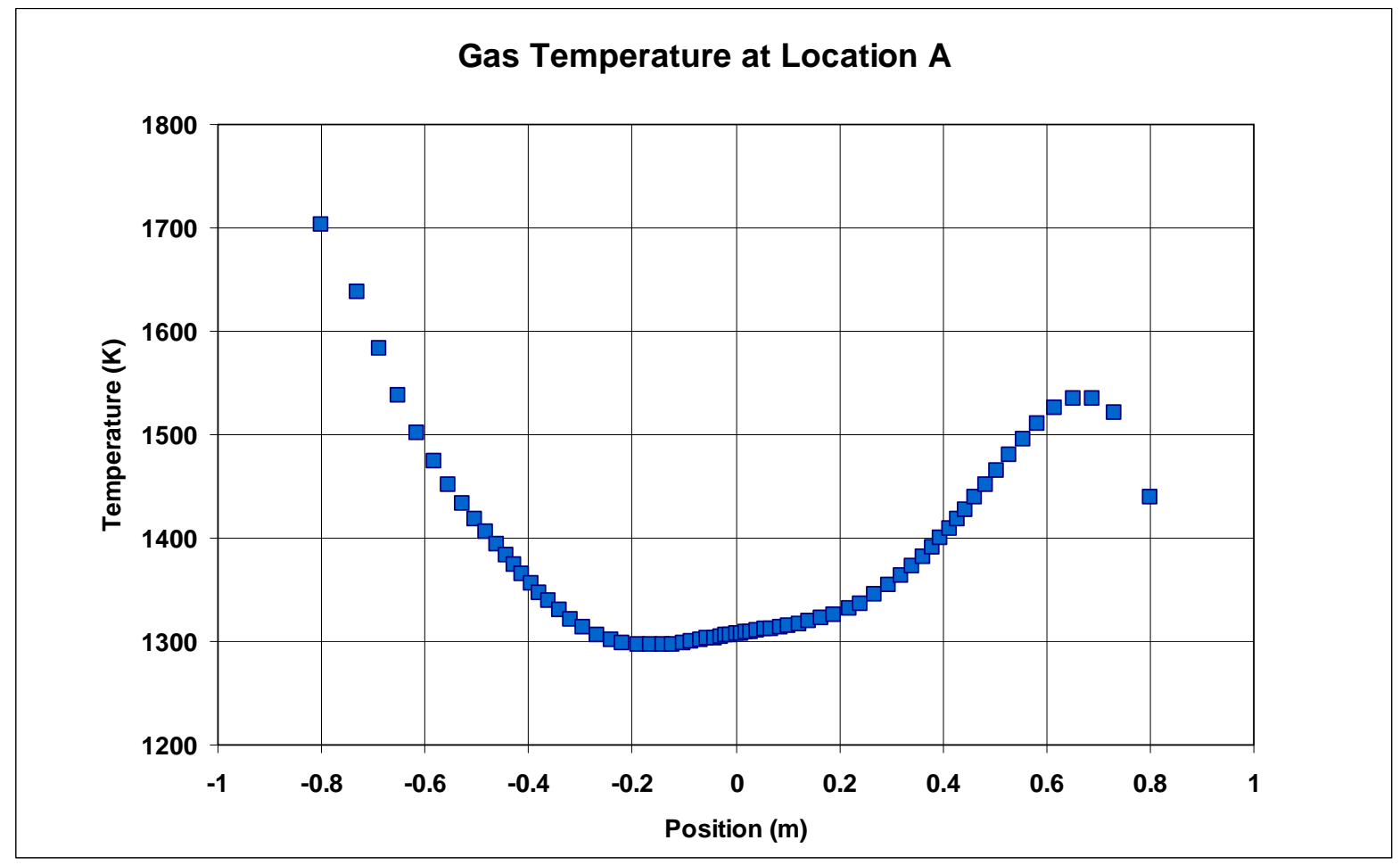

Figure 7. Temperature along line A from REI CFD simulation

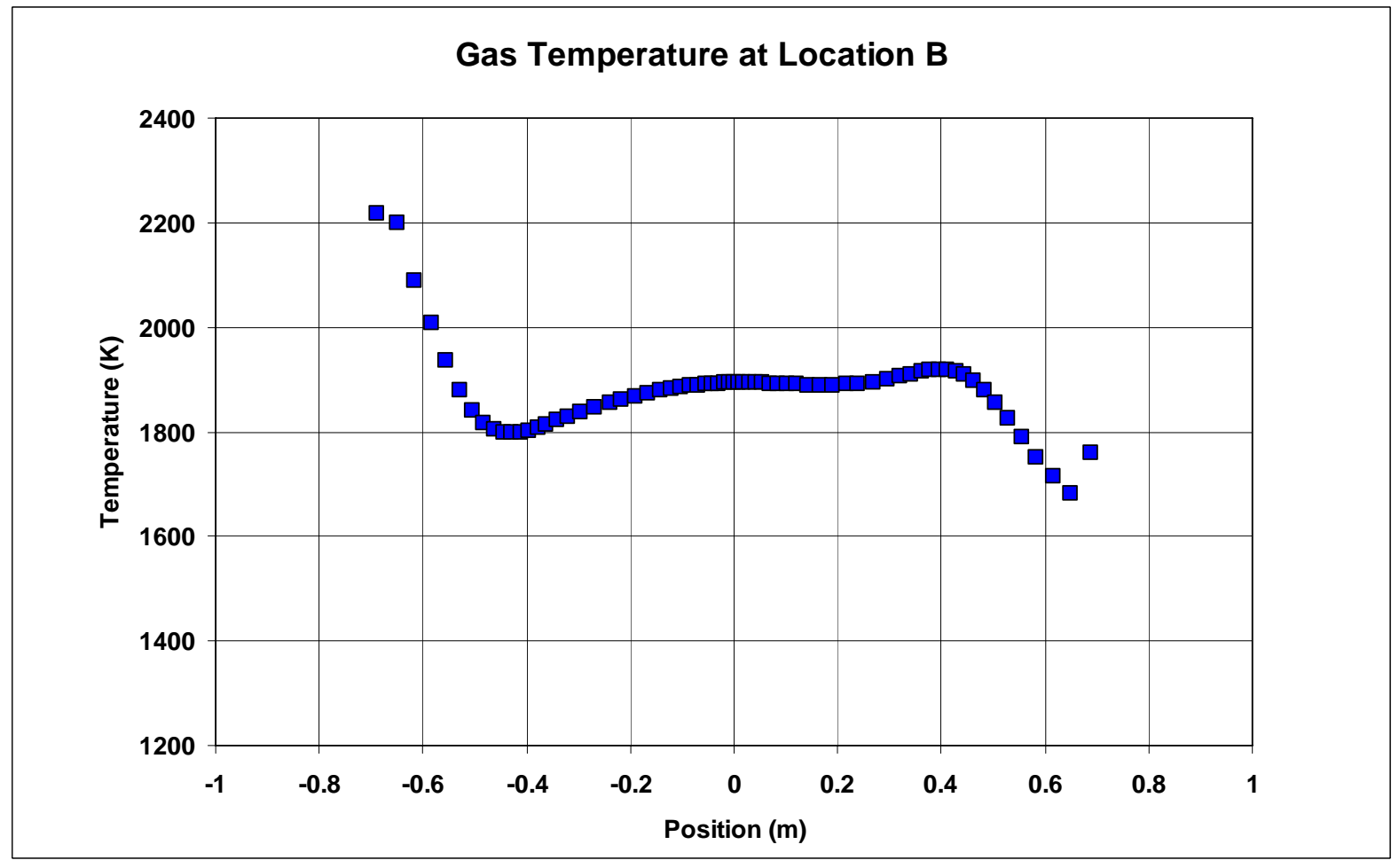

Figure 8. Temperature along line B from REI CFD simulation

Figure 9 and Figure 10 show the gas composition variation along lines A and B, respectively. 


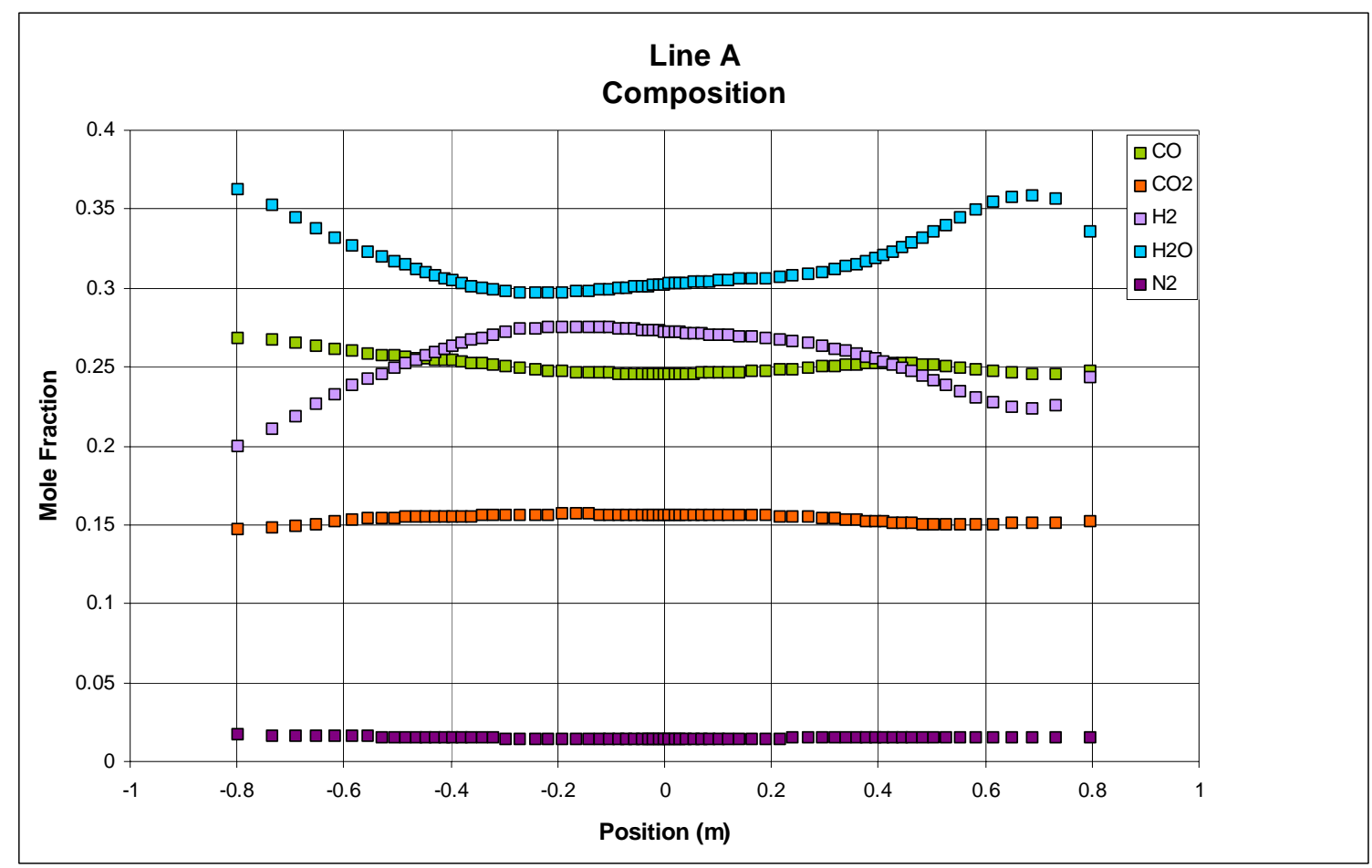

Figure 9. Composition along line A from REI CFD simulation

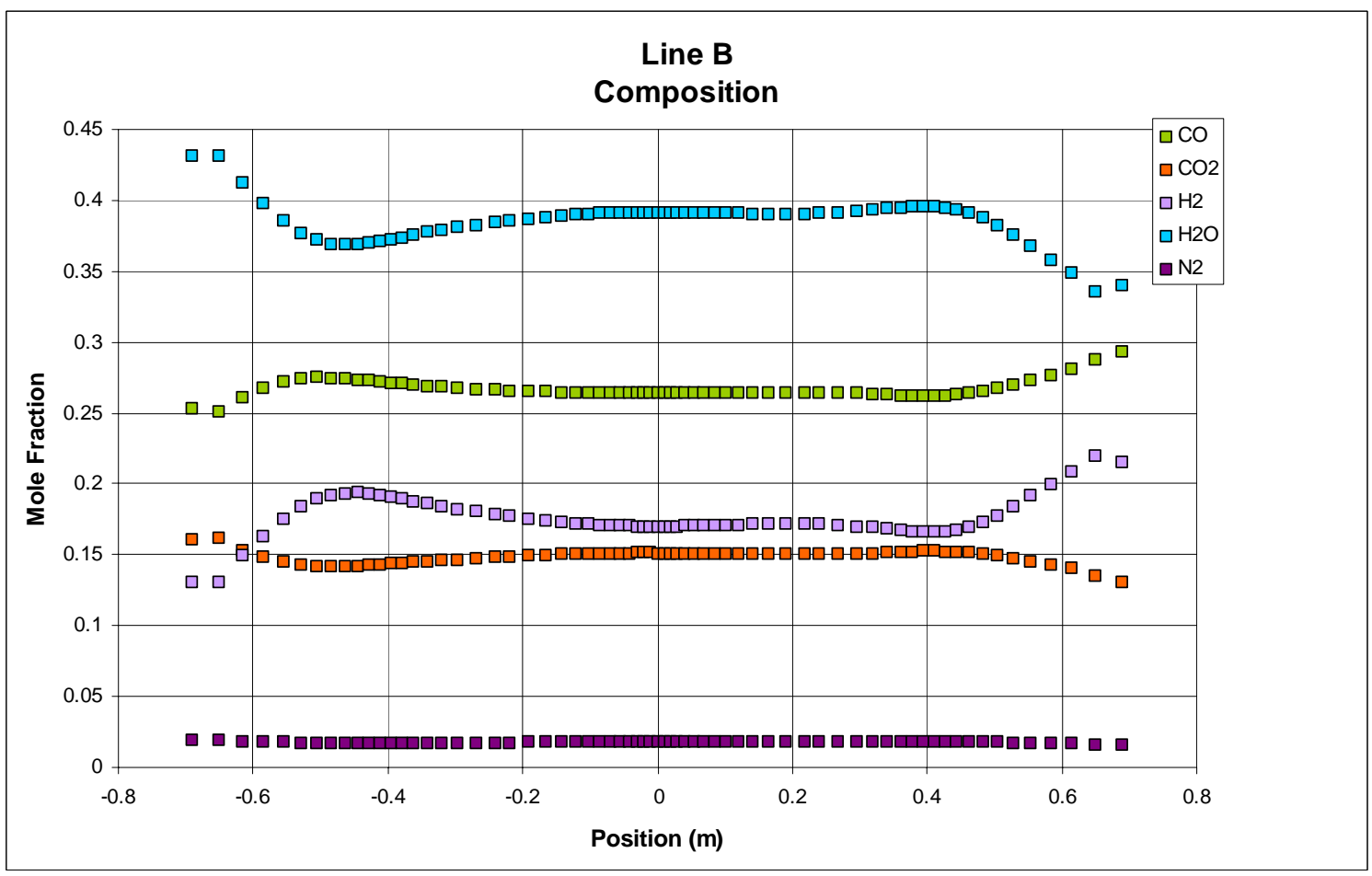

Figure 10. Composition along line B from REI CFD simulation 
Figure 9 and Figure 10 show that there is a significant variation in gas composition along these two paths. This will result in variation in sound speed along these paths which is shown in Figure 11 and Figure 12.

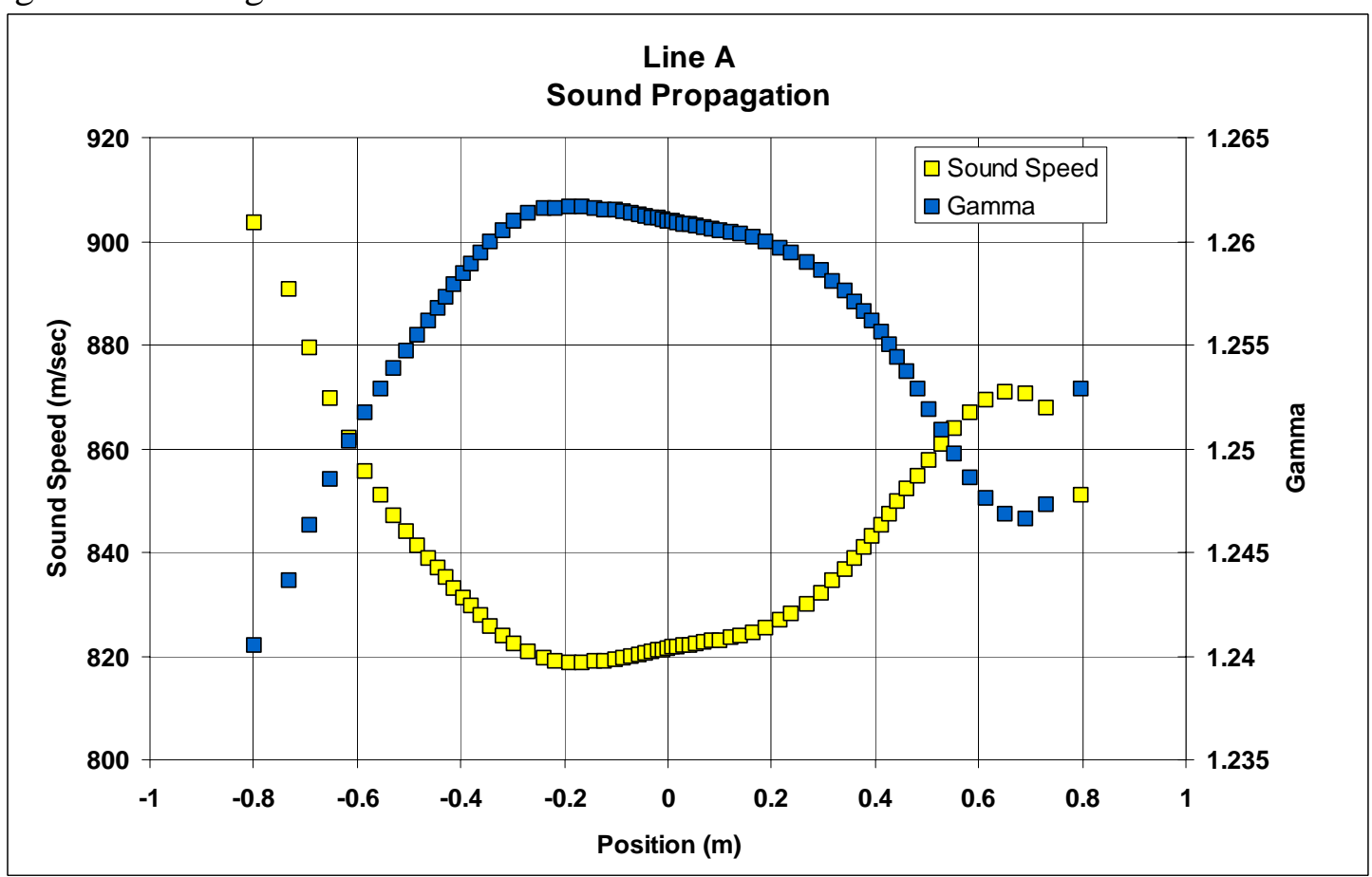

Figure 11. Variation of sound speed and specific heat ratio along line A

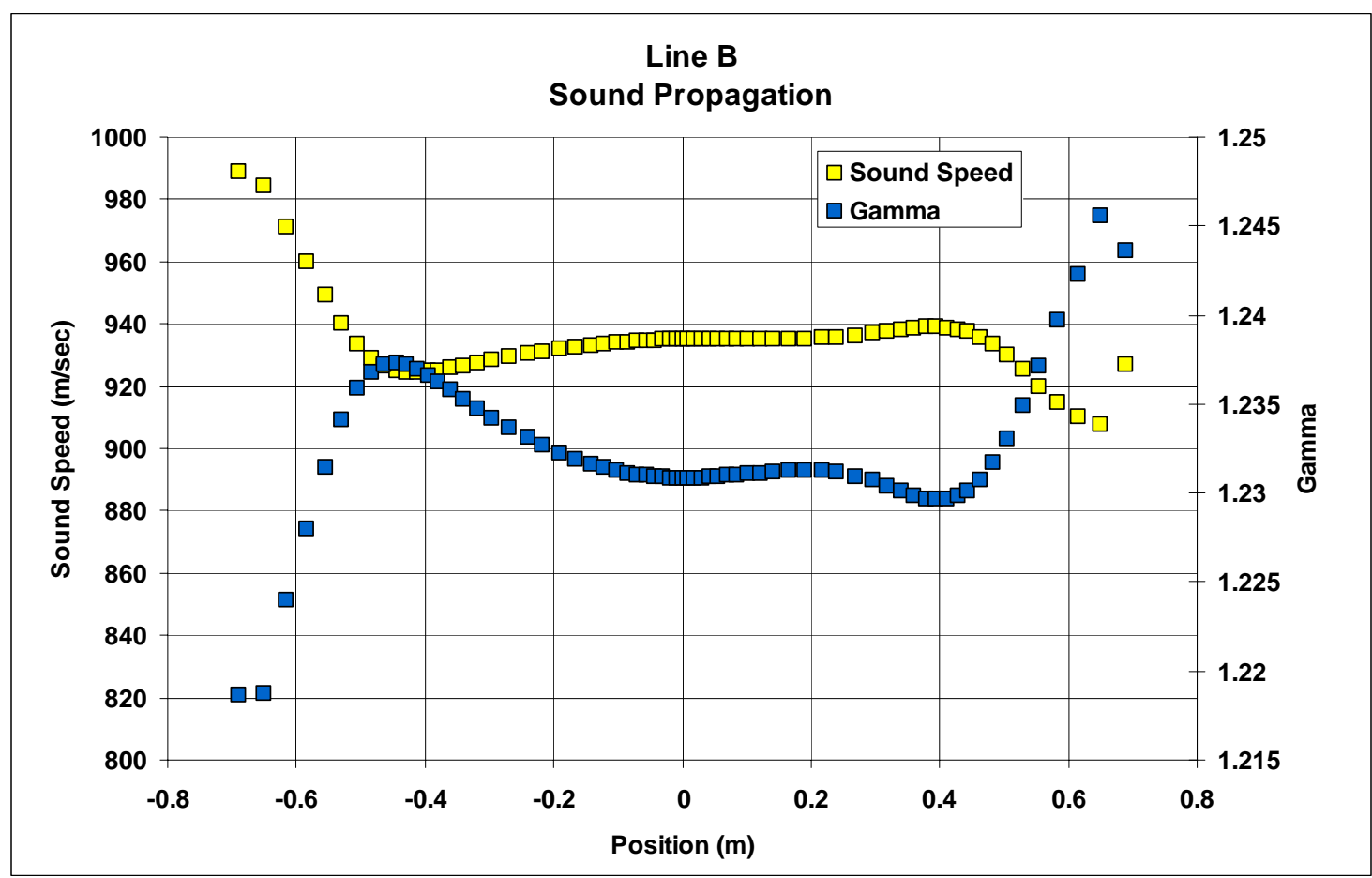

Figure 12. Variation of sound speed and specific heat ratio along line B 
Table 2 below, shows the range of values along line A for the CFD model predictions of gas temperature and molecular weight as well as values for specific heat ratio $(\gamma)$, and sound speed that we have calculated based on the CFD model values of local gas composition and temperature at each point along this line. Two sets of values are presented - the first based on the complete gas composition provided by REI which includes mole fractions of the following species: $\mathrm{CO}, \mathrm{CO}_{2}, \mathrm{H}_{2}, \mathrm{H}_{2} \mathrm{O}, \mathrm{N}_{2}, \mathrm{CH}_{4}, \mathrm{COS}, \mathrm{H}_{2} \mathrm{~S}, \mathrm{HCN}, \mathrm{NH}_{3}, \mathrm{H}, \mathrm{OH}$, and $\mathrm{SO}_{2}$, and the second based on just the first six species which constitute roughly $99.3 \%$ of the total moles of syngas.

\begin{tabular}{|r|c|c|c|c|c|c|c|c|}
\hline \multirow{2}{*}{ Line A } & \multicolumn{2}{|c|}{ CFD Model Results (all species) } & \multicolumn{3}{c|}{ CFD Model Results (major species) } \\
\cline { 2 - 9 } & $\begin{array}{c}\text { Temp. } \\
(\mathbf{K})\end{array}$ & $\begin{array}{c}\text { Mol. Wt. } \\
(\mathbf{k g} / \mathbf{m o l e})\end{array}$ & $\gamma$ & $\begin{array}{c}\text { Sound spd. } \\
(\mathbf{m} / \mathbf{s e c})\end{array}$ & $\begin{array}{c}\text { Temp. } \\
(\mathbf{K})\end{array}$ & $\begin{array}{c}\text { Mol. Wt. } \\
(\mathbf{k g} / \mathbf{m o l e})\end{array}$ & $\gamma$ & $\begin{array}{c}\text { Sound spd. } \\
(\mathbf{m} / \mathbf{s e c})\end{array}$ \\
\hline Minimum $=$ & 1296.5 & 20.38 & 1.240 & 816.7 & 1296.5 & 20.29 & 1.241 & 818.7 \\
Average $=$ & 1415.0 & 20.75 & 1.254 & 841.9 & 1415.0 & 20.66 & 1.255 & 843.9 \\
Maximum $=$ & 1702.6 & 21.60 & 1.261 & 901.4 & 1702.6 & 21.51 & 1.262 & 903.5 \\
Standard Deviation $=$ & 92.2 & 0.28 & 0.005 & 19.8 & 92.2 & 0.28 & 0.005 & 19.8 \\
\hline
\end{tabular}

Table 2. Range of variation of gas properties along line A

Table 2 shows that estimates of sound speed made by considering only the 6 most prevalent species differ from those made by considering all 13 species by only about $0.24 \%$. Therefore, we conclude that estimates based on the reduced set of species will introduce an error in the temperature inferred from a sound speed measurement of less than $0.5 \%$.

From the local values of sound speed calculated at each location along line A and the physical length of the cell at each location, a local time of flight of a sound pulse can be calculated. By adding up these local times of flight and dividing the sum into the total path length, we obtain the true average sound speed. This is the average sound speed shown in Table 2, above.

Table 3 shows similar results for line B.

\begin{tabular}{|c|c|c|c|c|c|c|c|c|}
\hline \multirow[t]{2}{*}{ Line B } & \multicolumn{4}{|c|}{ CFD Model Results (all species) } & \multicolumn{4}{|c|}{ CFD Model Results (major species) } \\
\hline & $\begin{array}{c}\text { Temp. } \\
(\mathrm{K})\end{array}$ & $\begin{array}{c}\text { Mol. Wt. } \\
(\mathrm{kg} / \mathrm{mole})\end{array}$ & $\gamma$ & $\begin{array}{c}\text { Sound spd. } \\
(\mathrm{m} / \mathrm{sec})\end{array}$ & $\begin{array}{c}\text { Temp. } \\
\text { (K) }\end{array}$ & $\begin{array}{c}\text { Mol. Wt. } \\
(\mathrm{kg} / \mathrm{mole})\end{array}$ & $\gamma$ & $\begin{array}{c}\text { Sound spd. } \\
(\mathrm{m} / \mathrm{sec})\end{array}$ \\
\hline Minimum $=$ & 1682.2 & 21.15 & 1.219 & 907.5 & 1682.2 & 21.06 & 1.219 & 909.8 \\
\hline Average $=$ & 1883.7 & 22.02 & 1.232 & 935.5 & 1883.7 & 21.91 & 1.233 & 937.9 \\
\hline Maximum $=$ & 2218.6 & 23.02 & 1.246 & 988.7 & 2218.6 & 22.87 & 1.246 & 992.1 \\
\hline Standard Deviation = & 83.5 & 0.31 & 0.004 & 12.7 & 83.5 & 0.31 & 0.004 & 12.9 \\
\hline
\end{tabular}

Table 3. Range of variation of gas properties along line B

In this case, the sound speed based on only 6 species differs from that based on all 13 species by just over $0.25 \%$. Thus, the conclusion that a reduced model based on six species is adequate holds in this location as well as along line A.

Our inference of gas temperature from a measurement of sound speed requires us to apply the following formula: 


$$
T=c^{2} M / \gamma R
$$

where $\mathrm{T}$ is the gas temperature in Kelvins, $\mathrm{c}$ is the sound speed, $\mathrm{M}$ is the average molecular weight of the gas mixture, $\gamma$ is the specific heat ratio, and $\mathrm{R}$ is the universal gas constant. To determine the potential effect of variations in gas composition on the inferred temperature, we have applied this formula using a variety of assumed values for $\mathrm{M}$ and $\gamma$. In these calculations we have assumed that the measured path-average sound speed on line $\mathrm{A}$ is that shown in Table 2 and for line B it is the value shown in Table 3. In this analysis we assume that we have measured a sound speed experimentally, but do not know the actual gas composition or its variation along the line of sight. Therefore, we apply equation 1 above using the path average sound speed in combination with the minimum and maximum values of the averages of $\mathrm{M}$ and $\gamma$ along the path and assume that these values represent the maximum range of variation in the path averages that would be encountered during normal operation of the gasifier. These estimates assume that the spatial average values of $M$ and $\gamma$ along each line can vary within a range bounded by the extremes of the local values of these properties along each line. This probably represents an upper bound on the likely variation that would be encountered during normal operation of the gasifier.

There are four cases we may consider: the combination of the local minimum $\mathrm{M}$ and local minimum $\gamma$, the local maximum $\mathrm{M}$ and local maximum $\gamma$, the local minimum $\mathrm{M}$ and local maximum $\gamma$, and the local maximum $\mathrm{M}$ and local minimum $\gamma$. Interestingly, we can eliminate the first two cases on the basis of the observation that $\mathrm{M}$ and $\gamma$ are very strongly inversely correlated. This is shown in Figure 13 which presents all the local values of M plotted against the corresponding local values of $\gamma$ on both lines A and B. As can be seen, when $\mathrm{M}$ is at its maximum value, $\gamma$ will be at its minimum and vice versa.

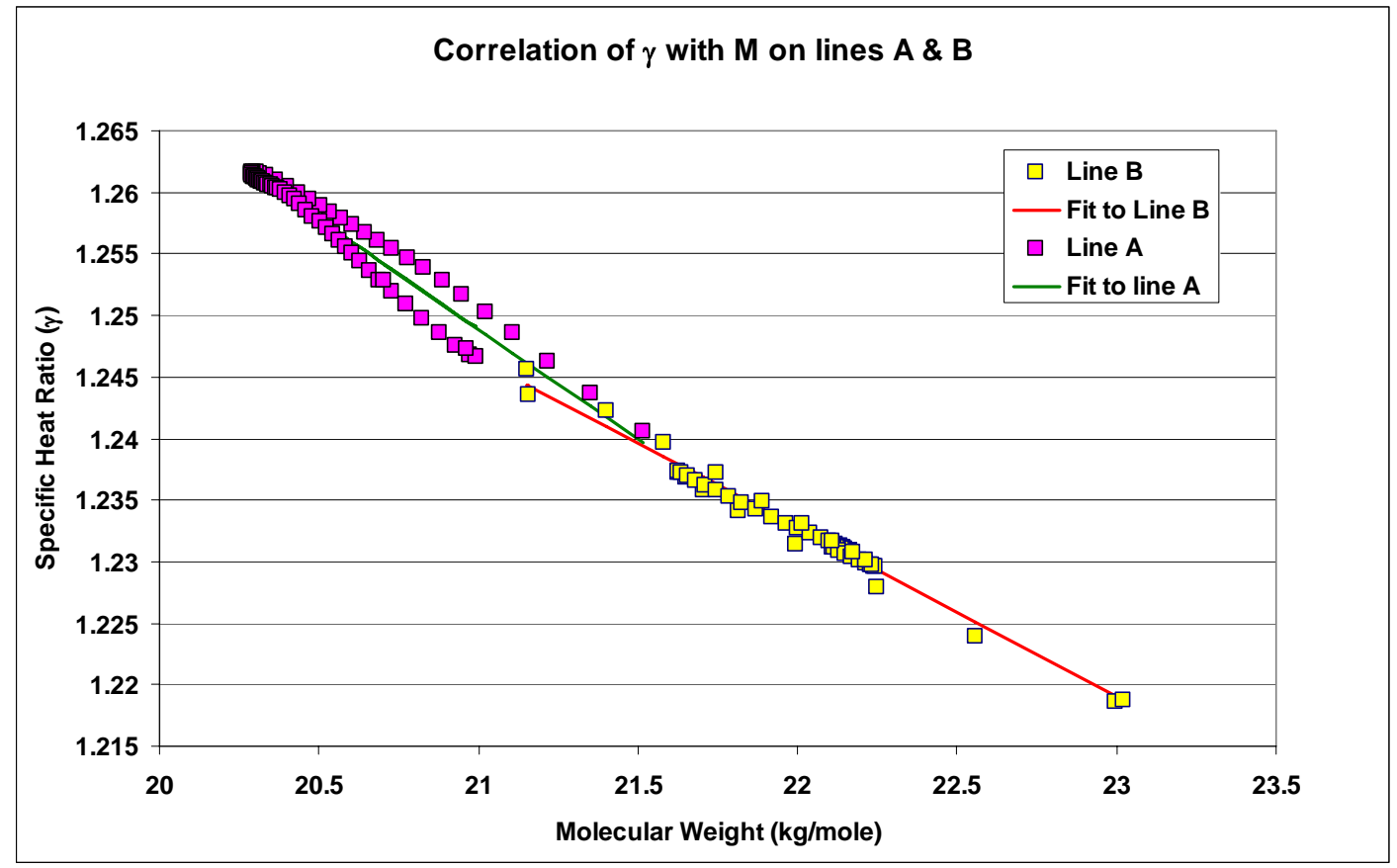

Figure 13. Correlation of molecular weight and specific heat ratio 
Table 4 shows a comparison of the actual average gas temperature with the inferred temperature based on average sound speed and a number of combinations of assumed molecular weight and specific heat ratio.

\begin{tabular}{|c|c|c|c|c|}
\cline { 2 - 5 } \multicolumn{1}{c|}{} & \multicolumn{2}{c|}{ Line A } & \multicolumn{2}{c|}{ Line B } \\
\hline Actual average temperature (K) $=$ & \multicolumn{2}{c|}{1415.0} & \multicolumn{2}{c|}{1883.7} \\
\hline Inferred Temperature (K) & all species & major species & all species & major species \\
\hline Based on average M and $\gamma$ & 1410.0 & 1410.1 & 1880.5 & 1880.5 \\
Based on min. M and max. $\gamma$ & 1377.6 & 1377.4 & 1787.6 & 1787.8 \\
Based on max. M and min. $\gamma$ & 1485.0 & 1485.5 & 1988.5 & 1985.2 \\
\hline Average temperature error $(\mathrm{K})=$ & -4.99 & -4.98 & -3.12 & -3.15 \\
Minimum temperature error $(\mathrm{K})=$ & -37.48 & -37.68 & -96.07 & -95.90 \\
Maximum temperature error $(\mathrm{K})=$ & 69.93 & 70.47 & 104.88 & 101.55 \\
\hline
\end{tabular}

Table 4. Potential range of errors in inferred temperatures

The first thing to notice from this analysis is that there is virtually no difference in the inferred temperatures whether we include all 13 species or consider only the 6 major species. The second thing to note is that the inferred temperature based on the true average $\mathrm{M}$ and $\gamma$ is very close to the actual path weighted average temperature. The differences between the inferred values and the true path average temperatures are shown in the line denoted as "Average temperature error". These are the errors due purely to the non-uniformity of properties along the line of sight assuming we have perfect knowledge of the true average values of molecular weight and specific heat ratio. In this case, the use of spatially averaged values rather than the complete profile along the line of sight leads to errors of between 3 and $5 \mathrm{~K}$ (5.4 to $9 \mathrm{deg} \mathrm{F}$ ) or $0.16 \%$ to $0.35 \%$ of the actual temperature. This is a very small error and is well within the target accuracy of the proposed measurement $( \pm 1 \%)$. This suggests that if we know the actual average gas composition at the measurement location and are able to make a very accurate measurement of sound speed, we can infer the average temperature to well within the desired accuracy.

\subsection{Temporal Variability}

In reality, however, the gas composition within the gasifier will not be constant over time. As shown in Table 4, the errors in the inferred temperature that would result from assuming a fixed gas composition (the average values predicted by the CFD model) when, in fact, the composition varies by the amounts shown in Table 2 and Table 3, would be on the order of $\pm 5 \%$. This estimate is based on a rather ad-hoc assumption about the probable degree of variation in the average composition during normal gasifier operation.

ConocoPhillips has also provided some estimates of the likely range of gas properties (molecular weight and specific heat ratio) in the second stage of the Wabash River gasifier resulting from changes in operating conditions but has not provided any information on the degree of temporal variability of gas composition at a fixed operating condition. The values provided by ConocoPhillips have been used to calculate the maximum range of temperature errors that would result from an assumption that these gas properties remain constant at the 
average value, while the actual properties vary over the maximum range estimated by ConocoPhillips.

From a measurement of the speed of sound in the gasifier, the gas temperature may be calculated using equation (1), above. If, as before, we assume that the molecular weight and specific heat ratio are inversely correlated as shown in Figure 13, then one extreme is given by using the maximum $\gamma$ and minimum MW to calculate temperature and the other extreme is given by using the minimum $\gamma$ and maximum MW. If we assume that the actual gas properties are represented by the average molecular weight and average specific heat ratio and use these average properties to calculate a "true" temperature, then the differences between this "true" temperature and the temperatures calculated using the extreme values of the gas properties will be the maximum errors in the estimates of gas temperature due to deviation of gas properties from the actual values. Figure 14 shows the results of this calculation. This plot shows that the difference between the inferred gas temperature and the "true" temperature varies from roughly $-45 \mathrm{~K}$ to $+100 \mathrm{~K}$ as the actual conditions vary within the expected range. This corresponds to percentage errors in the range of $-2.25 \%$ to $+5 \%$. These values compare very closely to the estimates obtained from the detailed REI model.

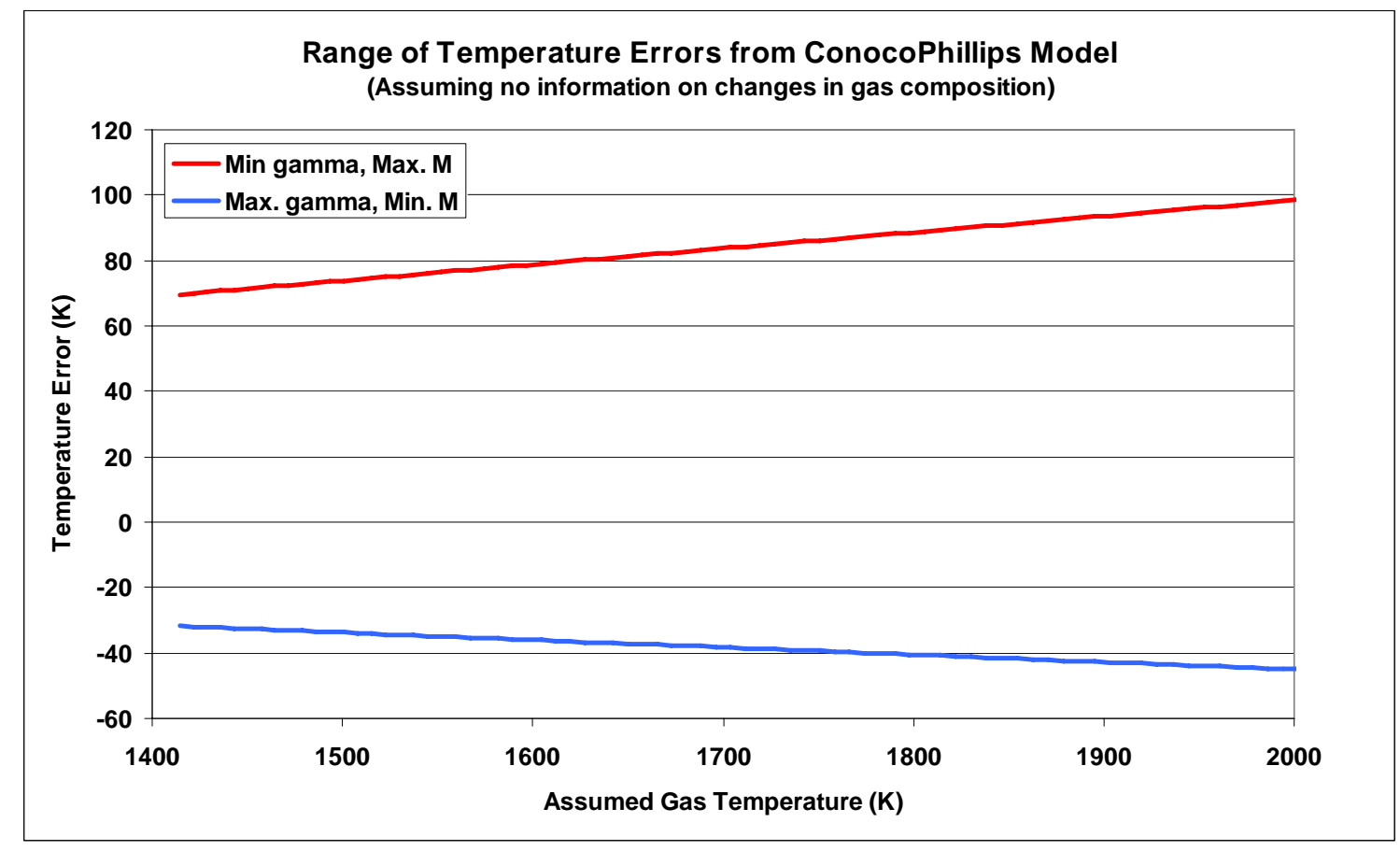

Figure 14. Potential range of temperature errors assuming fixed gas composition

Clearly, these errors are unacceptably large, so it will not be adequate to assume that the gas composition remains fixed over the entire range of operating conditions. However, ConocoPhillips personnel have assured us that they can provide periodic updates to the assumed gas properties that will allow us to refine our temperature measurement based on known changes in operating conditions. Although they have not provided detailed information that would allow us to estimate the improvement in our temperature estimate, they have indicated that they believe they can estimate gas composition to within a small 
fraction of the total range of variation. If this is the case, then we should be able to reduce the potential range of temperature measurement errors due to variations in gas composition to better than $\pm 0.5 \%$.

\section{Sound generation and coupling methods}

Several sound generation and coupling methods were investigated to identify a suitable approach for use in a high pressure process such as a coal gasifier.

\subsection{Acoustic Window}

Experiments were conducted to evaluate the use of an "acoustic window" as a method for coupling sound waves into and out of the gasifier. This concept is an extension of an approach commonly employed in optics to produce anti-reflection coatings and narrow-band interference filters in which partial reflections from interfaces between parallel layers of materials interfere destructively so as to cancel the reflected wave and result in nearly complete transmission. A simple model was developed to study multiple interference of acoustic waves propagating through multi-layer structures. The idea was to see if it would be possible to use this approach to propagate acoustic waves through the wall of the gasifier without the need to make physical penetrations through the wall. An attempt was made to confirm the predictions of this model with a simple experiment in our laboratory. Two threefoot long sections of 3 inch diameter PVC pipe were mounted on a bench with a loudspeaker placed at one end and a microphone at the other (see Figure 15).

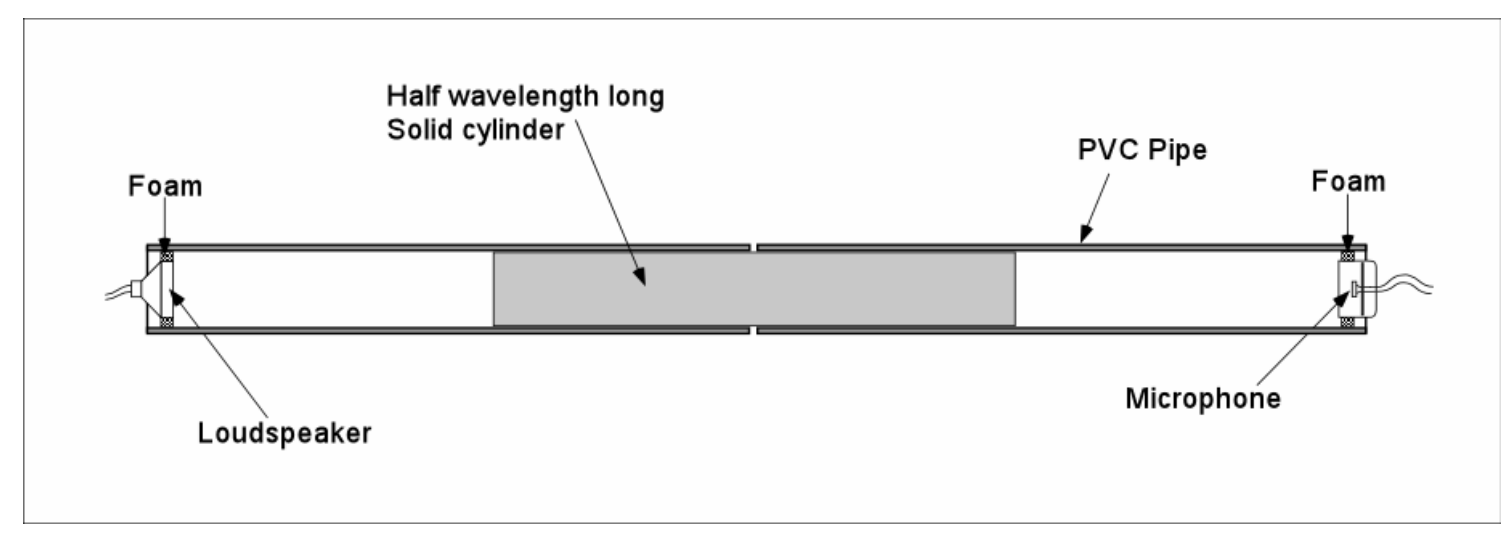

Figure 15. Acoustic Window Experiment

Two sections of PVC pipe were used in order to prevent direct transmission of acoustic energy along the wall of the pipe. A plug in the shape of a solid cylinder whose diameter was slightly smaller than the inner diameter of the PVC pipe was placed at the center of this arrangement as shown in figure 1.

The model predicts that when the plug is one half wavelength long, there should be $100 \%$ transmission of the acoustic energy through the plug. Experiments performed with an aluminum plug and a Plexiglas plug at about $6 \mathrm{kHz}$ using a tone generator and audio amplifier to drive the loudspeaker showed that only about $12 \%$ to $15 \%$ of the energy was transmitted. 
There are a number of possible explanations for this result. First, we have confirmed that in this setup, the closed ends of the pipe produce reflections which give rise to standing waves. Our model does not include this phenomenon which is an artifact of this particular experimental arrangement. Second, our model includes only longitudinal waves propagating along the axis of the apparatus. In any real material, the Poisson effect will cause the material to expand in the radial direction as it is compressed in the longitudinal direction and vice versa. This will give rise to radially propagating waves which have not been included in our model. Third, we have not accounted for acoustic losses in the solid material, although this is not likely to be a large factor with the materials we have been using in these tests.

Professor Joseph Rose at the Pennsylvania State University, an expert on guided acoustic waves in solids, reviewed our model and concluded that it was fundamentally correct. He was unable to determine the source of the relatively low transmission values observed in our experiments, and suggested we perform additional experiments with other materials.

However, after visiting the Wabash River facility and seeing the construction of the gasifier, we concluded that this approach was very unlikely to succeed due to the presence of multiple layers of ceramic bricks and mortar of highly variable thickness which will produce substantial attenuation and unwanted reflections of acoustic waves propagating through the wall of the gasifier vessel. Therefore, this approach was abandoned.

\subsection{Pneumatic "Hammer" and "Clapper" Experiments}

As promised in our initial proposal, an investigation was performed to look at two mechanical shock generation approaches. Both of these approaches were inspired by the observation that one can produce a relatively loud sound pulse merely by clapping one's hands.

The first mechanical device we examined was a pneumatically driven "hammer" in which a solid steel rod was mounted on the side of our EGS1 pressure vessel. A hammer was used to strike the end of the rod outside the vessel and the sound produced was monitored with a receiver on the opposite side of the EGS1 vessel. The setup is shown in Figure 16.

In these experiments, the only signal detected by the receiver transducer mounted on the opposite side of the EGS1 vessel was due to sound which propagated through the steel shell of the vessel. A careful analysis of this sound coupling method revealed that striking the end of the steel bar compresses the steel in the vicinity of the struck end. This compression propagates along the length of the bar as a compression wave to the other end where there is a similar displacement of the free end of the bar. This displacement produces a sound wave by compressing the gas in the vicinity of the free end of the bar. In order for the displacement of the free end of the bar to produce a shock wave, it would have to move at supersonic velocity and its displacement would have to be sufficiently large to compress a significant volume of gas. The first condition can easily be met since the speed at which compression waves propagate (the sound speed) in steel is roughly 14 times the sound speed in air and about 7 times that in the syngas inside a coal gasifier. However, because of the very large elastic modulus of steel, the displacement of the end of the bar will be very small. 


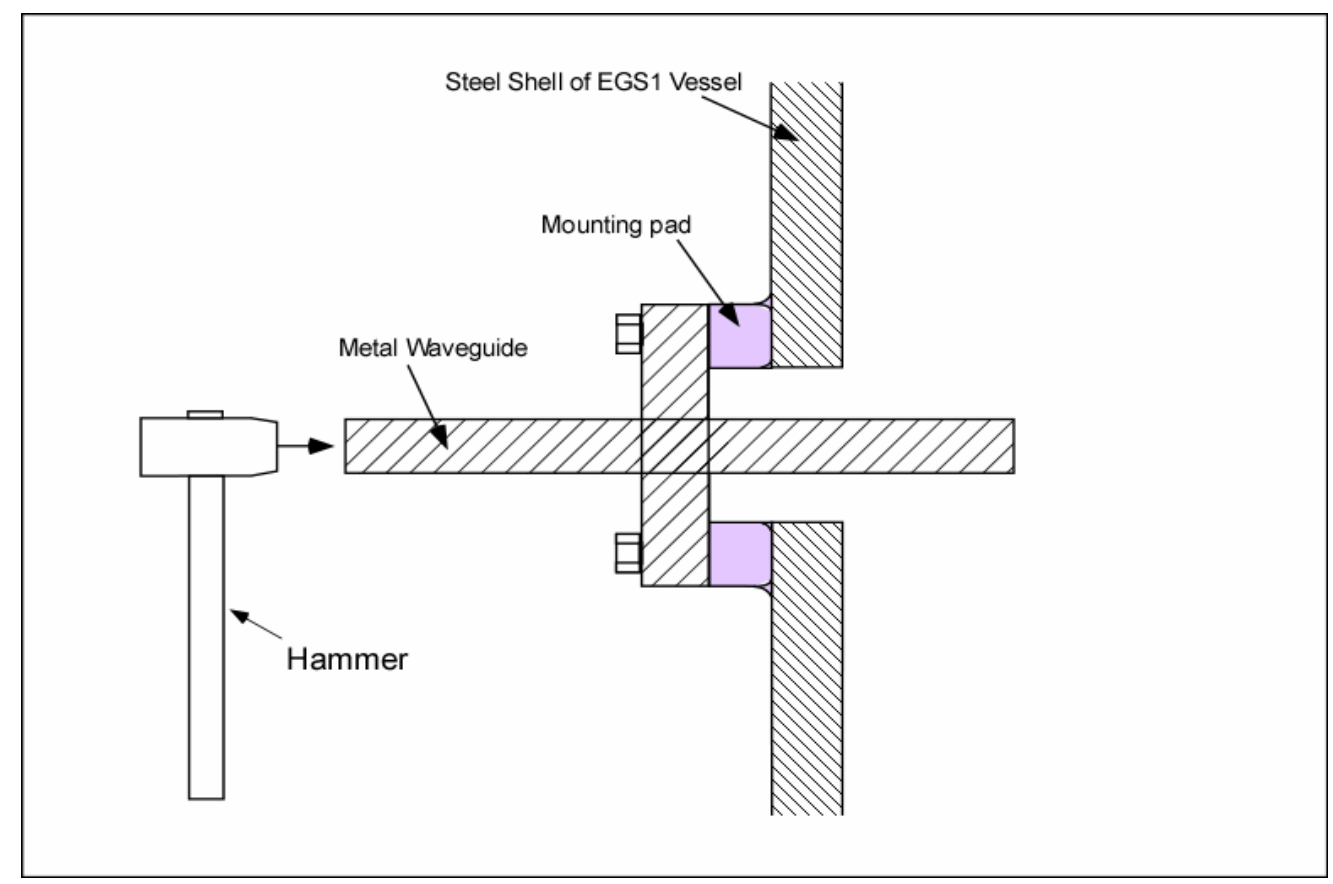

Figure 16. Hammer experiment on EGS1 vessel

To study this quantitatively, the same model used to study transmission of sound through layered media was employed. A two layer structure was modeled in which the first layer was an infinite thickness of steel and the second, an infinitely thick layer of air. The model predicts that the fraction of the energy contained in the pressure wave propagating in the steel that is transmitted into the air is only about $4 \times 10^{-5}$. Because of the very large acoustic impedance mismatch between the two materials, almost all of the energy is reflected back into the steel at the steel/air interface. This observation confirms the negative result obtained experimentally. Therefore, this approach was abandoned.

The second mechanical approach that was explored was a "clapper" consisting of two flat pieces of metal connected by a hinge at one end. Figure 17 shows a sketch of the experimental apparatus used to investigate this approach.
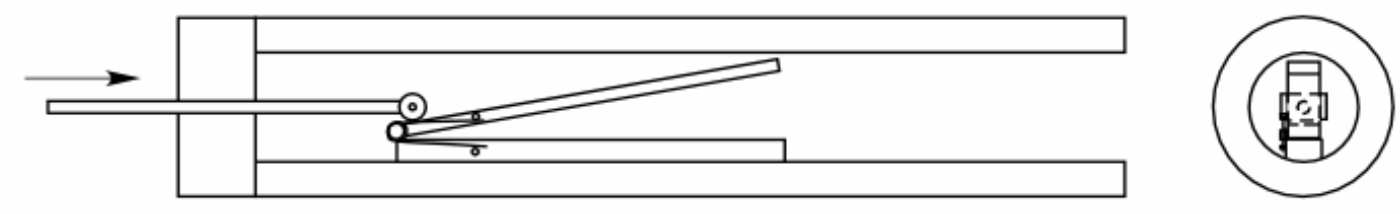

Figure 17. Experimental "clapper" apparatus

Several experiments were conducted with the receiver transducer placed about 24 inches from the clapper apparatus. Various methods were used to force the clapper strips together as rapidly and with as much force as possible. Although the sound produced was relatively loud, 
it was very much weaker than the sound pulses produced with our shock tube approach (described below) even when the shock tube was operated at relatively low pressure. Therefore, we concluded that this approach was not promising enough to warrant any further investigation.

\subsection{Shock Tube}

As discussed in section 1, the pressure inside the gasifier presents a significant challenge when it comes to generating a sound pulse that can be injected into the gasifier from the outside environment. However, we have observed that the ratio of the gasifier pressure to atmospheric pressure is between 25:1 and 65:1, more than sufficient to generate a strong shock wave. Unfortunately, the pressure acts in the wrong direction. On the other hand, we have also observed that shock waves can be reflected from a solid surface, so a major part of our effort has been the development and testing of a reflected shock sound generator. To understand how this device works, it is instructive to look at the behavior of a shock tube - a device commonly used to generate shock waves for experimental investigations. A shock tube normally consists of a pipe closed at both ends and divided into two sections by a diaphragm. Initially the two halves are filled with gases having either the same or different compositions. The driver gas on one side of the diaphragm is pressurized until the diaphragm bursts and a shock propagates into the test gas on the other side of the diaphragm. In addition to the shock wave, an expansion wave propagates in the opposite direction into the driver gas and a "contact surface" separating the driver and test gases propagates in the same direction as the shock but at much slower speed. The behavior of these waves and the response of the gases in the shock tube have been extensively studied and there are many references that describe the relationships that pertain in the various regions [see, e.g, 5, 6].

Figure 18 shows a schematic of the various waves that propagate in the shock tube. In this case, the region to the left of the diaphragm is initially at high pressure and when the diaphragm bursts, the shock propagates to the right. In this case, the left end of the shock tube is open to a reservoir (the gasifier) which contains syngas, and the right end of the shock tube is closed. In the diagram, time increases along the vertical axis. Region 1 contains the gas that initially fills the region to the right of the diaphragm. Region 4 contains gas that initially fills the region to the left of the diaphragm. As the shock propagates to the right, it passes through the gas in region 1, heating it above its initial temperature and producing higher temperature conditions in region 2. Trailing behind is the contact surface that propagates at a much slower speed and separates regions 2 and 3. The expansion fan that separates regions 3 and 4 propagates to the left with the leading characteristic traveling at sonic velocity into the gas in region 4 and the trailing characteristic traveling at a slower velocity. 


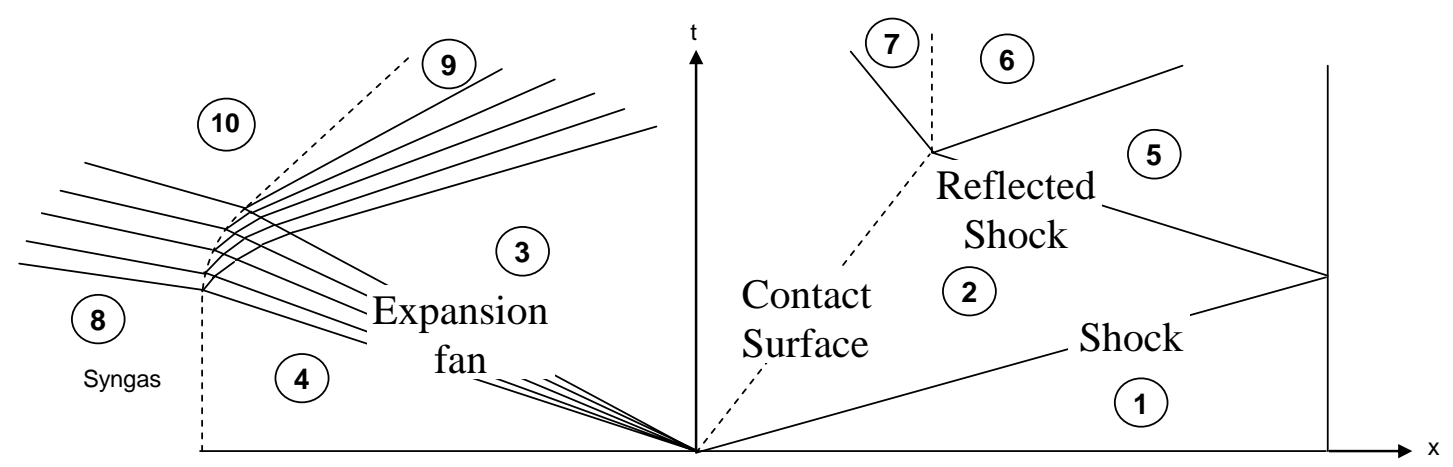

Figure 18. Wave propagation in a shock tube

When the shock encounters the right end of the shock tube, it reflects and travels into the gas in region 2. When the reflected shock encounters the advancing contact surface, it passes into a region with different pressure, temperature, and possibly different composition. This produces a refraction of the shock wave which causes it to change its propagation speed. To the left of the diaphragm, the expansion wave propagates towards the open end of the shock tube and when it encounters the boundary between the gas initially in the shock tube and that outside the shock tube, it is partially reflected and partially transmitted. Again there is a contact surface that propagates to the right drawing gas into the shock tube from the region to the left. Eventually, the shock encounters the reflected expansion wave and is refracted again. Then it encounters the contact surface and undergoes yet another refraction changing speed in the process. Once the shock enters the gas in region 10, it propagates at constant speed through the gas initially to the left of the shock tube (assuming the gas in region 10 has uniform composition and temperature).

Enertechnix has constructed a detailed model of all of these processes to allow us to accurately predict the strength and Mach number of the shock that is projected into the region to the left of the shock tube (the gasifier) and to accurately predict the time that the shock takes to propagate in each region of the shock tube.

\subsection{Initial Concept}

Our observation that a reflected shock wave is produced and will propagate towards the open end of the shock tube, led us to consider this approach for generating sound pulses that could be injected into the gasifier and used to measure syngas temperature. Our initial concept consisted of a shock tube in which the diaphragm is replaced with a very fast-acting valve as shown in Figure 19. In this case, the region to the right of the valve is initially brought to atmospheric pressure. When the valve opens, the shock propagates to the right, reflects from the closed end and then propagates back to the left and into the gasifier. 


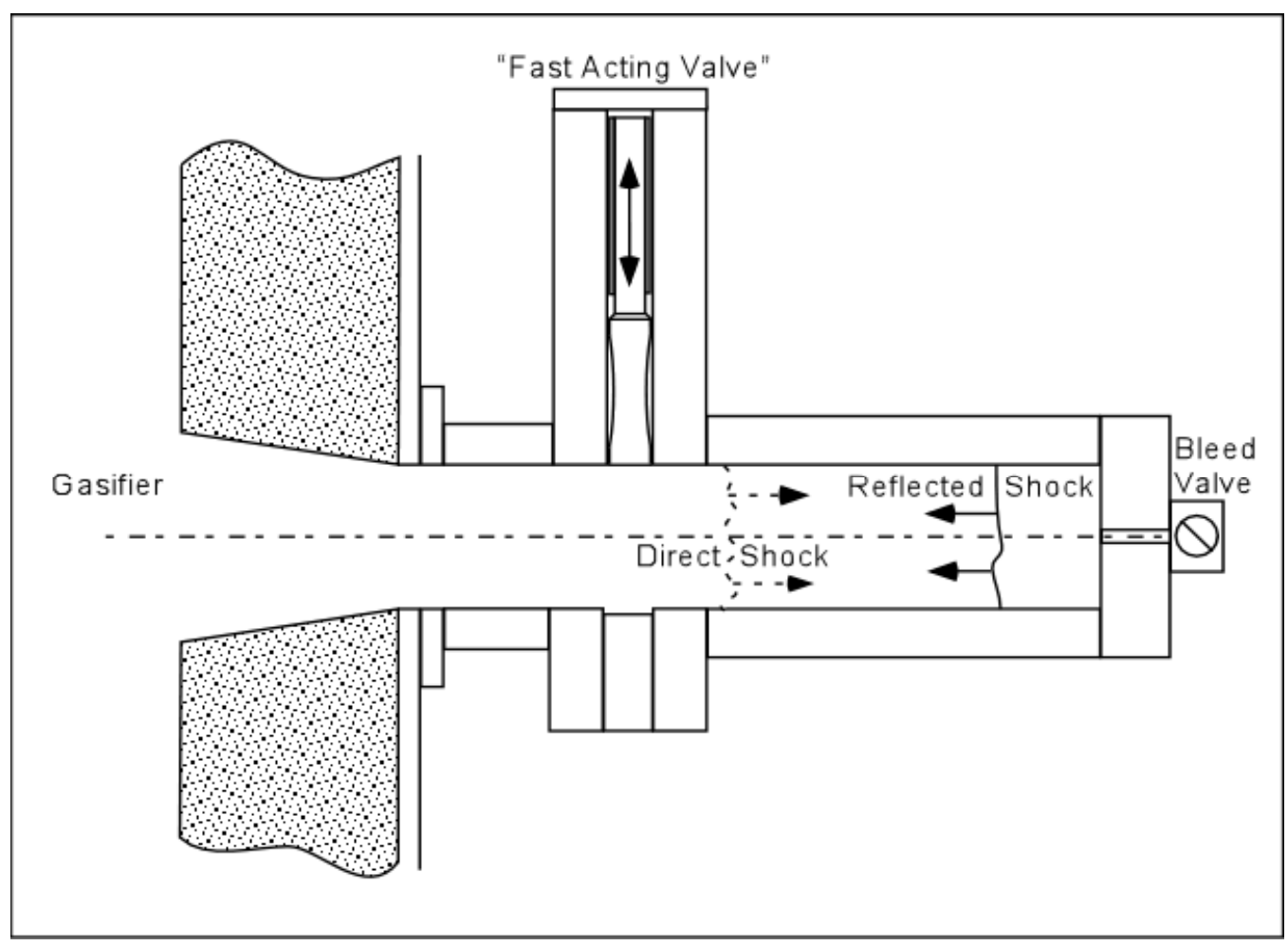

Figure 19. Initial concept for a reflected shock sound source

Considerable effort was expended in an attempt to identify a valve with the necessary speed and sealing characteristics and one that would be able to stand up to exposure to hot syngas, ash, and molten slag. No such valve was found. In order to make this process work, the valve needs to be able to go from fully closed to fully open in about 1 or 2 milliseconds, and, when open, it must offer no obstruction in the path of the shock wave. The only two possibilities are gate valves and ball valves. Unfortunately, those types of valves are not nearly fast enough and they are not well suited to use in a very dirty, high temperature environment.

Therefore, the bursting diaphragm approach was selected for investigation. This method is certainly capable of producing strong shock waves and, by using a roll of diaphragm material and a clamping mechanism that opens to allow a new piece of material to be used on each shot, the presence of high temperature, particle-laden gases is of little concern so long as the clamping mechanism can be kept clean.

\subsection{Lab Shock Tube Testing}

Our investigation began with a manual apparatus that was constructed to allow us to test a number of diaphragm materials and to test the sound generation capabilities of this approach.

This apparatus is shown schematically in Figure 20. In this apparatus, the diaphragm may be burst either by pressurizing the shock tube (the region to the right of the diaphragm) until the diaphragm bursts and produces a shock propagating to the left, or it may be operated in reflected shock mode by first pressurizing both sides of the diaphragm and then bleeding off 
pressure inside the sock tube until the diaphragm bursts - creating a shock that propagates to the right, reflects from the right end of the shock tube, and then propagates to the left and into the test vessel.

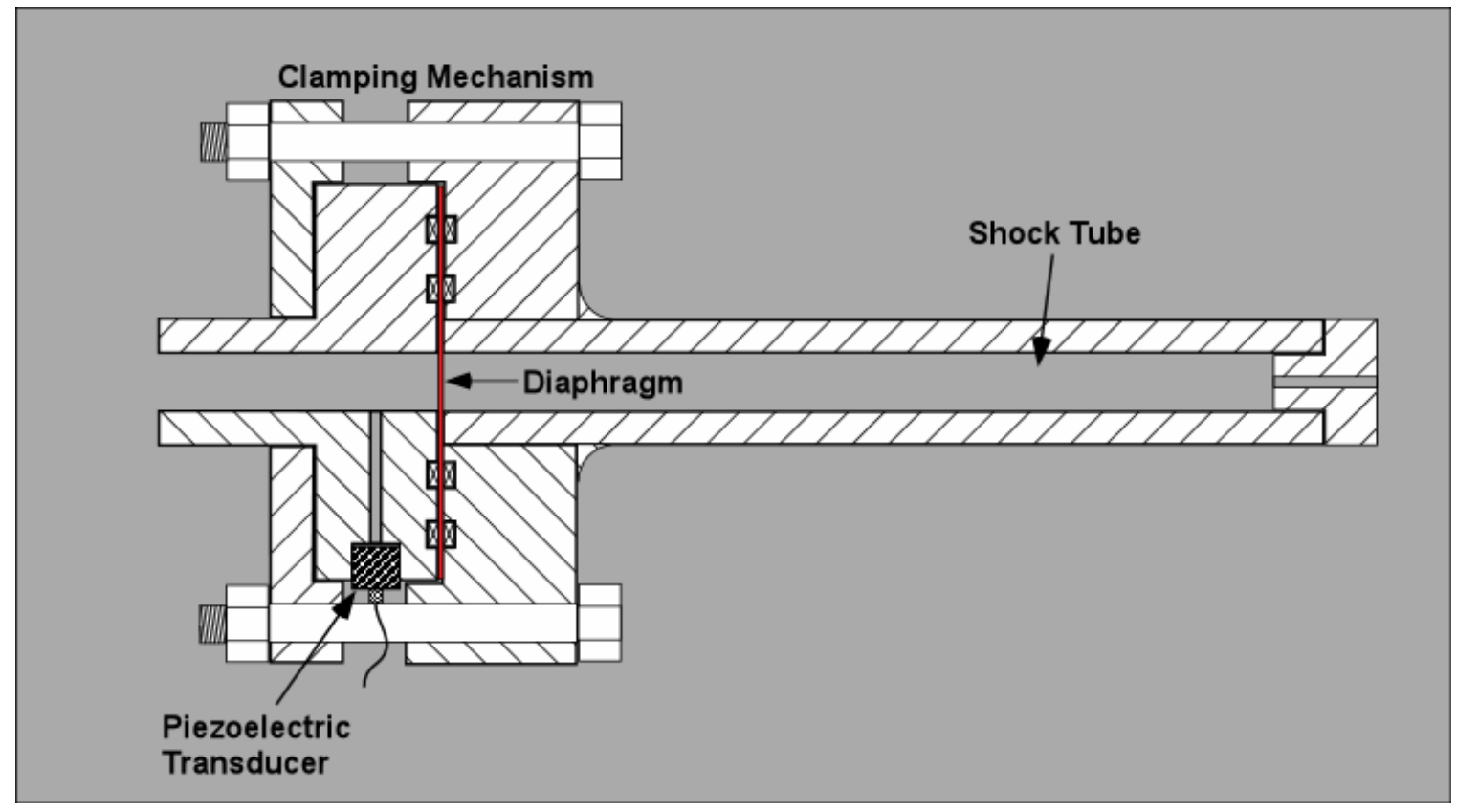

Figure 20. Shock tube apparatus for diaphragm testing

A piezoelectric transducer was mounted in the clamping mechanism, just to the right of the diaphragm as shown. This served as the trigger transducer in our time-of-flight experiments.

Initial experiments were performed by pressurizing the shock tube itself to determine the bursting pressure of several materials and determine a suitable diaphragm material to use for initial testing using shop air at up to 100 psi. We determined that one layer of 1 mil aluminum foil had a bursting pressure of 52 psi and 2 layers of aluminum foil had a bursting pressure of 91 psi. The bursting pressure was found to be extremely repeatable and for initial testing of the transducers and data acquisition system, most tests were performed with two layers of aluminum foil.

Subsequently, a model of the bursting pressure as a function of diaphragm thickness and diameter and the elastic properties of the material was developed. By including tensile strength, elastic modulus, percent elongation at failure and Poisson's ratio in the model, we were able to predict the bursting pressure for a variety of materials and diaphragm dimensions with very good accuracy. As mentioned above, we found that aluminum has the most repeatable performance of all the materials studied. In addition, it is readily available in spools which can be obtained in any desired width and material thickness and it is relatively inexpensive.

Tests were performed in the laboratory to establish our ability to properly trigger our data acquisition system using the signal from the transducer mounted on the side of the diaphragm clamp and to detect acoustic waves received by a second piezoelectric transducer placed at 
distances from two to five feet away from the open end of the shock tube. In these experiments the shock tube was operated in the "direct shock" mode in which the shock tube was pressurized until the diaphragm burst and the shock produced propagated directly outward (to the left in Figure 20). The piezoelectric transducers selected for these experiments were chosen for their high frequency response (up to $2 \mathrm{MHz}$ ) which allows us to determine the arrival of the acoustic wave with the very high timing accuracy required for short propagation times. The data acquisition board was also selected to allow us to digitize the signal at very high sampling rates for the same reason. Figure 21 shows a typical trace obtained from these initial laboratory experiments.

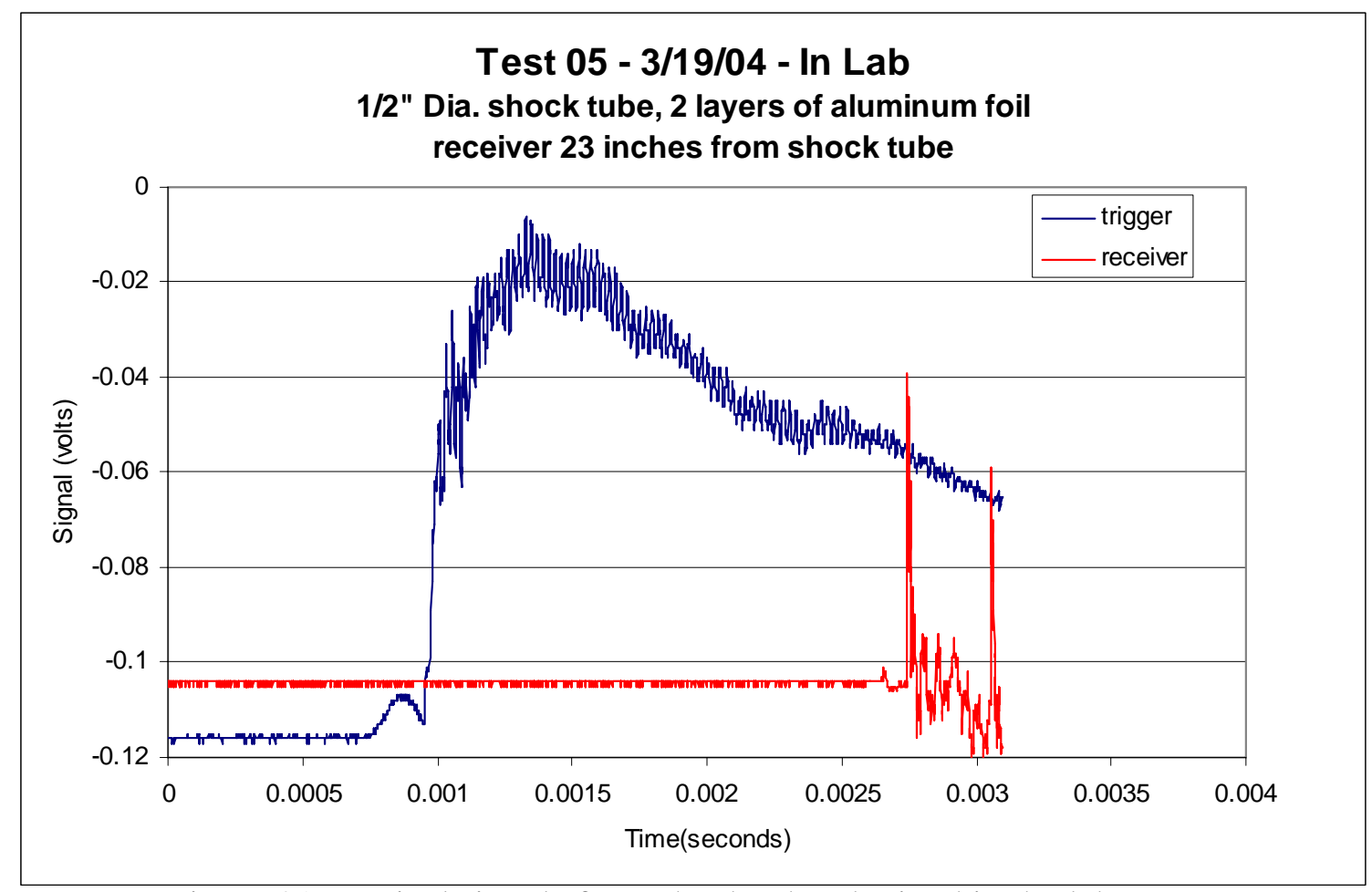

Figure 21. Typical signals from shock tube obtained in the laboratory

In this test, the receiver was placed approximately 23 inches from the shock tube. Applying the appropriate end corrections, this time of flight translates into an air temperature of about 68.3 degrees Fahrenheit. However, the actual laboratory temperature at the time of the test was about 55 degrees F. The supersonic velocity of the shock when it first leaves the shock tube is insignificant in large boilers where the path lengths are tens of meters long. However, for very short paths and strong shocks, this effect will be significant, although it will be less so in the real gasifier where the path length will be greater. If we take this effect into account, we find that the corrected time of flight corresponds to a measured temperature of about 55.5 degrees $\mathrm{F}$ which is almost exactly the correct value.

It should be noted that the rise time of the receiver signal is about 2 microseconds. This timing resolution corresponds to about a $0.25 \%$ resolution in temperature measurement in the gasifier environment which should be quite adequate to allow for the desired temperature measurement accuracy. 


\subsection{EGS1 Direct Shock Experiments}

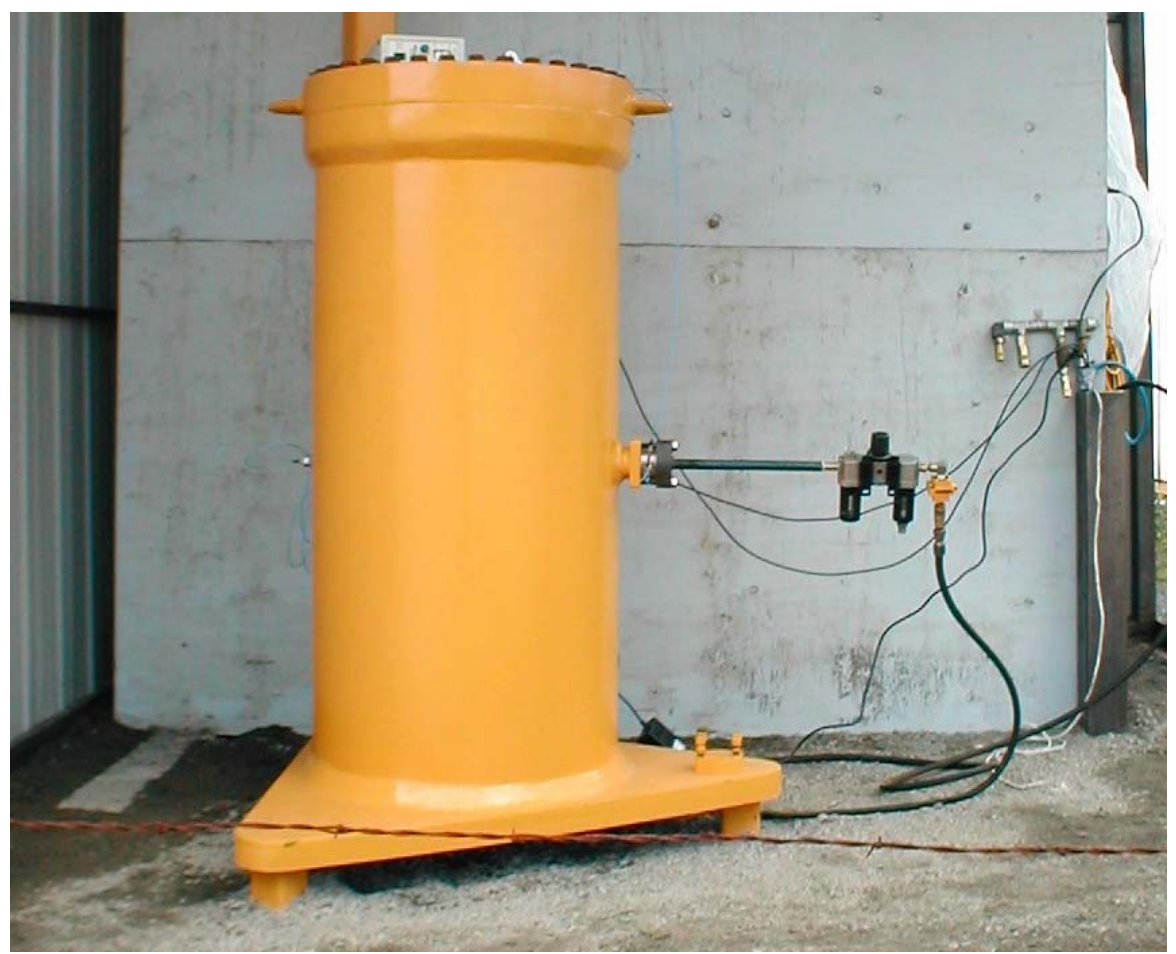

Figure 22. EGS1 test rig with shock tube and receiver

The same shock tube used in the laboratory for the tests described above was used to conduct tests in the EGS1 pressure vessel shown above. For these preliminary tests, the EGS1 vessel was at atmospheric pressure and the shock tube was pressurized to about 100 psi producing a direct shock when the aluminum foil diaphragm burst. Figure 22 shows the shock tube and receiver mounted on the EGS1 test rig. The shock tube is the blue tube on the right of the yellow EGS1 pressure vessel. Air is supplied to the apparatus through the regulator and filter set at the right end of the shock tube. In this arrangement, the diaphragm is mounted in the clamping device between the shock tube and the pressure vessel. The receiver can be seen opposite the shock tube on the left side of the pressure vessel.

As in the laboratory experiments, the pressure in the shock tube was increased until the diaphragm burst and a shock was produced. The shock traveled across the pressure vessel to the receiver where it was detected. For these initial tests on the EGS1 unit, the pressure vessel was at atmospheric pressure. 
Figure 23 shows a typical signal obtained inside the EGS1 unit.

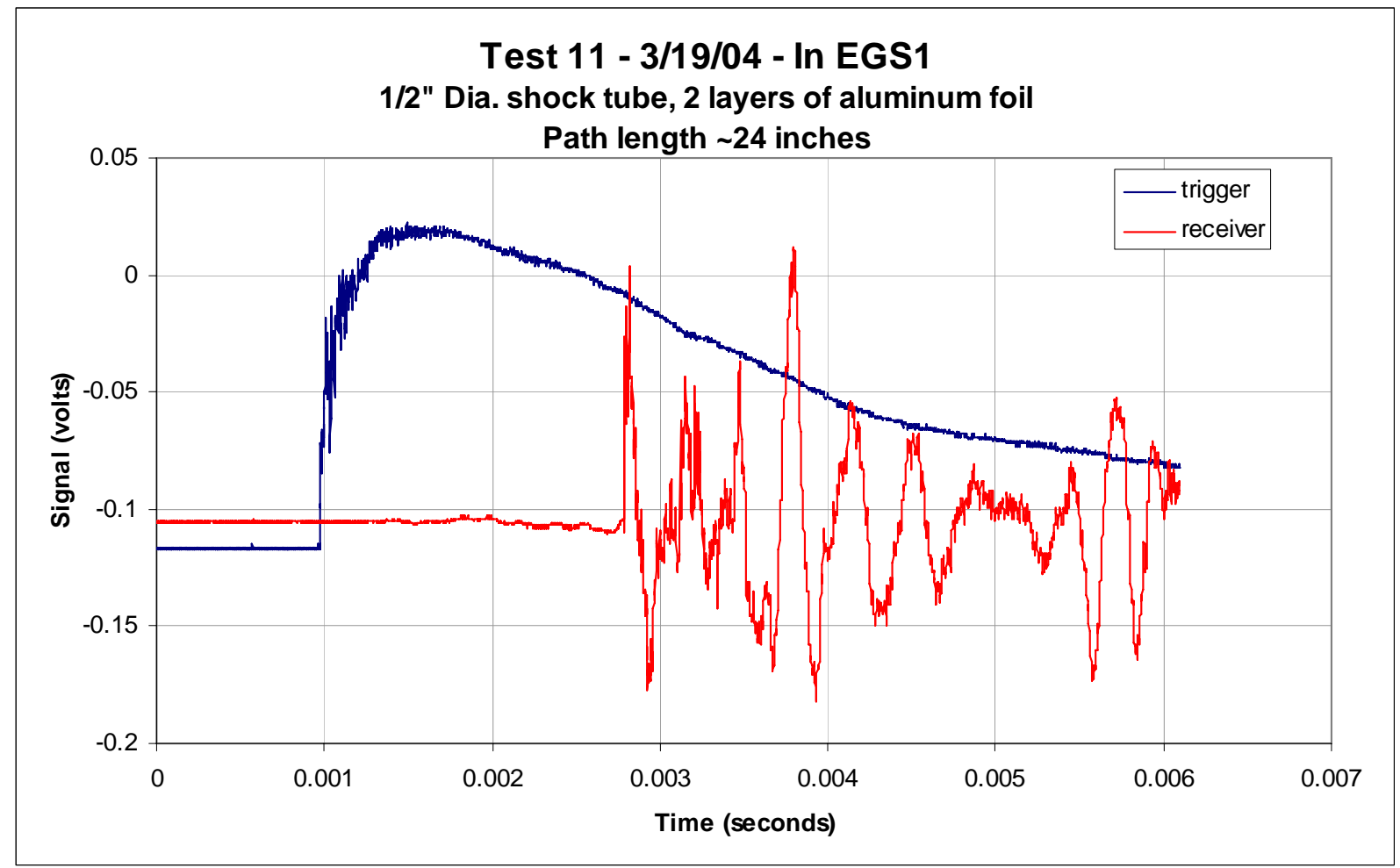

Figure 23. Signal obtained in EGS1 vessel using direct shock setup

In this test, the receiver signal (red trace) has an initial spike when the shock wave arrives 1.815 milliseconds after the trigger. After applying the appropriate end corrections to account for supersonic shock propagation in the plumbing between the trigger transducer and the pressure vessel, the propagation time in the trigger tube itself, the supersonic propagation of the shock in the first few inches of its expansion inside the pressure vessel, and taking account of the exact positions of all the components, we find that the average sound speed inside the EGS1 unit is 337.7 meters/second which corresponds to 49 deg. F. The ambient temperature on the date of this test was about 50 deg F.

\subsection{EGS1 Reflected Shock Experiments}

In order to operate the shock tube in the manner proposed for the actual gasifier application, it is necessary to pressurize the EGS1 test vessel and use that pressure to create the shock. This is accomplished by the following set of steps.

1. A ball valve between the shock tube and the EGS1 pressure vessel is closed

2. The EGS1 unit is pressurized

3. A piece of diaphragm material is inserted into the diaphragm clamp and the clamp is closed.

4. Both sides of the diaphragm are brought up to pressure simultaneously.

5. The ball valve is opened exposing one side of the diaphragm to the EGS1 atmosphere. 
6. The pressure in the shock tube on the other side of the diaphragm is reduced to atmospheric pressure.

7. The diaphragm bursts producing a shock that propagates down the shock tube away from the EGS1 unit.

8. The shock reflects off the back wall of the shock tube and propagates back into the EGS1 unit.

9. The shock is detected at the receiver.

To implement these steps, the shock tube was modified slightly and the necessary valves and plumbing were added to the apparatus.

Figure 24 shows the modified shock tube with the associated valves and plumbing needed to carry out the first reflected shock experiments. The blue tube in the lower left is the shock tube. The hexagonal block with rounded corners immediately ahead of the shock tube is the diaphragm clamp. Next is the manual ball valve which has a brass body. This whole apparatus is clamped to the EGS1 pressure vessel using appropriate high pressure seals. The electrical box on the left houses the switches which operate the solenoid valves, one of which is visible attached to the left side of the switch box. The white box to the right of the EGS1 vessel is the signal conditioning unit for the piezoelectric transducers.

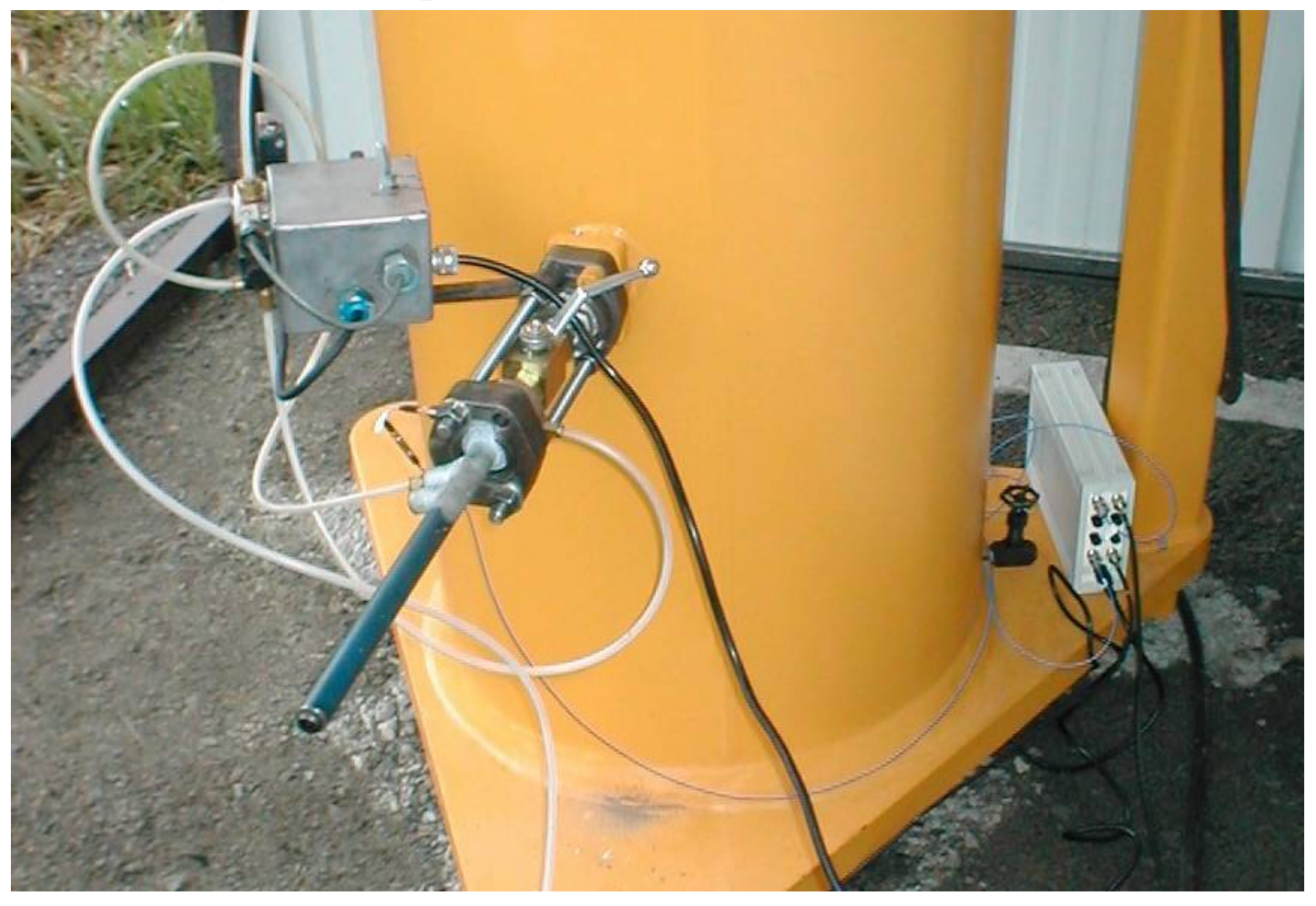

Figure 24. Reflected shock apparatus mounted on EGS1 pressure vessel.

The first tests with this arrangement verified that the concept of using the pressure inside the gasifier to create a shock wave which can be detected on the opposite side of the vessel after being reflected in a shock tube attached to the side of the gasifier is valid. 
Figure 25 shows a typical signal obtained in this manner which clearly shows the arrival of a distinct shock wave at the receiver location (red trace) at roughly 6.35 milliseconds and a trigger signal at about 2.45 milliseconds.

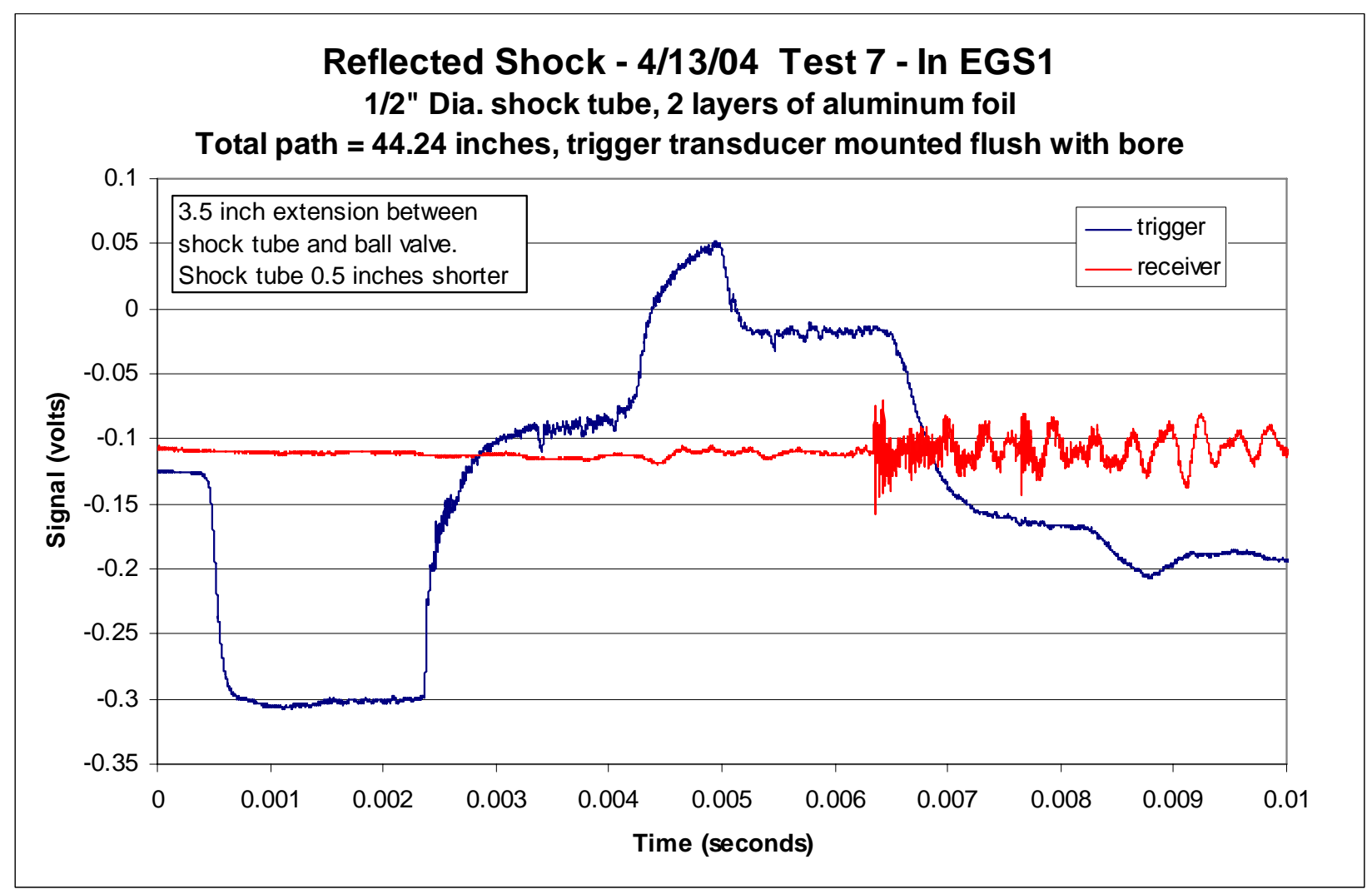

Figure 25. Reflected shock results

These experiments demonstrate the feasibility of the reflected shock method of generating acoustic signals in a simulated gasifier environment. The pressure inside the gasifier vessel can be used to produce the shock wave which, after reflection from the end of a simple shock tube, will propagate across the interior of the gasifier vessel and provide sound speed information that can be used to infer gas temperature inside the vessel.

\section{Prototype sensor development}

\subsection{Field prototype sensor conceptual design}

At the end of phase I, a conceptual design a field prototype sensor was developed. This design is very similar to the design of the reflected shock proof of concept prototype except that it incorporates a number of additional features and refinements. Figure 26 shows the layout of the sound source portion of the proposed prototype. 


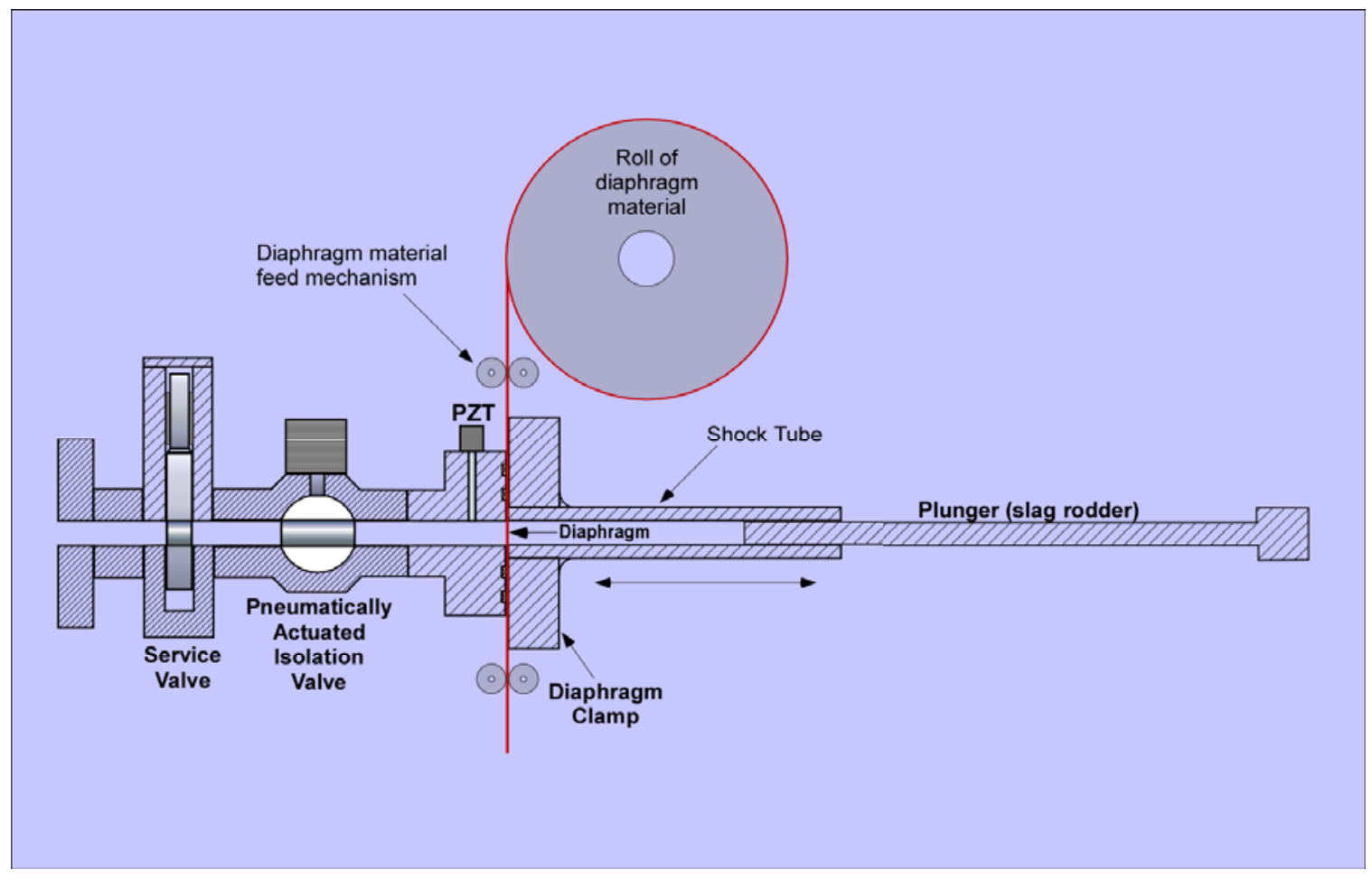

Figure 26. Conceptual design of experimental prototype acoustic gas temperature sensor sound source.

In this figure, the gasifier is located at the left and it is assumed that an open nozzle provides access through the steel wall and through the refractory to the interior of the gasifier. During normal operation, the service valve will be kept open, but it can be closed to allow the acoustic pyrometer sound source to be installed or removed while the gasifier is operating. Initially, the pneumatically actuated isolation valve is closed and the pressure throughout the device to the right of the isolation valve is reduced to atmospheric pressure. This allows the diaphragm clamp to be opened to move a new portion of the strip of diaphragm material into position. Once the new piece of diaphragm material is in place, the clamp is closed and plant nitrogen is introduced on both sides of the diaphragm until the pressure equals that inside the gasifier. To fire the device, the isolation valve is opened creating a clear path from the front of the diaphragm to the inside of the gasifier through the isolation and service valves and the nozzle. At this point, the pressure to the right of the diaphragm is reduced by venting the nitrogen in the shock tube to atmosphere. When the pressure to the right of the diaphragm falls to a sufficiently low value, the diaphragm bursts and a shock propagates first to the right down the length of the shock tube, and then - after reflecting from the tip of the slag rodder to the left and into the gasifier. Once the measurement is completed, the apparatus is purged by blowing high pressure plant nitrogen through the device to clear out any slag and remnants of diaphragm material that may have gotten into the device. The pneumatically actuated rodding mechanism is then forced down the bore of the sound source, through the service and isolation valves, and through the nozzle to the edge of the refractory where it will remove any slag that may have built up. Once the rodder is retracted, the isolation valve is closed and the process is repeated. It may be preferable to leave the ruptured diaphragm material in place until it is desired to make a measurement, at which time the isolation valve can be opened just 
long enough to purge the system with nitrogen and rod out the slag before closing the isolation valve and moving a new piece of diaphragm material into place.

Although this device exhibits a certain degree of mechanical complexity, all of the technology required to implement the various functions is available in the form of standard commercial components that are routinely used in harsh industrial environments. Therefore, this design is quite robust and can be made to operate reliably in the gasifier environment. The use of a bursting diaphragm avoids the need for a sophisticated rapidly-acting valve and should be quite tolerant to particles of slag being ingested into the device when the diaphragm bursts and gas is drawn into the device from the gasifier.

\subsection{Field prototype mockup}

Prior to building a complete prototype sensor for field testing, a full-scale mockup was constructed to test the various components and to provide a test bed for developing and testing the control software. This mockup was mounted on the EGS1 unit and tested thoroughly to determine the operating characteristics of the system. Based on this testing, several modifications were implemented and tested and the control software was refined to ensure reliable operation. Figure 27 shows the mock-up of the field prototype mounted on the EGS1 unit.

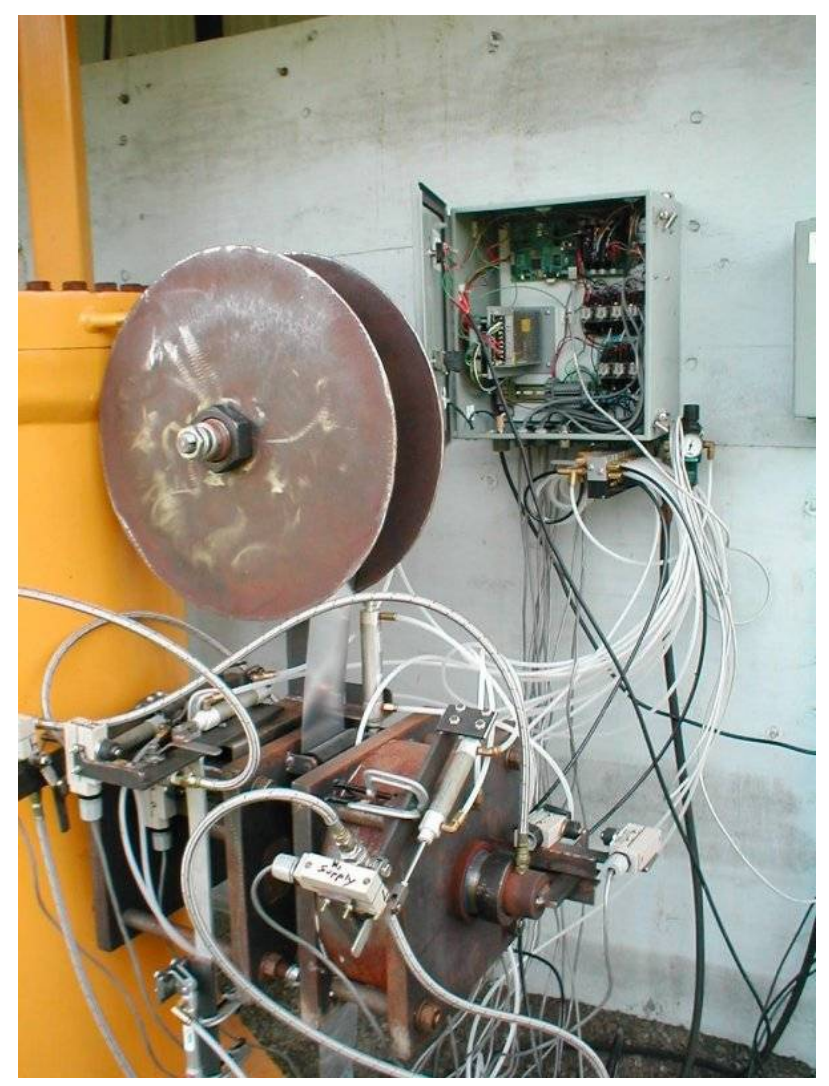

Figure 27. Mock-up of field prototype mounted on EGS1 


\subsection{Field prototype \#1}

Once the mock-up of the prototype had been thoroughly tested and necessary modifications had been identified, implemented and tested, and the control software had been developed and tested, a first field prototype sensor was designed and fabricated. Figure 28 shows a photograph of the sound generator portion of the first field prototype sensor (auto-GAP 1) without its protective covers. The black pipe connecting the device to the yellow EGS1 pressure vessel simulates the length of plumbing that would connect the device to the gasifier (including the nozzle that protrudes through the steel shell and the refractory lining inside the gasifier.

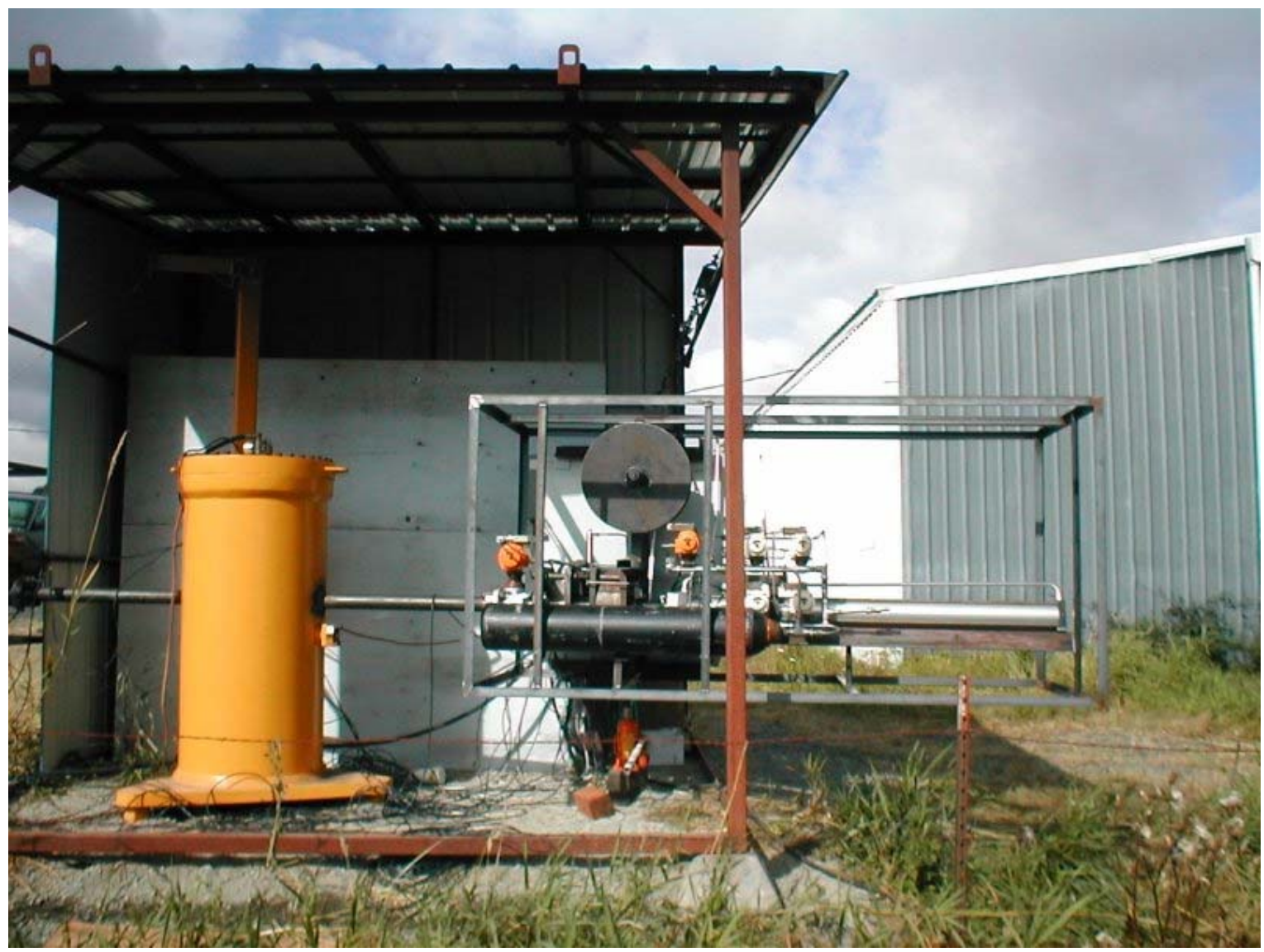

Figure 28. Field prototype “auto-GAP 1" sensor mounted on the EGS1 pressure vessel

To the right of the black pipe is the isolation valve (white) and its actuator (orange). The clamping mechanism is to the right of the isolation valve and the black spool above carries the roll of aluminum diaphragm material. The black compressed gas cylinder in front of the clamping mechanism is an accumulation tank that receives any syngas aspirated into the system when the diaphragm bursts. This accumulation tank is then backflushed with nitrogen to force any syngas back into the gasifier. Once the accumulation tank is full of clean nitrogen and isolated from the rest of the system it can be vented to bring it to atmospheric pressure. Once at atmospheric pressure, it is then isolated from the atmosphere and when the time comes to burst the diaphragm, it serves as a low pressure reservoir into which the shock tube 
is evacuated to reduce the pressure behind the diaphragm and allow it to burst. In this way, there is no possibility of syngas escaping when the diaphragm bursts since it is dumping into a sealed vessel. The long silver cylinder at the right hand side of the generator is the actuator for the port rodder.

All of the functions of this prototype were automated and controlled by a Galil motion control computer. A supervisory computer was used to handle the data acquisition and storage functions and to send commands to the Galil controller. The data acquisition functions were handled using LabView ${ }^{\mathrm{TM}}$. Figure 29 shows a block diagram of the control architecture of the prototype.

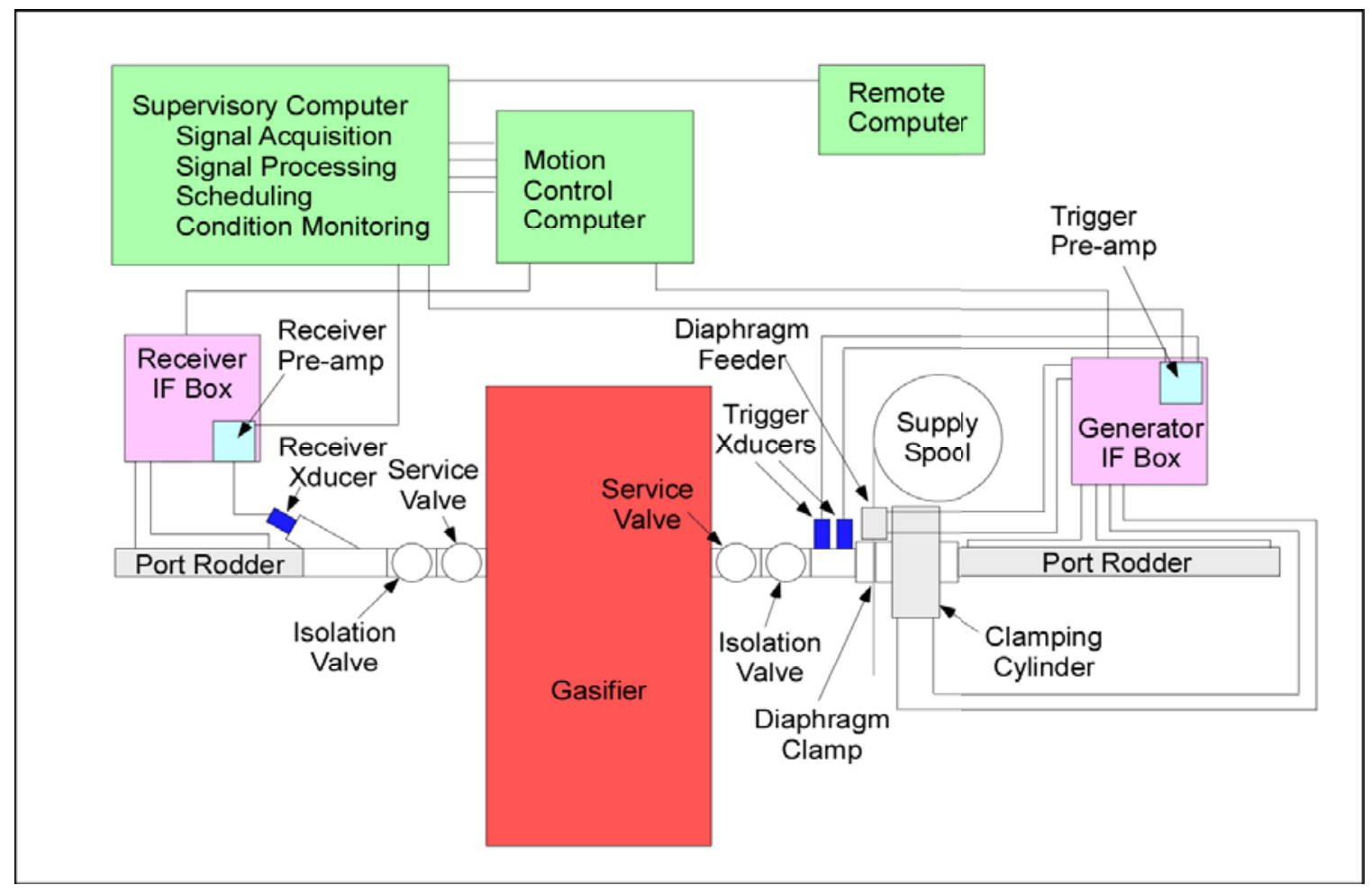

Figure 29. Schematic of Sensor Control System

This schematic is only intended to show the hierarchy of the control system components and does not show all of the control elements. For instance, none of the flow control valves or the pneumatic controls for those valves are shown. Also not shown are the pressure and temperature transducers that are incorporated into the sensor to ensure safe operations.

Figure 30 shows a typical set of signals obtained with this prototype sensor. 


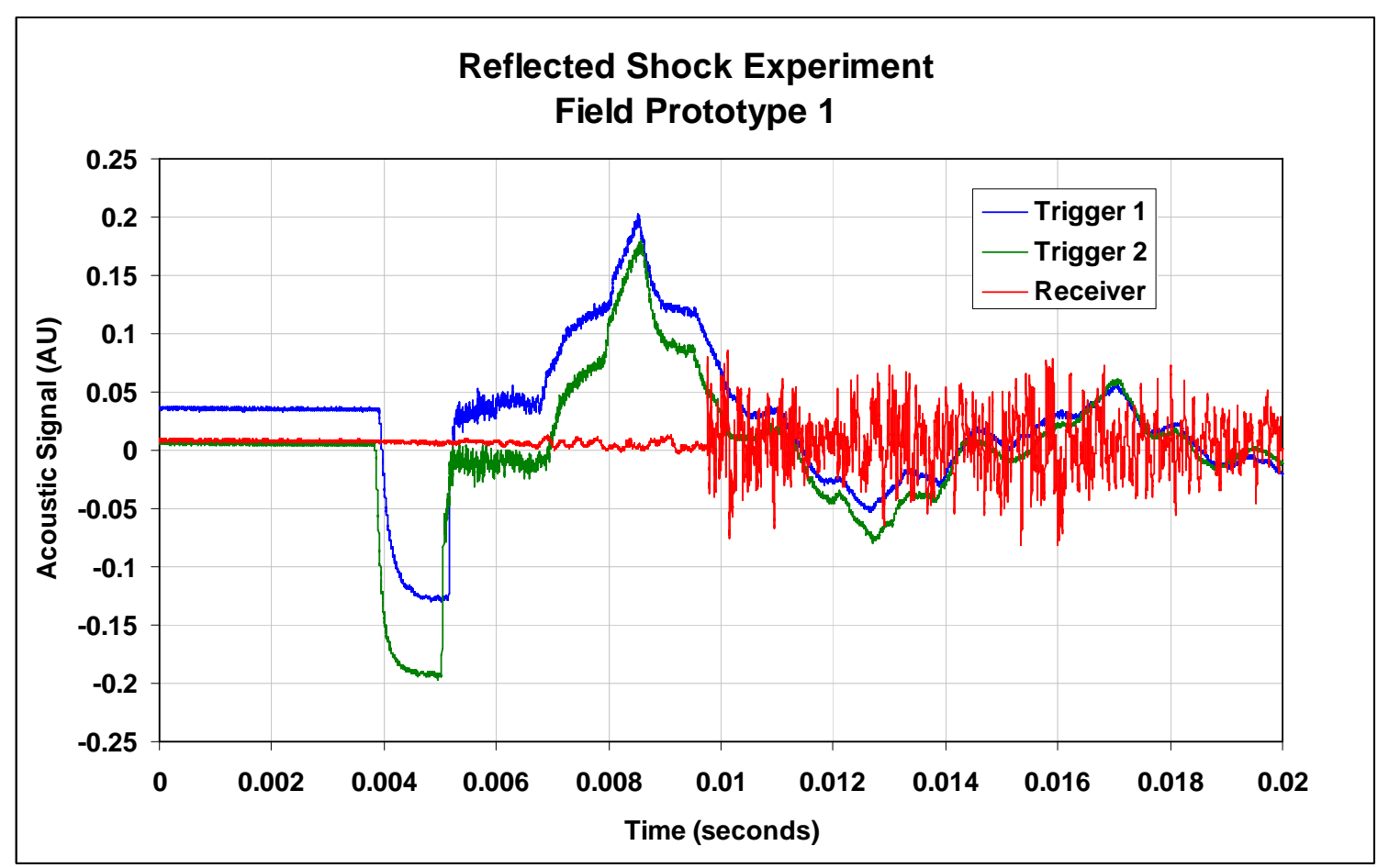

Figure 30. Typical signals from tests of the first field prototype sensor on the EGS1 unit

In this case, there are two trigger transducers mounted a short distance apart along the shock tube which provides redundancy and also a direct measure of the shock propagation speed from which the shock Mach number may be inferred. The signals from these transducers are shown as the blue and green traces. The red trace is from the receiver transducer. In this experiment the EGS1 unit was filled with air at 400 psi and a temperature of about 57 deg F. The temperature inferred from the acoustic measurement is $58 \mathrm{deg} \mathrm{F}$.

In this prototype, the determination of wave arrival times and conversion of propagation times into temperatures was handled manually. Enertechnix has developed a software program that automates the determination of wave arrival times and the conversion of propagation times into temperature. This program, which currently operates in a DOS environment, is being ported to a MS Windows ${ }^{\mathrm{TM}}$ platform and will ultimately be used to automate these procedures in the gasifier acoustic pyrometer.

This prototype was tested extensively using the EGS1 test facility. The control software was automated to allow the system to operate and generate acoustic signals completely under computer control. This capability was demonstrated through extended testing at the Enertechnix facilities.

\subsection{Field prototype \#2}

Prior to installing the field prototype on the gasifier, several additional modifications were implemented. In order to avoid interference with structural steel members at the plant site, it was necessary to substantially rearrange the components of the generator. Several valves were 
replaced with fire rated versions, seals were replaced with plant-approved materials, flexible tubing was replaced with stainless steel tubing for almost all of the gas plumbing, and changes were made to the purging sequence to ensure safe operation of the sensor. One additional valve was incorporated into the piping system to allow the sensor to be purged continuously during normal operation rather than closing the isolation valve except when firing.

Figure 31shows a side view of the reconfigured sound generator unit and Figure 32 shows an end view of the receiver unit.

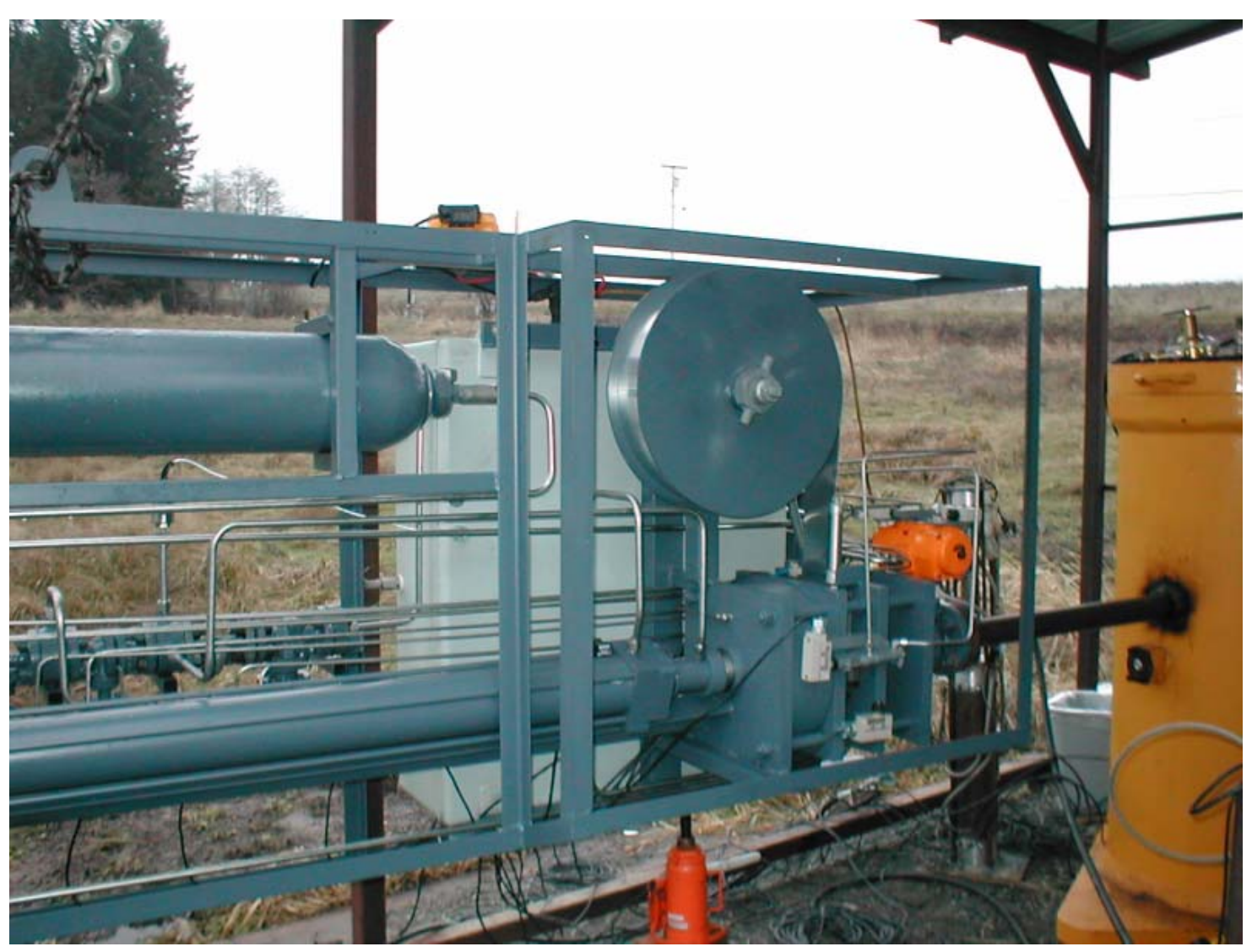

Figure 31. Sound generator unit of the auto-GAP 2 prototype 


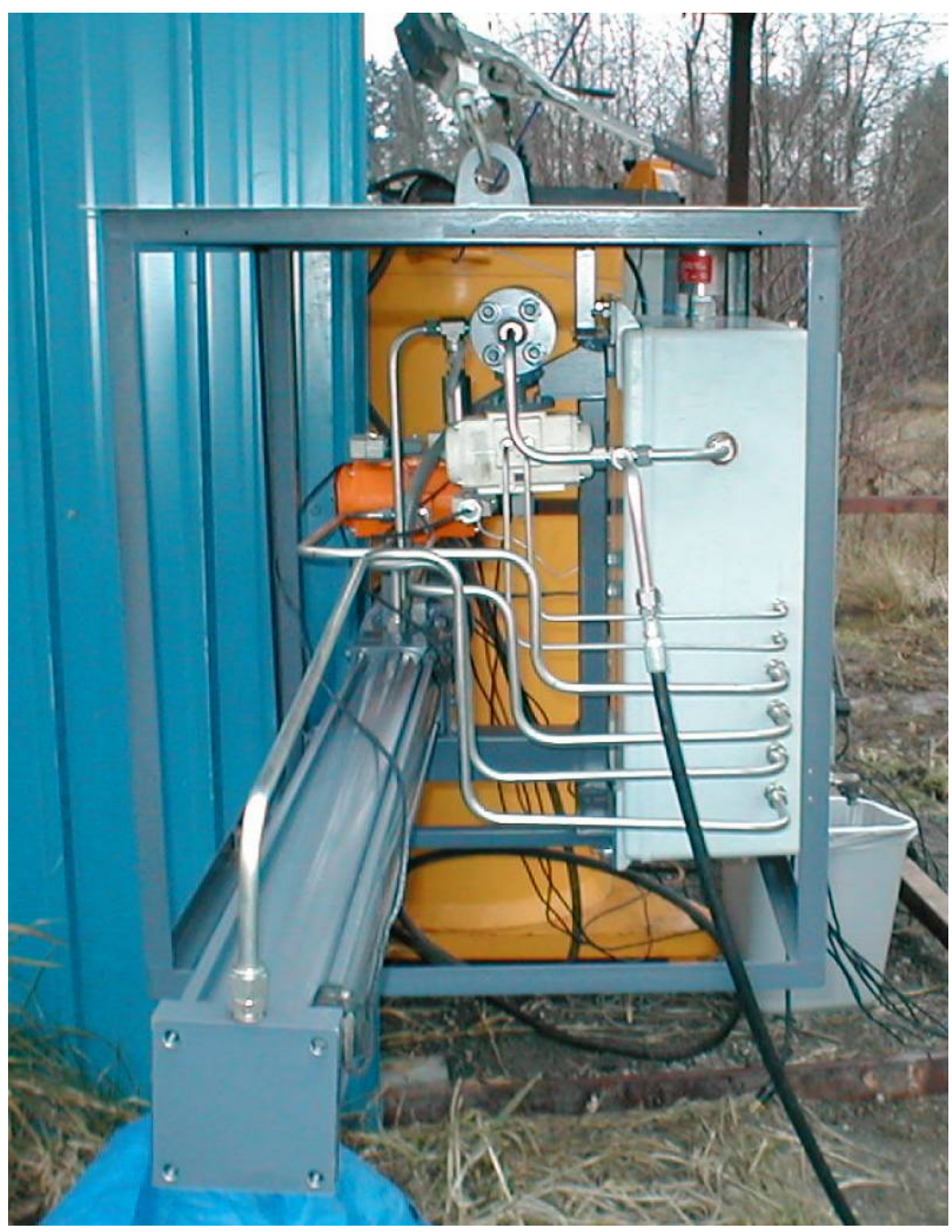

Figure 32. End view of receiver unit of auto-GAP 2 prototype

Tests of the modified prototype (auto-GAP 2) on the EGS1 unit showed that its performance was essentially identical to the performance measured before the modifications.

Figure 33 shows a schematic of the plumbing which handles the major flows of nitrogen and syngas through the generator unit. This figure shows the system in its initial state at installation. Figure 34 shows the system during a port rodding operation.

Figure 35 shows a schematic of all the control components and Figure 36 shows the control actions associated with each step in the measurement sequence. 


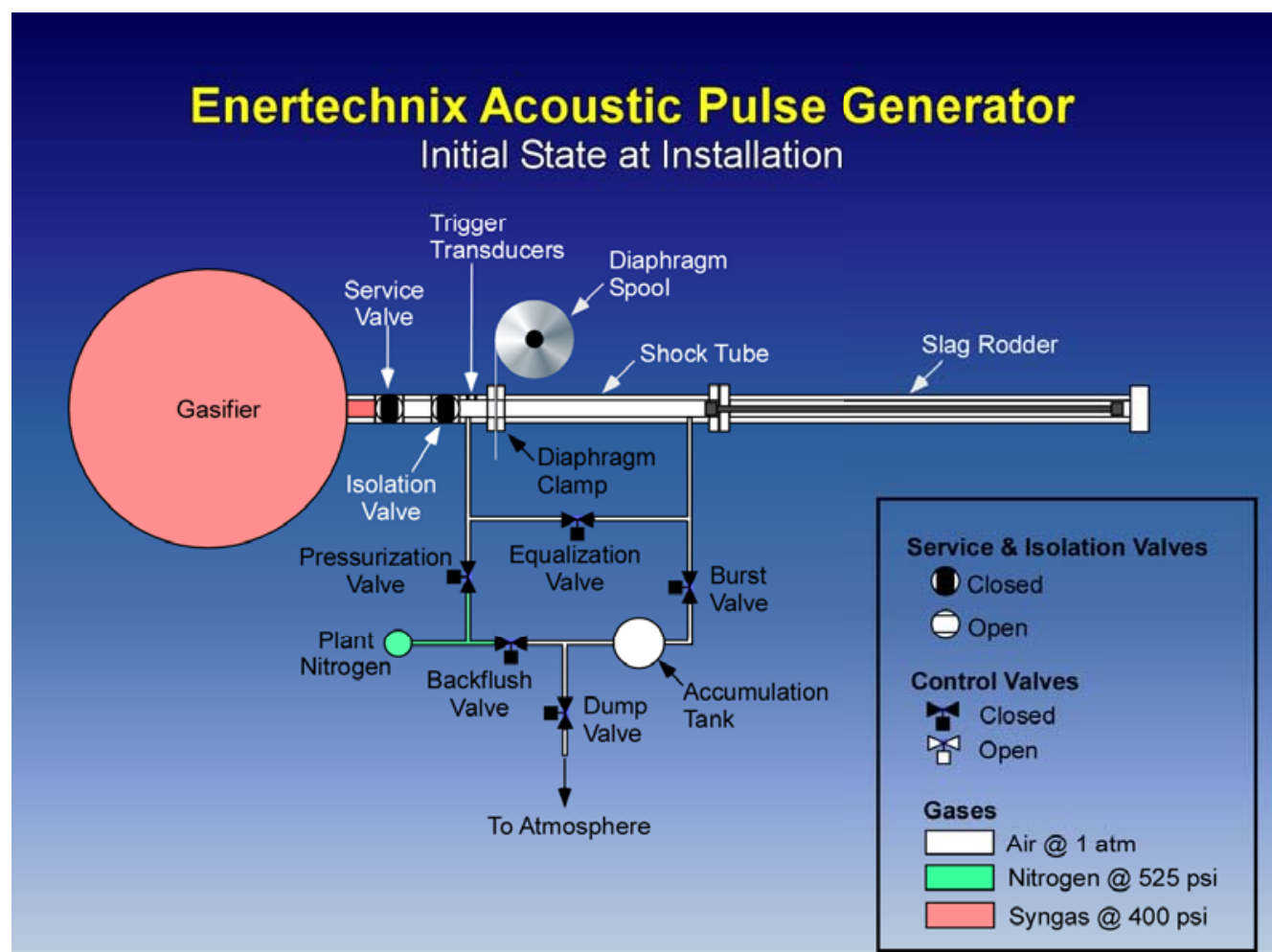

Figure 33. Schematic of major plumbing components

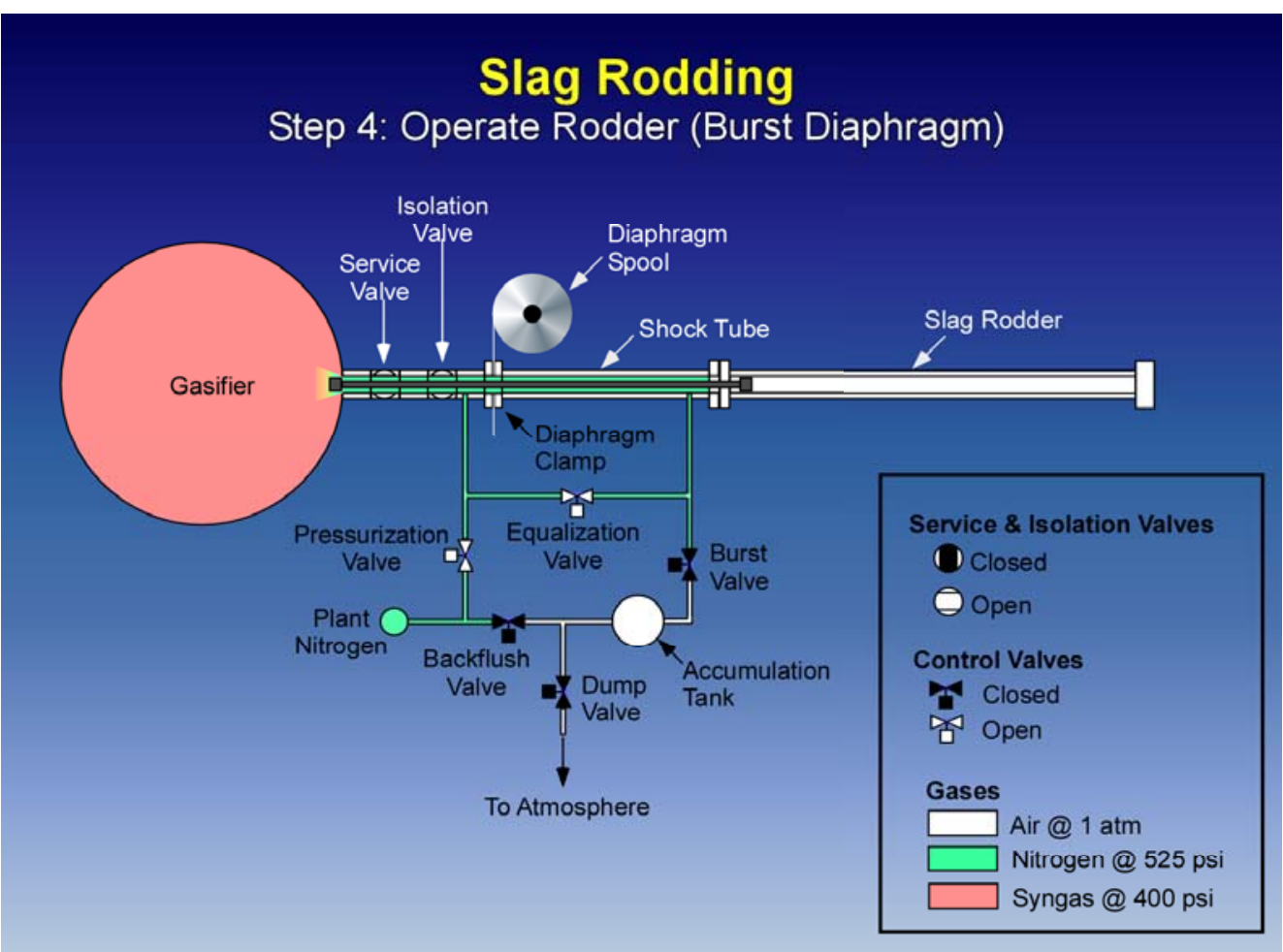

Figure 34. Major plumbing circuit during port rodding 


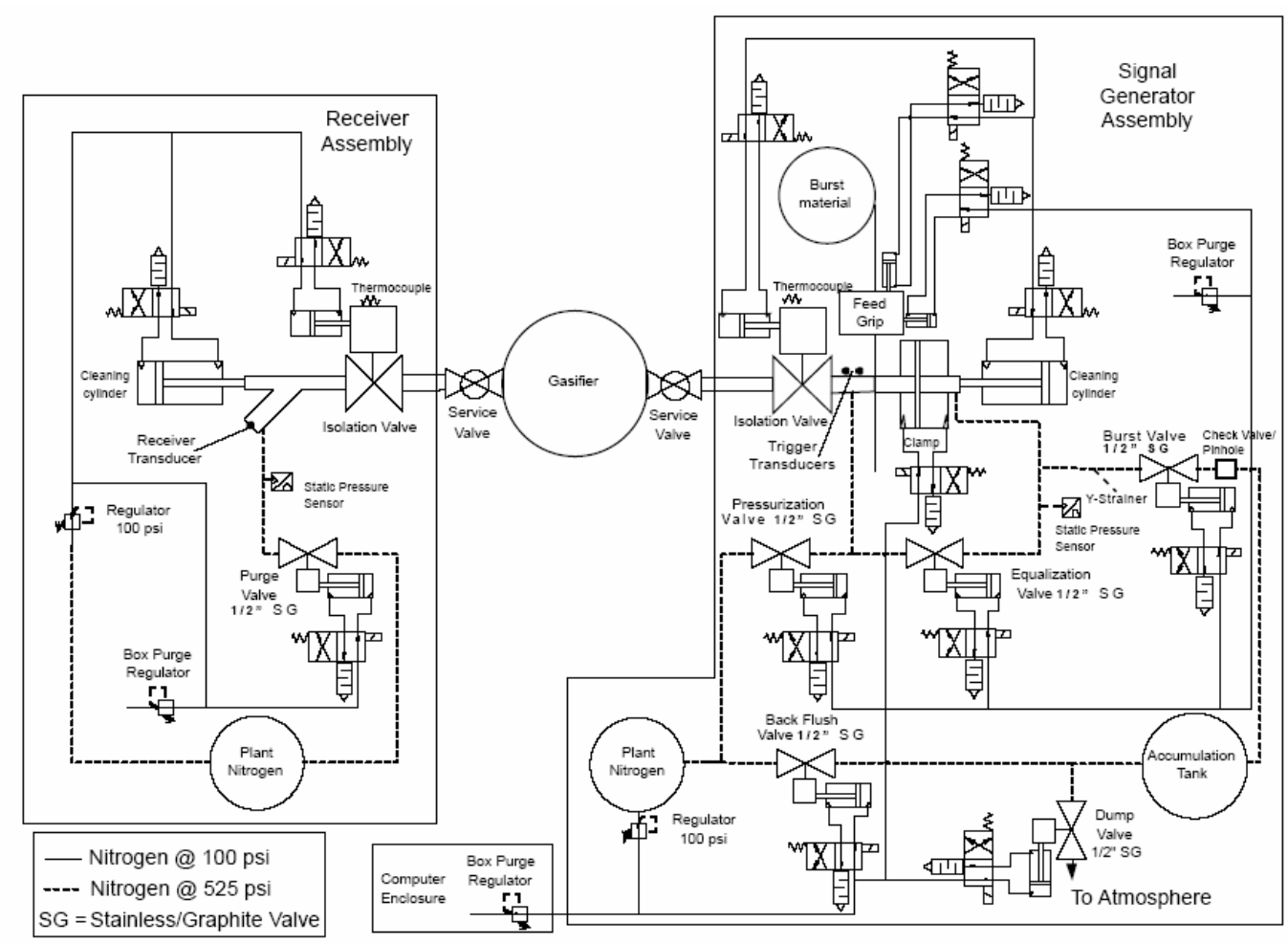

Figure 35. Schematic of all plumbing components and pneumatic actuators

The following is a list of the steps performed to make a measurement:

\begin{tabular}{|c|c|c|c|c|c|c|c|c|c|c|c|c|c|}
\hline Step & Action & 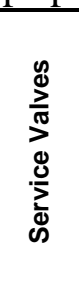 & 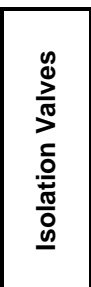 & 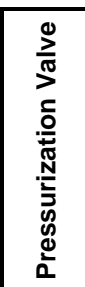 & 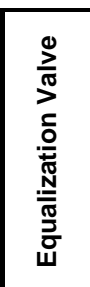 & 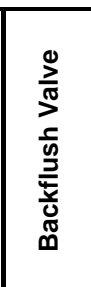 & 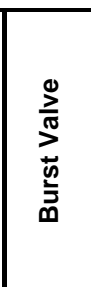 & 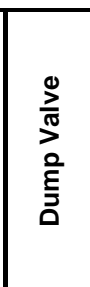 & 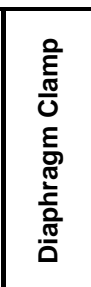 & 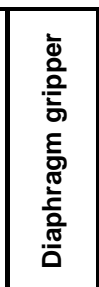 & 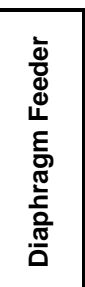 & 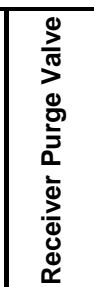 & $\begin{array}{l}\frac{n}{0} \\
\frac{0}{0} \\
\frac{0}{0} \\
\frac{\alpha}{\alpha} \\
\frac{T}{0} \\
0\end{array}$ \\
\hline 0 & Initial State & Closed & Closed & Closec & Closed & Close & Closed & Closed & Closed & Closed & Idle & Closed & Out \\
\hline$\overline{1}$ & Enable Pressure Equalization & Open & Closed & Closed & Open & Closed & Closed & Closed & Closed & Closed & Idle & Closed & Out \\
\hline$\overline{2}$ & Pressurize with Nitrogen & Open & Closed & Open & Open & Closed & Closed & Closed & Closed & Closed & Idle & Open & Out \\
\hline 3 & Begin Purging with Nitrogen & Open & Open & Open & Open & Closed & Closed & Closed & Closed & Closed & Idle & Open & Out \\
\hline$\overline{4}$ & Rod Ports & Open & Open & Open & Open & Closed & Closed & Closed & Closed & Closed & Idle & Open & In \\
\hline 5 & Isolate System from Gasifier & Open & Closed & Open & Open & Closed & Closed & Closed & Closed & Closed & Idle & Open & Out \\
\hline 6 & Turn off Nitrogen Supply & Open & Closed & Closed & Open & Closed & Closed & Closed & Closed & Closed & Idle & Closed & Out \\
\hline 7 & Bring System to Atmospheric Pressure & Open & Closed & Closed & Open & Closed & Open & Open & Closed & Closed & Idle & Closed & Out \\
\hline 8 & Open Diaphragm Clamp & Open & Closed & Closed & Open & Closed & Open & Open & Open & Closed & Idle & Closed & Out \\
\hline$\overline{9}$ & Advance Diaphragm Strip & Open & Closed & Closed & Open & Closed & Open & Open & Open & Closed & orwarc & Closed & Out \\
\hline 10 & Close Diaphragm Clamp & Open & Closed & Closed & Open & Closed & Open & Open & Closed & Open & Reverse & Closed & Out \\
\hline 11 & Isolate System from Atmosphere & Open & Closed & Closed & Open & Closed & Closed & Closed & Closed & Closed & Idle & Closed & Out \\
\hline$\overline{12}$ & Pressurize with Nitrogen & Open & Closed & Open & Open & Closed & Closed & Closed & Closed & Closed & Idle & Open & Out \\
\hline 13 & Turn off Nitrogen to Receiver & Open & Closed & Open & Open & Closed & Closed & Closed & Closed & Closed & Idle & Closed & Out \\
\hline 14 & Open System to Gasifier & Open & Open & Open & Open & Closed & Closed & Closed & Closed & Closed & Idle & Closed & Out \\
\hline 15 & Isolate Back Side of Diaphragm & Open & Open & Open & Closed & Closed & Closed & Closed & Closed & Closed & Idle & Closed & Out \\
\hline 16 & Fire! & Open & Open & Open & Closed & Closed & Open & Closed & Closed & Closed & Idle & Closed & Out \\
\hline 17 & Halt Syngas Flow \& Purge Receiver & Open & Open & Closec & Closed & Closed & Closed & Closed & Closed & Closed & Idle & Open & Out \\
\hline$\overline{18}$ & Pressurize Accumulation Tank with $\mathrm{N}_{2}$ & Open & Open & Closed & Closed & Open & Closed & Closed & Closed & Closed & Idle & Open & Out \\
\hline 19 & Backflush Accumulation Tank & Open & Open & Closec & Open & Open & Open & Closed & Closed & Closed & Idle & Open & Out \\
\hline 20 & Prepare for Next Cycle & Open & Open & Open & Open & Closed & Closed & Closed & Closed & Closed & Idle & Open & Out \\
\hline 21 & Evacuate Accumulation Tank & Open & Open & Open & Open & Closed & Closed & Open & Closed & Closed & Idle & Open & Out \\
\hline 22 & Go to Step 4 (Rod Ports ) & Open & Open & Open & Open & Closed & Closed & Closed & Closed & Closed & Idle & Open & In \\
\hline
\end{tabular}

Figure 36. Control Actions 


\section{Field Trials}

Following completion of the testing of the reconfigured "auto-GAP 2" (automated Gasifier Acoustic Pyrometer) sensor on the EGS1 unit at Enertechnix facilities in Tenino, WA in January, 2006, the unit was removed from the EGS1 unit, crated, and shipped to the Wabash River plant in Terre Haute, Indiana. The unit was delivered on January $16^{\text {th }}$ and preparations were made for initial checkout and installation of the sensor on the gasifier.

\subsection{Safety Review and Modifications}

Prior to installing the sensor, a safety review meeting was held to examine all potential issues that might impact plant operations and personnel safety. During that meeting the mechanical design of the sensor, the materials of construction, the safety precautions that had been designed into the sensor and its software, and the operation of the sensor were all discussed in detail to surface any potentially hazardous conditions that might be encountered during the installation and operation of the sensor. The plant identified the need for a number of warning labels to alert plant personnel about potential hazards and also to warn plant personnel against actions that could create hazardous conditions. Also, a number of hardware modifications were identified to provide redundant safety precautions and to ensure against the creation of hazardous conditions in the event of equipment malfunction. The plant requested that we install pressure relief valves to protect against over-pressuring the accumulation tank and the port rodding cylinders. Also, the plant insisted that we perform a complete functional demonstration test of the generator and receiver in their shop before mounting the units on the gasifier.

An initial checkout of the units revealed that one of the isolation valves had been damaged and it was necessary to order a replacement which was delivered to the plant in February.

During the January visit we made final arrangements for installation of the necessary supports for the sensor components at the gasifier. This entailed ordering several spring cans to support the weight of the generator and receiver units.

During February and March, we made a number of minor changes to the software requested by the plant which involved incorporating additional safety checks to ensure that the sensor cannot be left in an unsafe state in the event of a power failure or loss of plant nitrogen pressure. The modified software was installed during our next visit to the plant in April.

\subsection{Installation}

A second visit was made to the Wabash River plant in April, 2006 during which the damaged valve was replaced, all other modifications to the sensor units requested by the plant were completed, and a complete functional demonstration test was performed. Following this, the generator and receiver units were installed on the gasifier, electrical conduit was installed and the electrical wiring was installed and connected, necessary plumbing connections were made and tested for leaks and a complete checkout of the system was performed. In order to allow us to operate the sensor, collect data and perform system diagnostics from the control room, a 
fiber-optic link was employed between the supervisory computer (located next to the gasifier) and a remote computer located in the control room.

Figure 37 and Figure 38 show the generator and receiver units mounted on the gasifier.

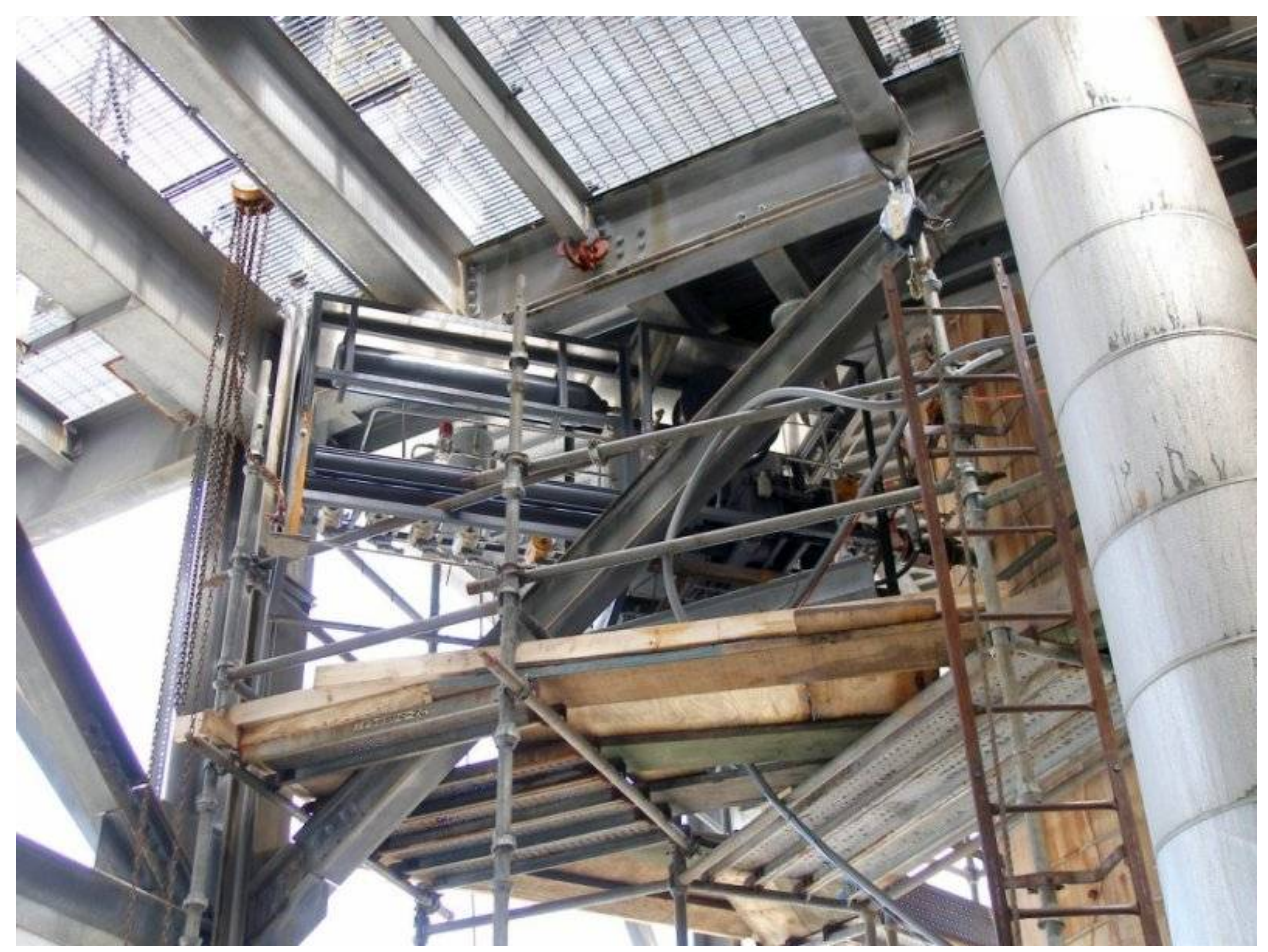

Figure 37. Generator unit mounted on the Wabash River gasifier

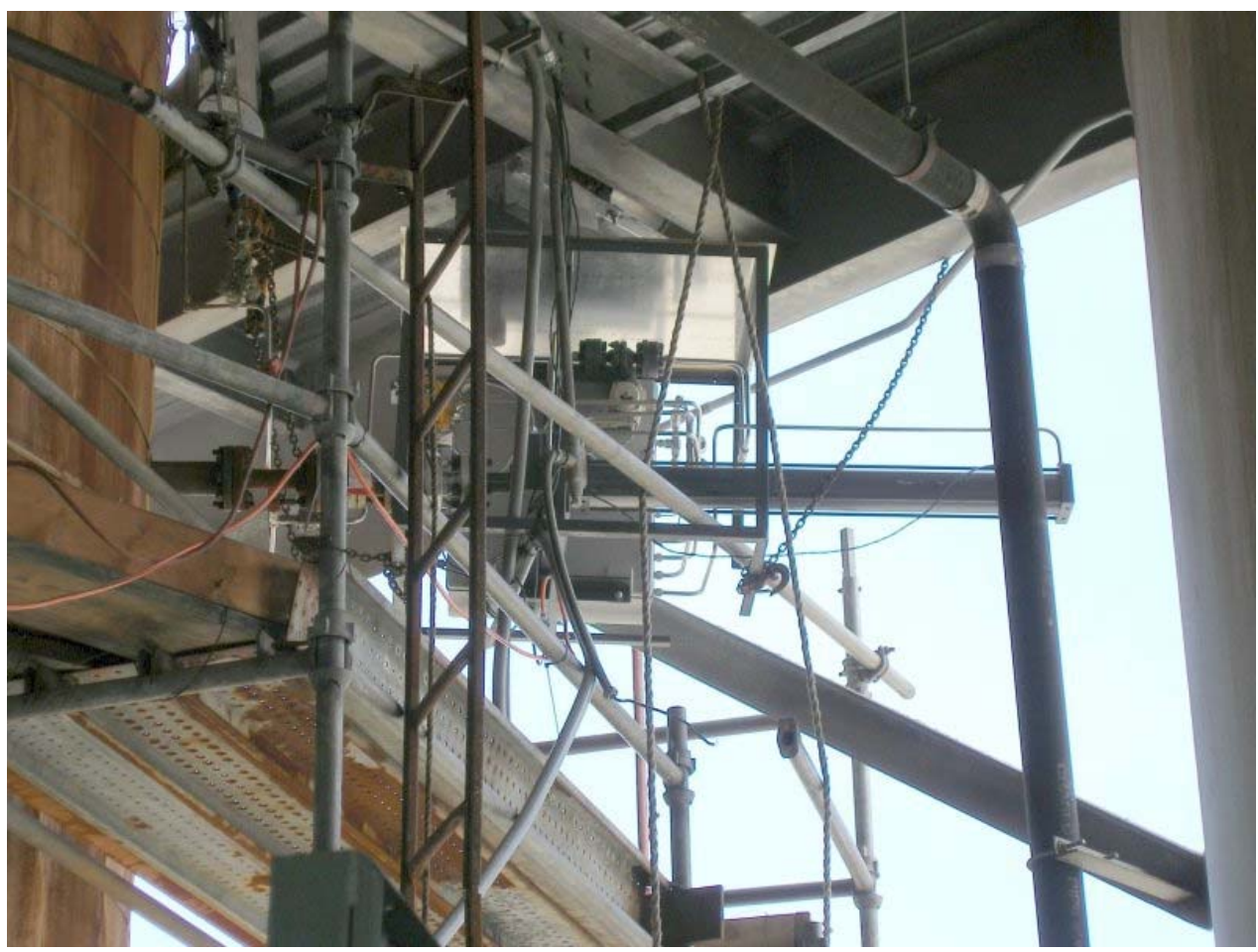

Figure 38. Receiver unit mounted on the Wabash River gasifier 
The system checkout performed during the last week of April, revealed the need to make a number of minor plumbing changes related to purging the enclosures which house the electronics associated with the generator and receiver units and the enclosure for the supervisory computer. Also, during a safety inspection of the installed sensor components, the plant identified the need to replace some of the scaffolding to provide better escape routes in case of emergency. These changes were completed the day before the plant's scheduled Spring outage.

\subsection{First Field Test}

On April $28^{\text {th }}$ (the last day before the Spring outage) the autoGAP system was operated on the gasifier for the first time. After an initial checkout, two measurements were made and signals recorded. Figure 39 shows the signals from the first measurement.

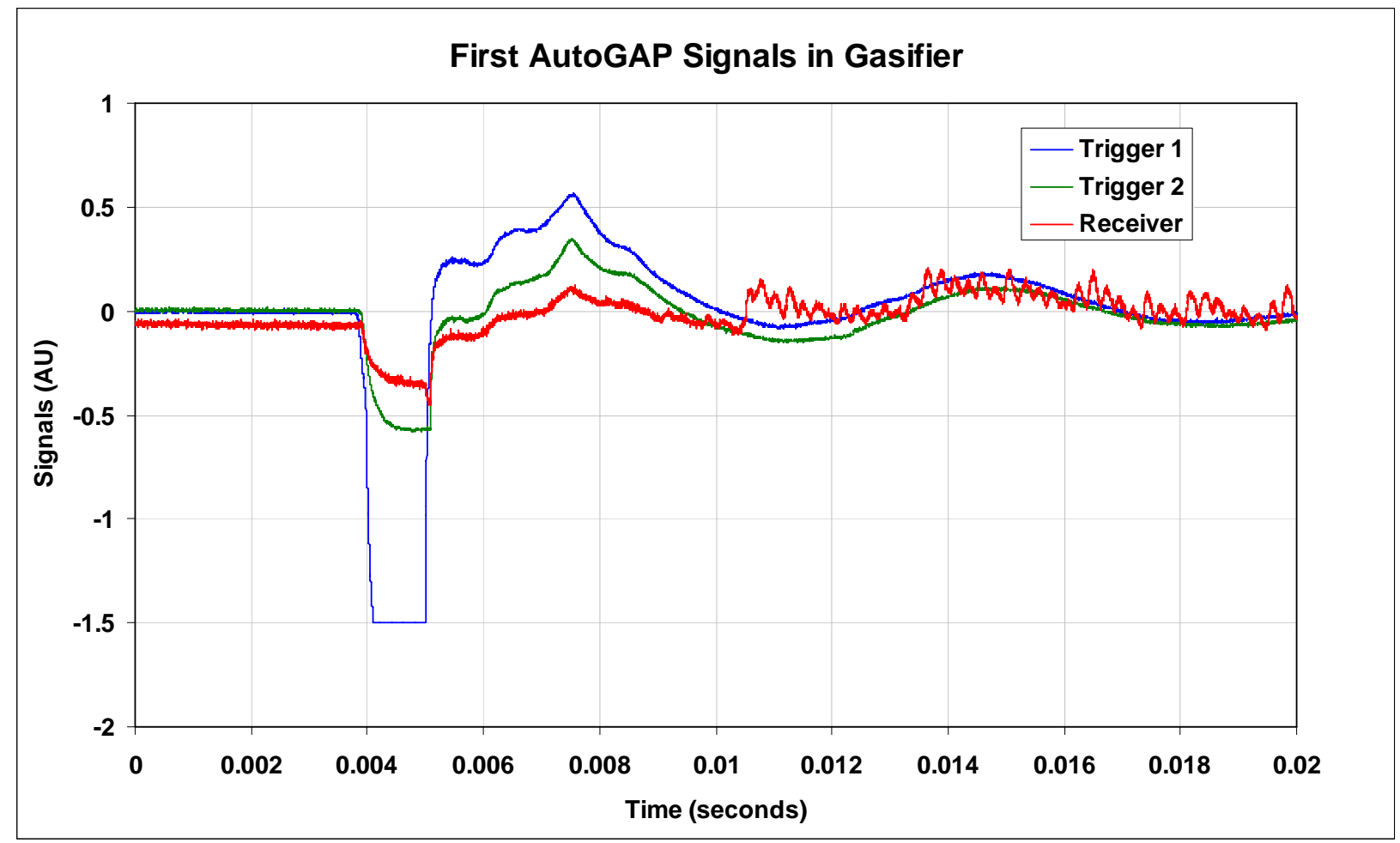

Figure 39. Signals from first measurement in the Wabash River gasifier

As before, the blue and green traces are the trigger transducer signals and the red trace is the receiver signal. In this measurement, the trigger 1 transducer becomes saturated when the diaphragm bursts and the arrival time of the shock wave (at about 5 milliseconds) could not be determined. Also, the arrival of the acoustic pulse at the receiver (at about 10.5 milliseconds) produced a relatively weak signal and the arrival time is not as clear as one would like. Nevertheless, the measured temperature is in a reasonable range - within 200 deg $\mathrm{F}$ of the temperature expected at this location by the plant personnel. As part of our collaboration agreement with ConocoPhillips, we have agreed to refrain from reporting the actual measured temperature. The second measurement was almost identical to the first. 
The fact that one of the trigger transducers was saturated and the receiver signal was very weak led us to conclude that it would be very desirable to be able to adjust the gain on the transducers independently. The analog to digital converter card we were using had this capability, but we had been unsuccessful in our attempts to program the card to do so at that time.

Following these two measurements, the port rodders were operated and functioned as expected - inserting and retracting without difficulty. The plant had been quite apprehensive about this operation, fearing that if the port rodder were to become stuck, there would be no way to shut the service or isolation valves and the only option would be to leave the rods in place and continue to purge the ports until the next outage. This turned out to be an unwarranted concern.

However, following the port rodding operation, subsequent attempts to operate the sensor were unsuccessful, primarily because the diaphragm failed to burst on most of the subsequent firings and no acoustic signal was produced. One possible explanation for this is that the flow passage between the shock tube and the accumulation tank became clogged with ash. This would have prevented the pressure behind the diaphragm from bleeding off rapidly enough and would have caused the diaphragm to deform slowly and ultimately tear without producing the sudden rupture required to generate a shock wave. We had installed a flow restrictor in this passage in order to limit the flow of syngas into the accumulation tank and this small orifice may have become clogged with ash. Since the plant's scheduled Spring outage was going to require them to shut down the gasifier within an hour or so, we chose to terminate the test and shut down our equipment.

\subsection{Second Field Test}

After examining the results of the first field trial and reviewing the design of the hardware and software, we concluded that a number of minor changes could be made that would significantly improve the chances of conducting a successful test. These included the following:

- Moving the purge inlet on the receiver unit to ensure adequate purging of the receiver transducer and prevent accumulation of ash on the front of the receiver transducer,

- Removing the flow restrictor in the line connecting the shock tube to the accumulation tank and also removing the strainer that had been installed to trap any ash that might flow through this line,

- Replacing one of the trigger transducers that had failed during the first field trial,

- Modifying the control software to minimize the amount of time between the bursting of the diaphragm and the beginning of the backflushing process so as to minimize the time that hot syngas would be present inside the generator unit, 
- Refining the model of shock propagation and gas flows inside the sound generator to provide more accurate estimates of sound propagation time inside the generator (end correction).

- Modifying the data acquisition software to allow us to independently set the gains on the individual transducers to avoid saturating the trigger transducer channels.

In August we requested an 8 week extension to the project to implement these modifications and to conduct another field trial of the sensor. This request was granted and Mr. Fitzgerald returned to the Wabash River plant on September $5^{\text {th }}$ to begin making the needed modifications.

The modifications were completed on September $15^{\text {th }}$ and testing began on September $18^{\text {th }}$. The modifications appear to have been very successful and the testing went very smoothly. The system was operated in automatic mode firing approximately once every 10 minutes under computer control for a period of almost 4 hours on the $18^{\text {th }}$ and again for several hours on the $19^{\text {th }}$. During this time, the sensor functioned smoothly, firing properly on each attempt; the acoustic signals were very strong and highly repeatable; and the inferred temperatures were in good agreement with the temperature readings from the two thermocouples mounted in the same plane as the acoustic sensor. Figure 40 shows the acoustic signals from a typical measurement during testing on the $18^{\text {th }}$.

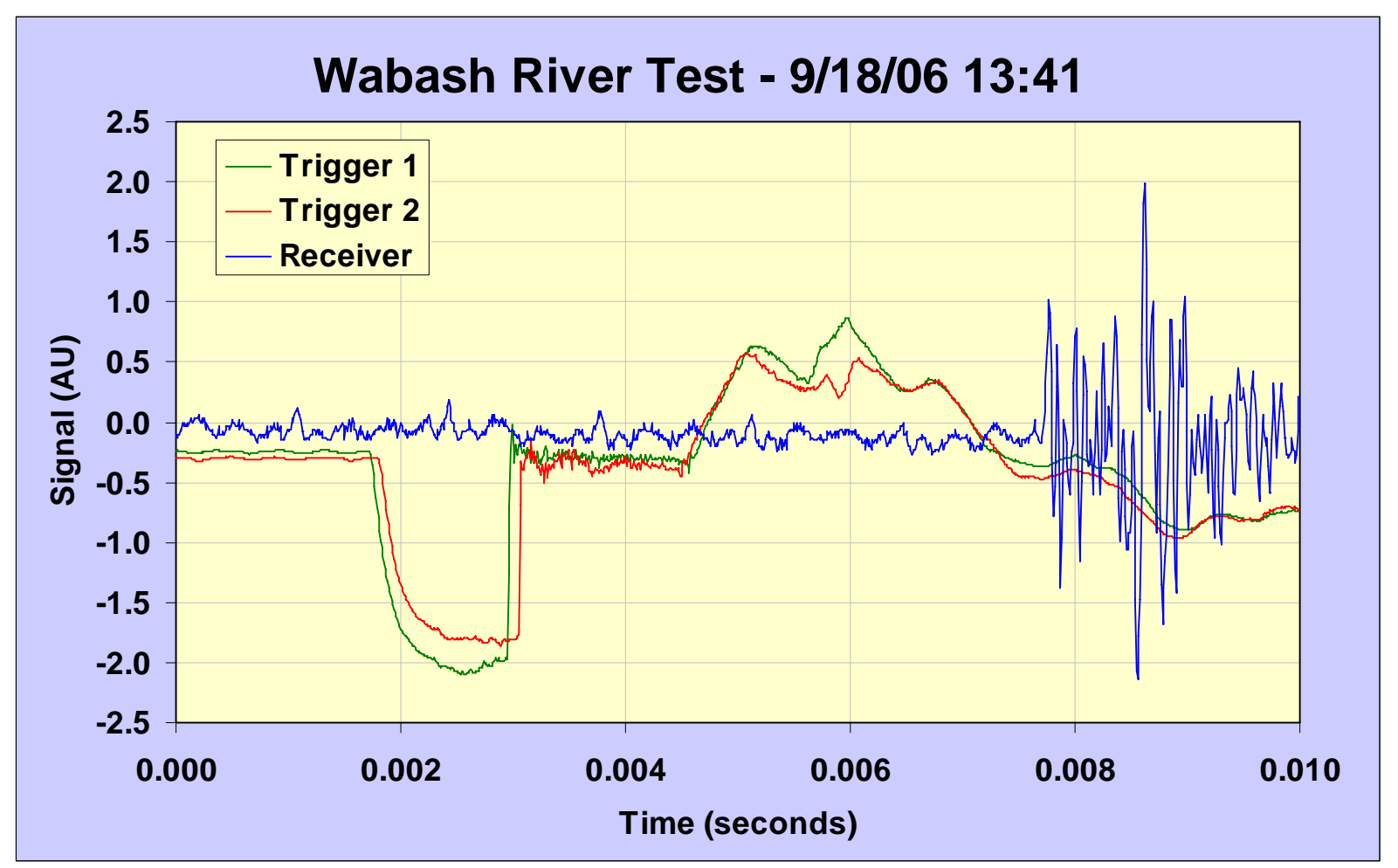

Figure 40. Acoustic signals from a measurement in the Wabash River gasifier.

As before, the red and green traces are the signals from the two trigger transducers and the blue trace is the receiver signal. The arrival of the acoustic wave at the receiver is quite 
distinct and is many times stronger than the background noise; the time of flight is easily determined from these traces without any ambiguity. All of the measurements made during the tests conducted on September $18^{\text {th }}$ and $19^{\text {th }}$ produced signals that were extremely strong and nearly identical in appearance. Figure 41 shows the temperatures measured with the autoGAP sensor relative to the temperature readings of the plant thermocouples.

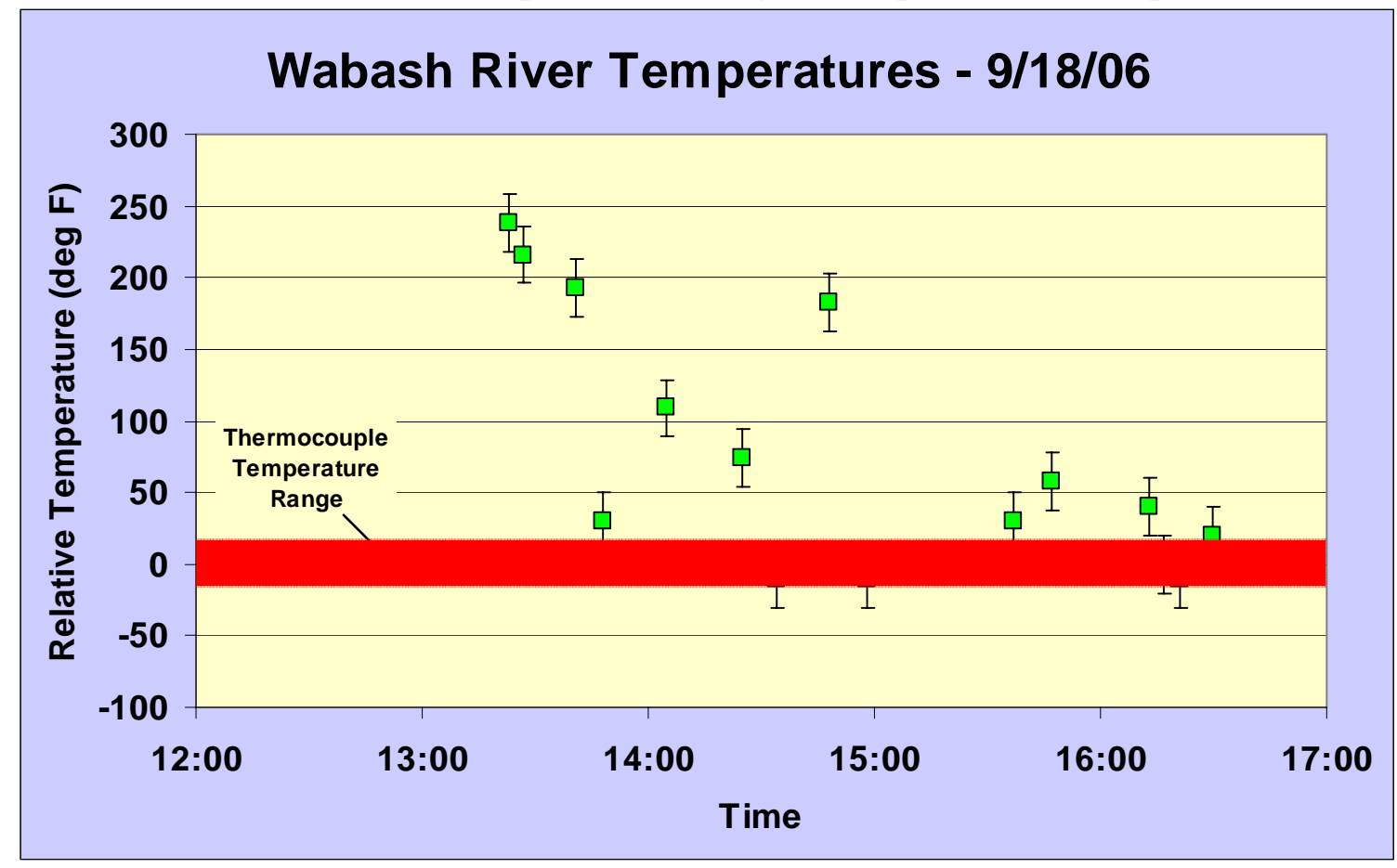

Figure 41. Temperature readings measured with the autoGAP sensor relative to the plant thermocouple readings during testing on September $18^{\text {th }}$

This figure shows that initially, the acoustic sensor measured temperatures that were significantly higher than those measured with the plant's thermocouples and later in the afternoon there was closer agreement. The fact that the acoustic sensor measures temperatures that differ from the thermocouples is understandable for two reasons. First, the thermocouples are located approximately 1 foot from the inner surface of the refractory and measure temperatures only at those points, whereas the acoustic measurement is an average over the full width of the gasifier. If there is significant non-uniformity in temperature in the radial direction within the gasifier, the thermocouple readings may not accurately reflect the average temperature; the acoustic measurements would be more representative. Second, the thermocouples are enclosed in protective housings (thermo-wells) that have significant "thermal mass"; therefore, the thermocouples are unable to respond to rapid changes in temperature. It is likely that the thermocouple response time is on the order of several tens of seconds or even minutes. The acoustic measurement, by contrast, is almost instantaneous since the propagation time of the sound pulse across the gasifier is on the order of a few milliseconds. Therefore, short duration temperature excursions would be completely invisible to the thermocouples, but would be detected by the acoustic measurement. The actual degree of temporal variation in gas temperature within the gasifier is presently unknown but the acoustic pyrometer measurement offers a means of determining its magnitude. 
One should also notice in figure 41 is that there were two occasions (at 13:23 and at 16:17) when measurements were taken much closer together in time than during the rest of the testing period. At those two times, we intentionally acquired successive temperature readings at an interval of about 3 to 4 minutes to test the maximum repetition rate of the system. This is probably the minimum time interval that can be achieved with this sensor given the large number of steps that have to be carried out during the firing sequence. Usually, however, process operators are only interested in seeing measurements every 15 to 30 minutes, so this should not be seen as a deficiency.

Also, there are some relatively long gaps in the data during the test period. In the current prototype data acquisition must be triggered manually just before the sensor fires and data saving requires that files be manually copied from the supervisory computer to the remote computer in the control room. Therefore, during periods when files are being copied, it is easy to miss triggering the data acquisition process at the proper time. This happened on a number of occasions even though the sensor was firing at regular intervals all during the test periods. We plan to fully automate the system in the near future so that sensor operation, signal collection, signal analysis, temperature determination and data recording will all be carried out automatically.

On September $19^{\text {th }}$ testing was resumed and the sensor again functioned properly for several hours under computer control. Figure 42 shows a typical set of acoustic signals acquired at

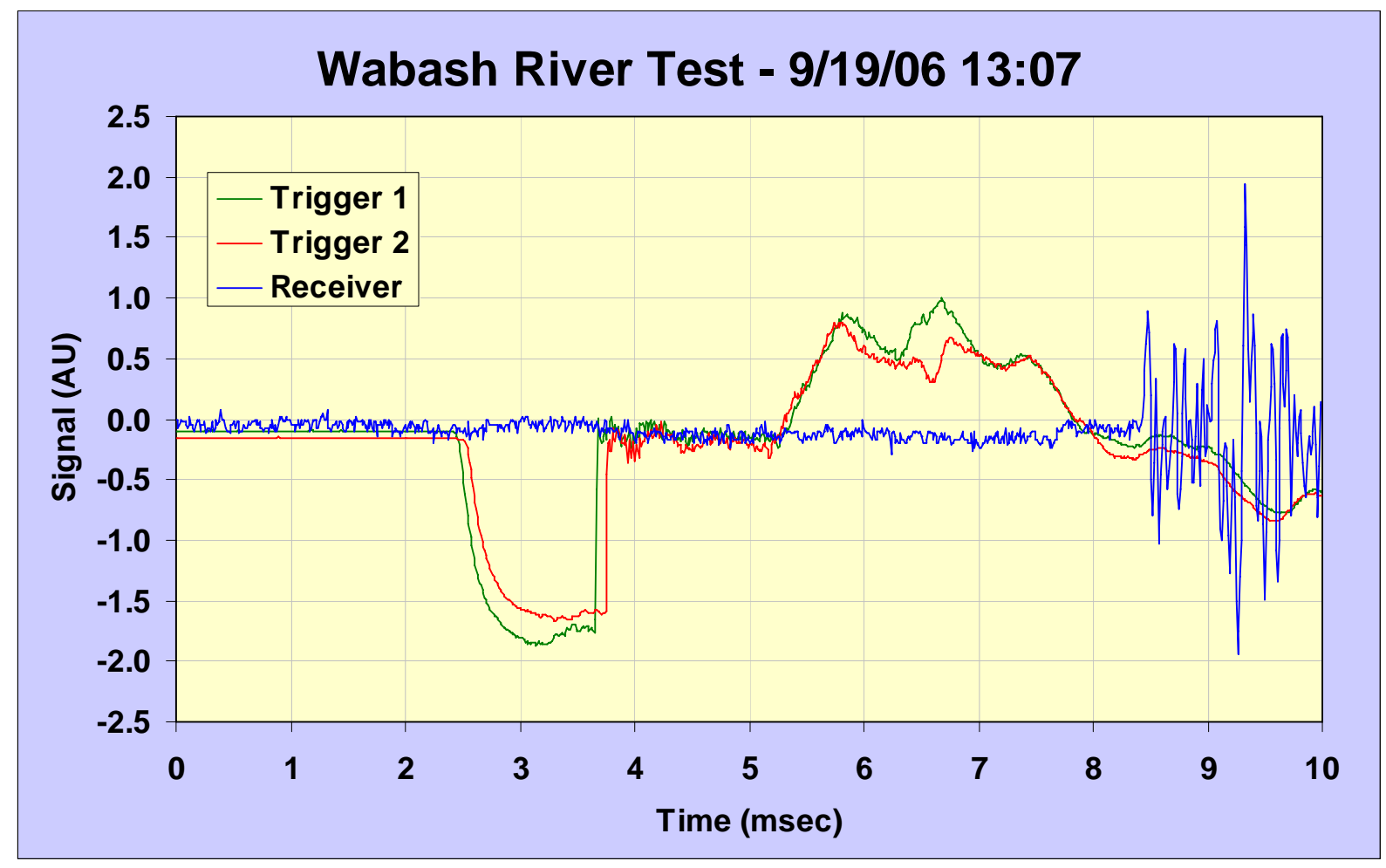

Figure 42. Acoustic signals acquired on September $19^{\text {th }}$ in the Wabash River gasifier. 
As on the previous day, the sensor produced clear, unambiguous signals and the signal to noise ratio was almost 10:1 on every shot. Data was collected throughout the day and temperatures were calculated manually from the timing of the acoustic signals. Figure 43 shows the temperature readings obtained during the testing on September $19^{\text {th }}$. As before, these temperatures are reported relative to the approximate range of thermocouple readings obtained during the testing which were observed to remain nearly constant throughout the test.

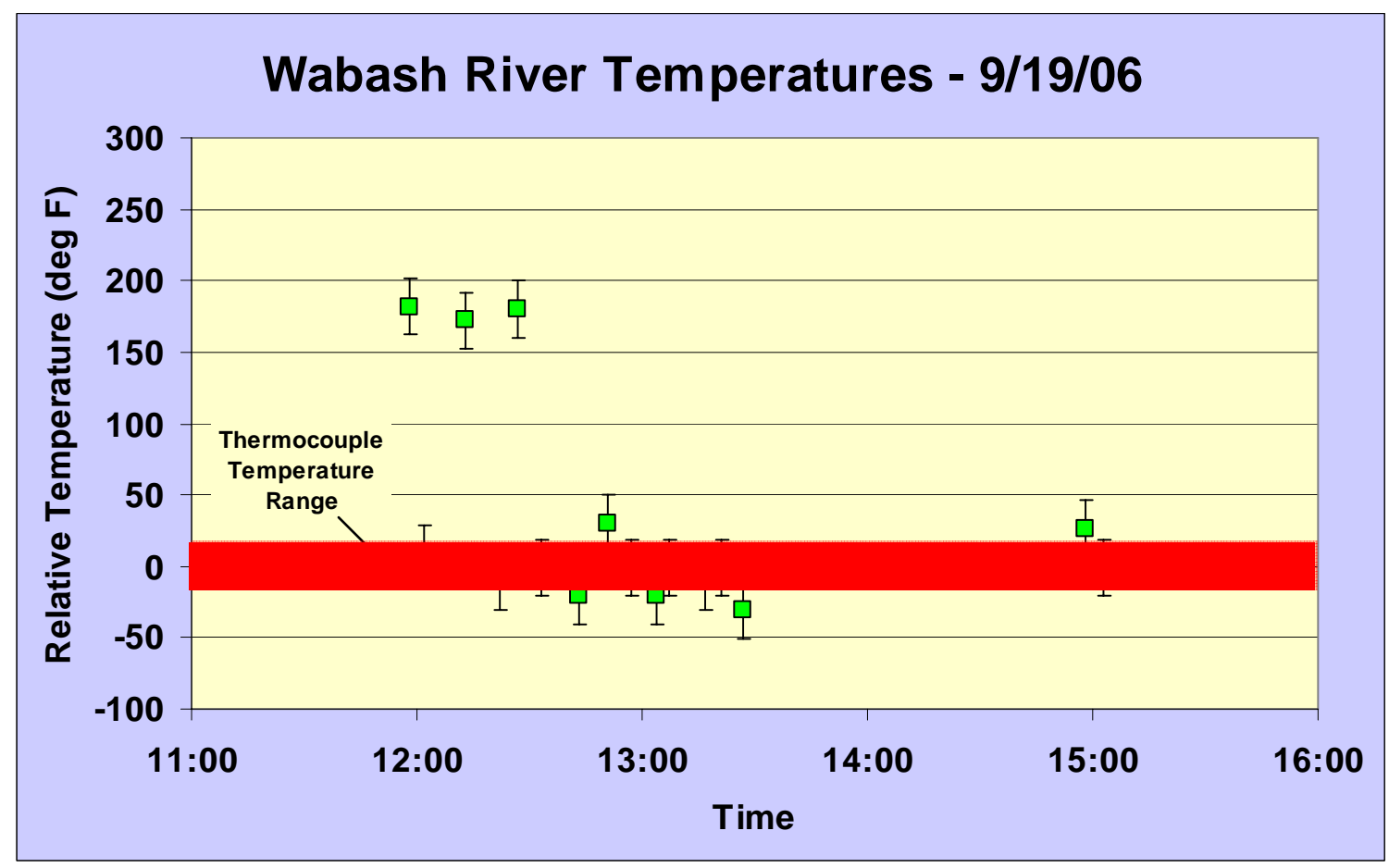

Figure 43. Temperature readings measured with autoGAP relative to the plant thermocouple readings during testing on September $19^{\text {th }}$

At the start of testing there were a three occasions when the acoustic measurements yielded temperatures much higher than those measured with the thermocouples, but all through the latter part of the test, there was very good agreement between the thermocouples and the acoustic sensor. During the period from about 13:30 to about 15:00 we were downloading files from the supervisory computer to the remote computer and we failed to trigger the data acquisition process. Nevertheless, the sensor continued to operate normally during this period.

Following the last measurement shown above, the sensor failed to pass the pressure test that is performed each time a new piece of diaphragm material is loaded into the diaphragm clamp. Repeated attempts to feed new sections of the aluminum ribbon into the clamp failed to correct this problem. Upon inspection, it was discovered that one of the teflon seals had become severely deformed (probably due to exposure to hot syngas) and was incapable of making a tight seal. Due to the very cramped quarters in the vicinity of the acoustic generator unit and the very small gap between the two halves of the clamping mechanism even when it 
is fully open, it was not possible to replace the seal without partially dismantling the generator unit. Therefore, we decided to terminate the test at that time.

When the prototype was designed, we believed that the use of a flow restrictor in the passage connecting the shock tube to the accumulation tank would prevent syngas from flowing into the sensor and that teflon seals would be adequate. However, the removal of the flow restrictor resulted in syngas being aspirated into the generator on each firing, and this probably overheated the teflon seal.

\subsection{Sensor Upgrades}

Following the second field test, the AutoGAP unit was returned to Enertechnix' Tenino facility and was dismantled and thoroughly inspected. A new sealing arrangement for the diaphragm clamp was designed, fabricated and tested. This new arrangement employed a metal-on-metal seal that is able to withstand very high temperatures. Several of the stainless steel ball valves which showed evidence of corrosion were replaced with valves employing nickel-plated balls. Several new ultrasonic transducers were obtained and tested. These new transducers are much more rugged than the original ones, although they have lower sensitivity and lower frequency response. However, given our experience during the second field test which showed that we had extremely high signal-to-noise ratios and given the predictions of our attenuation modeling that showed that frequencies above $100 \mathrm{kHz}$ would not propagate through the gasifier environment, we concluded that these new transducers would perform adequately and would survive much better than the original ones. Many other electrical and mechanical components were replaced with more rugged versions.

In addition, the software was substantially upgraded to allow for completely autonomous operation and a detailed one-dimensional compressible flow model of the shock generation and reflection process was developed to allow us to accurately predict the propagation time of the shock inside the AutoGAP hardware. The predictions of this model were compared against CFD modeling performed by our collaborator, Prof. Hans Hornung, at Cal Tech and were also used to interpret the data obtained during the second field trial. Both of these tests showed that the new model is capable of providing very accurate estimates of the "end corrections" needed to convert the time-of-flight measurements into accurate gasifier temperatures.

These upgrades were completed in December, 2007 and the AutoGAP sensor was shipped to Wabash River in January, 2008. The unit was installed on the gasifier in February, 2008 and commissioning commenced at the end of February, 2008.

\subsection{Extended Testing}

The AutoGAP sensor was mounted on the Wabash River gasifier on February $20^{\text {th }}$ and wiring and plumbing were connected during the remainder of that week. During the week of February $25^{\text {th }}$, preliminary tests were performed to verify proper operation of the hardware and to check for leaks. These tests were successfully completed on March $3^{\text {rd }}$. On March $5^{\text {th }}$ further tests were performed to demonstrate successful port rodding-an operation that the 
plant was concerned about and wanted to have demonstrated before proceeding with further operation of the system.

On March $6^{\text {th }}$ the sensor was operated in automatic mode for the first time and collected several signals that provided temperature measurements in good agreement with the plant's thermocouples. Around noon on March $6^{\text {th }}$, the system was operating in fully automatic mode and was successfully making temperature measurements every 10 minutes. At about 1:30 PM the system reported an alarm indicating a failure of the leak test that is performed prior to each firing of the sound generator. The Enertechnix engineer who was commissioning the system began performing diagnostic tests from the main computer which is located on the $7^{\text {th }}$ deck. The main computer is approximately 25 feet from the sound generator unit which is about 14 feet above the $7^{\text {th }}$ deck. After operating the system manually several times, three more successful measurements were performed without any problems. During the process of diagnosing the system, the engineer started and stopped the automatic program that was running in the motion control computer several times. At about 4 PM several more alarms were reported indicating a leak in the system and at 4:25 PM the engineer once again began performing diagnostic tests to isolate the leak. However, unbeknownst to him, the automatic program which resides in the motion control computer next to the sound generator unit was still running at that time. The fact that valves were being actuated both manually and by the motion control program automatically was probably a significant contributing factor in the subsequent incident. Just before 5 PM, the engineer opened the vent on the accumulation tank and the burst valve that connects the shock tube to the accumulation tank, in order to bring the shock tube to atmospheric pressure. At that point, the automatic program opened the isolation valve allowing syngas to flow from the gasifier through the AutoGAP system and out through the accumulation tank vent. This condition persisted for about 30 seconds resulting in severe overheating of the $1 / 2$ inch stainless steel tube that connects the shock tube to the accumulation tank. At that point the stainless steel tube failed. The engineer closed the vent from the accumulation tank and the isolation valve between the generator and the gasifier which stopped the flow of syngas. However, he was unaware of the tube failure and continued performing diagnostic tests to determine the cause of the original alarms. During this process, the isolation valve was opened again and syngas flowed out of the hole in the tube that had failed. At this point, the syngas caught fire and ignited the cardboard and plastic spool that holds the aluminum diaphragm material. Plant personnel extinguished the fire and closed the service valves that are placed between the AutoGAP sensor and the gasifier.

Further inspection revealed that the stainless steel tube that failed had also been significantly thinned, possibly by erosion due to the ash entrained in the syngas that flows through this tube during normal operation. Our current procedure allows syngas to flow through this tube after the diaphragm bursts and the flow of syngas is not halted until the pressure in the shock tube rises to a level close to that inside the gasifier. This is taken to indicate a successful firing of the generator. However, this may take 30 seconds or more and syngas will be flowing during this period. This very likely causes the stainless steel tube to overheat and also allows ash to flow through the tube probably abrading the inner surface of the tube.

Following the incident, using an internet connection to the main computer, Enertechnix personnel remotely exercised several of the valves and interrogated the limit switches, the 
pressure transducer and the temperature controller on the generator unit. These components all appeared to be functioning correctly. Also, the motion control computer which is located inside an enclosure mounted on the generator appeared to be functioning properly. Therefore, we concluded that the damage was relatively limited and destroyed only a few minor components.

\subsection{Incident Review}

On March $11^{\text {th }}$ Enertechnix personnel attended a review meeting at the plant to discuss the likely root causes of the incident. Three probable root causes were identified and fourteen action items were assigned to Enertechnix and plant personnel. On March $18^{\text {th }}$, Enertechnix conducted its own internal review and generated a list of problems and issues resulting from or contributing to the incident. From these discussions a list of 8 root causes and a separate list of 26 recommended corrective actions were generated.

On May $2^{\text {nd }}$ Dr. Ariessohn attended a review meeting at NETL in Pittsburgh at which he presented Enertechnix' recommendations for sensor improvements needed to allow for reliable operation during a six month trial at Wabash River and a budget to implement those improvements and conduct a six month trial. NETL concluded that the cost of this additional work was more than they were willing to invest and decided to terminate the project.

\section{Commercial Sensor Conceptual Design}

The current prototype has already undergone a great deal of engineering development and refinement in order to meet the safety requirements imposed by the Wabash River plant personnel. Therefore, this design has evolved to a point that is very close to what would normally be considered a commercial prototype. In developing a final commercial design we would seek to reduce cost, weight and size of the units and to employ components that are more robust and easier to install. We feel that if additional resources were available to overcome the deficiencies identified in our incident review process, the resulting sensor would constitute a first commercial product design that would require only minor modifications in order to be a viable commercial product.

\section{Final Briefing}

As discussed above, a final briefing on this project was presented to NETL staff on May $2^{\text {nd }}$ 2008.

\section{References}

1 Fundamentals of Classical Thermodynamics, G.Van Wylen and R. Sonntag, Wiley, 1966

2 Engineering Applications of Acoustics, J. A. Kleppe, Artech House Press, Boston, 1989.

3 Recent Developments in Aerosol Science, David T. Shaw, ed. - Chapter 13, Acoustic Agglomeration of Aerosols, D.T. Shaw, John Wiley \& Sons, 1978 
4 Samuel Temkin, Attenuation and Dispersion of Sound by Particulate Relaxation Processes, Report on ONR Contract Nonr 562(37), February, 1966

5 Elements of Gasdynamics, H.W. Liepmann and A. Roshko, Dover Publications, NY, 1957, 2001

6 Handbook of Supersonic Aerodynamics, Section 18: Shock Tubes, I.I. Glass and J. Gordon Hall, NAVORD Report 1488, vol. 6, 1959. 